International Scientific-Technical and Production Journal

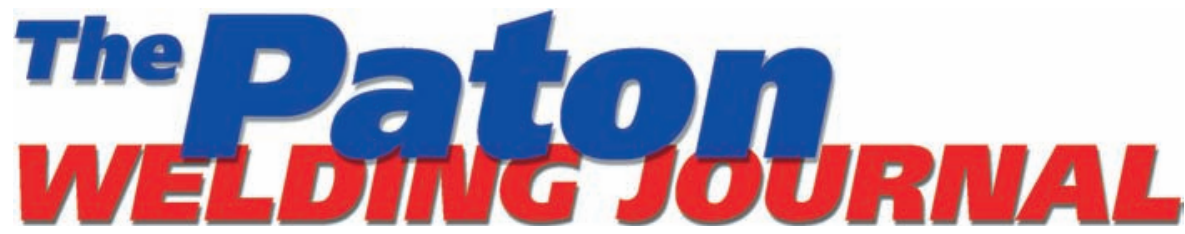

\section{EDITORIAL BOARD \\ Editor-in-Chief B.E. Paton}

Scientists of PWI, Kyiv S.I. Kuchuk-Yatsenko (vice-chief ed.),

V.N. Lipodaev (vice-chief ed.)

Yu.S. Borisov, G.M. Grigorenko,

A.T. Zelnichenko, V.V. Knysh,

I.V. Krivtsun, Yu.N. Lankin,

L.M. Lobanov, V.D. Poznyakov,

I.A. Ryabtsev, K.A. Yushchenko

Scientists of Ukrainian Universities V.V. Dmitrik, NTU «KhPI», Kharkov V.V. Kvasnitsky, NTUU «KPI», Kyiv

E.P. Chvertko, NTUU «KPI», Kyiv

Foreign Scientists

N.P. Alyoshin

N.E. Bauman MSTU, Moscow, Russia Guan Qiao

Beijing Aeronautical Institute, China

M. Zinigrad

Ariel University, Israel V.I. Lysak

Volgograd STU, Russia Ya. Pilarczyk

Welding Institute, Gliwice, Poland U. Reisgen

Welding and Joining Institute, Aachen, Germany G.A. Turichin

St. Petersburg SPU, Russia

Founders

E.O. Paton Electric Welding Institute, NASU

International Association «Welding» Publisher

International Association «Welding» Translators

A.A. Fomin, O.S. Kurochko, I.N. Kutianova Editor

N.G. Khomenko

Electron galley

D.I. Sereda, T.Yu. Snegiryova Address

E.O. Paton Electric Welding Institute,

International Association «Welding»

11 Kazimir Malevich Str. (former Bozhenko Str.),

03150, Kyiv, Ukraine

Tel.: (38044) 20060 16, 2008277

Fax: (38044) 2008277,2008145

E-mail: journal@paton.kiev.ua

www.patonpublishinghouse.com

State Registration Certificate

KV 4790 of 09.01 .2001

ISSN 0957-798X

DOI: http://dx.doi.org/10.15407/tpwj Subscriptions

$\$ 348,12$ issues per year

air postage and packaging included. Back issues available.

All rights reserved.

This publication and each of the articles contained herein are protected by copyright.

Permission to reproduce material contained in this journal must be obtained in writing from the Publisher.

\section{CONTENTS}

\section{SCIENTIFIC AND TECHNICAL}

Yushchenko K.A., Zadery B.A., Gakh I.S., Zvyagintseva A.V.,

Kapitanchuk L.M. and Khaskin Yu.V. Evolution of structure of oxide

dispersion strengthened nickel alloys in fusion welding

Marchenko A.E., Trachevsky V.V. and Skorina N.V. Effect of liquid glass composition and structure on the strength of low-hydrogen electrode coatings

Soloviov V.G. and Kuskov Yu.M. Influence of technological and electrical parameters of ESS in current-supplying mould on electrode melting rate and base metal penetration

Tsybulkin G.A. Algorithm of joint line «tracking» in tandem arc

welding

\section{INDUSTRIAL}

Falchenko Yu.V. and Petrushinets L.V. Modern methods of manufacturing three-layer panels of aluminium alloys (Review)

Miara D., Matusiak J., Pietras A., Krystian M. and Dyner M. High speed friction welding of titanium alloys - structure and properties of joints 40

\section{NEWS}

XII All-Ukrainian Festival of Science 43 


\title{
EVOLUTION OF STRUCTURE OF OXIDE DISPERSION STRENGTHENED NICKEL ALLOYS IN FUSION WELDING
}

\author{
K.A. YUSHCHENKO, B.A. ZADERY, I.S. GAKH, \\ A.V. ZVYAGINTSEVA, L.M. KAPITANCHUK and Yu.V. KHASKIN \\ E.O. Paton Electric Welding Institute of the NAS of Ukraine \\ 11 Kazimir Malevich Str., 03150, Kyiv, Ukraine. E-mail: office@paton.kiev.ua
}

\begin{abstract}
Changes of nanodispersed structure of nickel ODS-alloys as a result of fusion welding were considered. Welded joints, produced at different modes of argonarc, electron beam and laser welding were investigated. It is shown that degradation of nanosized structure takes place in all considered cases. It is expressed mainly in change of strengthening particles up to microsized level, some variation of their chemical composition and morphology. A level of structure degradation depends on a level of overheating of weld pool metal, which in turn, is determined by value of specific power of heat source, welding rate, heat input and cooling nature. It is shown that the positive result, i.e minimum degradation of initial metal nanostructure, can be reached at optimum combination of the maximum technologically acceptable welding rate and heat input concentration, minimum margin and controlled distribution of power, which provide through penetration and formation of weld with parallel fusion surfaces. 19 Ref., 9 Figures.
\end{abstract}

Keywords : ODS-nickel alloys, fusion welding, weld pool, degradation of nanodispersed structure, particle coarsening, welding rate, heat input nature, weld formation

Oxide dispersion strengthened nickel alloys and steels due to combination of unique properties exceeding characteristics of the materials strengthened by micron size particles [1-9] recently find more and more application as alternative structural material in perspective developments of nuclear mechanical engineering, aerospace equipment, energy generating branches, including renewable power sources, high-temperature heat exchangers, engine construction etc. [2, 10-13].

The main problem that should be solved for realizing the properties of these materials in industrial structures is to guarantee nanodimension structure during the whole process chain of their manufacture. The main characteristics of such a structure is size of the strengthening particles, their morphology, composition, uniformity of distribution in matrix.

The particular difficulty for performance of this task during welding lies in high-temperature heating of metal, nonequilibrium of thermal, hydrodynamic, thermal deformation, solidification and other processes accompanying formation of welded joint.

Probably, the maximum preservation of the parameters of ODS-alloy nanostructure in their welding is possible with using the methods eliminating or minimizing metal overheating above dissociation or melting temperature as well as oxide coagulation during joint formation. These are diffusion, friction, friction stir and other welding methods. However, they have limitations in their realizing, it is technical impossibility of welding of structures with complex developed geometry, application of the methods under conditions of special production or repair, not proved technology and equipment. And even growing in popularity in the recent time friction stir welding method does not always allow getting quality joint and keep initial structure [14-17]. Therefore, today it is a still relevant task to weld ODS-alloys using the methods of wide commercial application, namely argonarc (ArAW), laser (LW), electron beam (EBW).

Present work was carried out using single-phase nickel alloy Inconel MA758 (Ni-31Cr-1.0Fe-0.5Ti$0.3 \mathrm{Al}-0.6 \mathrm{Y}_{2} \mathrm{O}_{3}$ ) as a model one. Such a choice was caused by the need to eliminate negative effect of phase transformations on nanostructure formation. The welded samples of 1.5-2.0 mm thickness were cut by spark method from a rod produced by mechanical alloying method. The cut places were polished, the samples were rinsed by acetone in ultrasonic pool.

Welding experiments were carried out using the methods mentioned above.

Welding rate was the main parameter used for regulation of heat input in weld metal. It allowed taking into account efficiency and mobility of impact as well as quality effect similarity on nature of heat input and weld pool hydrodynamics at different fusion welding methods. During the experiments the welding rate was 
varied in a wide range of values from 12 to $180 \mathrm{~m} / \mathrm{h}$. The values of other mode parameters were selected based on the need of achievement of through penetration and quality formation of the weld. It should be underlined that a significant difference of thermophysical characteristics of oxides and base metal (such as specific weight, melting temperature, oxides' wetting, etc.) considerably complicates quality formation of the welds. It is shown by undercuts, spattering, blowing-out and splashes of metal, floating of oxides, appearance of porosity and other defects.

This is particularly obvious in welding at low rates. Weld metal, produced at $10-20 \mathrm{~m} / \mathrm{h}$ rates, differs by insufficient mixing, structural and chemical inhomogeneity, considerable coarsening and loss of nanosized oxides (Figure 1).

Therefore, the main metal physical investigations were carried out on optimally formed welds produced at high welding rates (Figure 2). At that it was reasonable to use maximum amount of the samples to cover different heat input variants. The welding modes corresponded to overrated (EBW, $90 \mathrm{~m} / \mathrm{h}$ ), optimum (LW, $90 \mathrm{~m} / \mathrm{h}$ ) and underrated (LW $180 \mathrm{~m} / \mathrm{h}$ ) heat input. EBW produced welds ( $90 \mathrm{~m} / \mathrm{h}, 2.8 \mathrm{~kW}$ ) due to overrated melt volume corresponded to heat transfer mainly through weld pool melt surface and significant overheating, and based on this index were approximated to the welds made by ArAW. The welds, produced by LW at $90 \mathrm{~m} / \mathrm{h}$ rate, due to presence of open weld pool keyhole, were subjected to less overheating in contrast to welds made by LW at $180 \mathrm{~m} / \mathrm{h}$ rate, where heat transfer was performed through side walls of the keyhole, mirror and weld pool bottom. Effect of heat input excess in the latter case was compensated due to increase of welding rate.

Nature of the heat input can be estimated following the analysis of dimensions and geometry of welds (Figure 2).
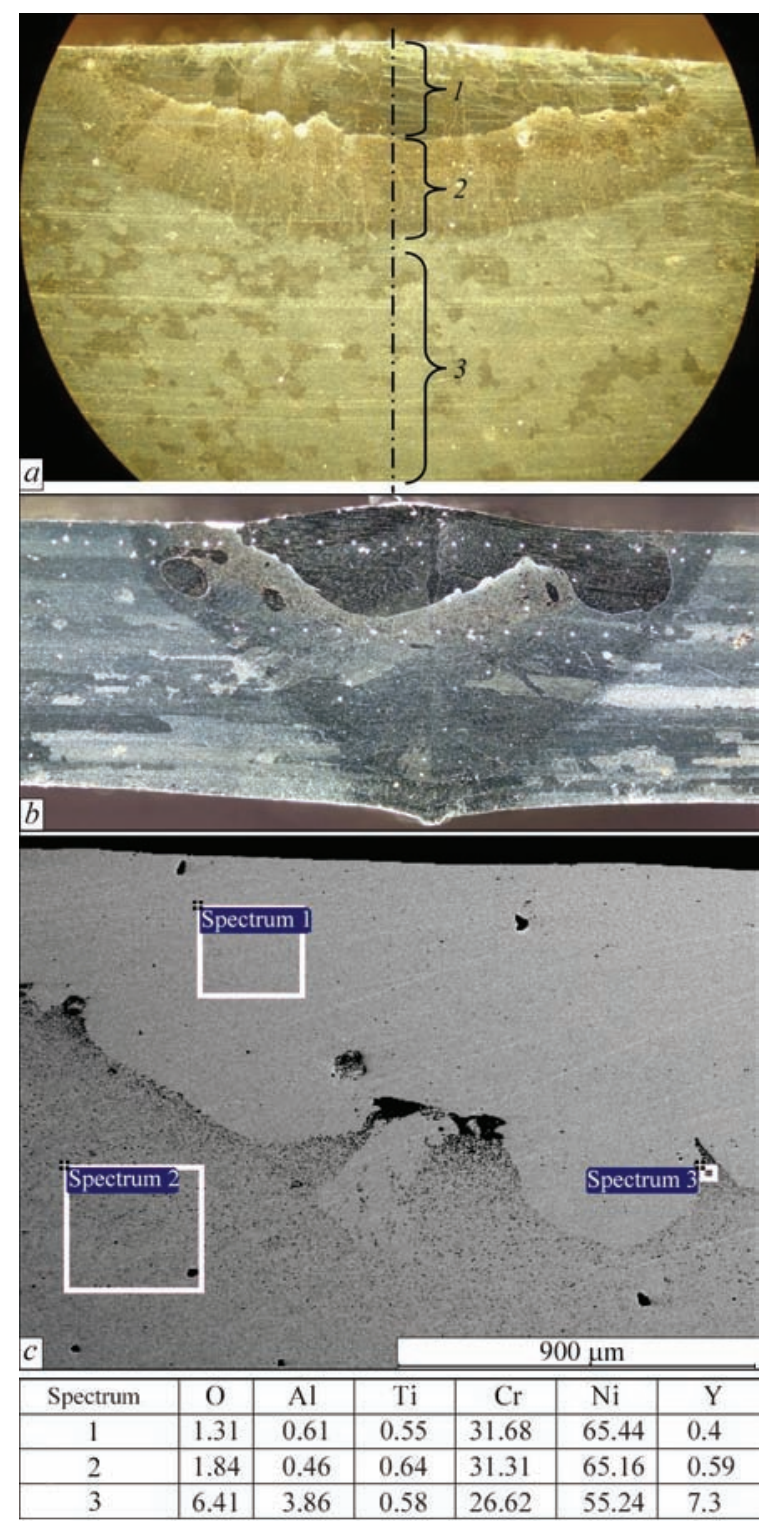

Figure 1. Macrostructure $(a-\times 40 ; b-\times 50)$ of welded joint produced by ArAW: $a$ - surface fusion of massive sample, $v_{\mathrm{w}}=$ $=8 \mathrm{~m} / \mathrm{h}\left(1-0.1 \mathrm{Y}_{2} \mathrm{O}_{3} ; 2-0.47 \mathrm{Y}_{2} \mathrm{O}_{3} ; 3-0.57 \mathrm{Y}_{2} \mathrm{O}_{3}\right) ; b-$ sample of $2 \mathrm{~mm}$ thickness, $v_{\mathrm{w}}=16 \mathrm{~m} / \mathrm{h} ; c$ - section of weld $b$ and its element-by-element analysis, at.\%
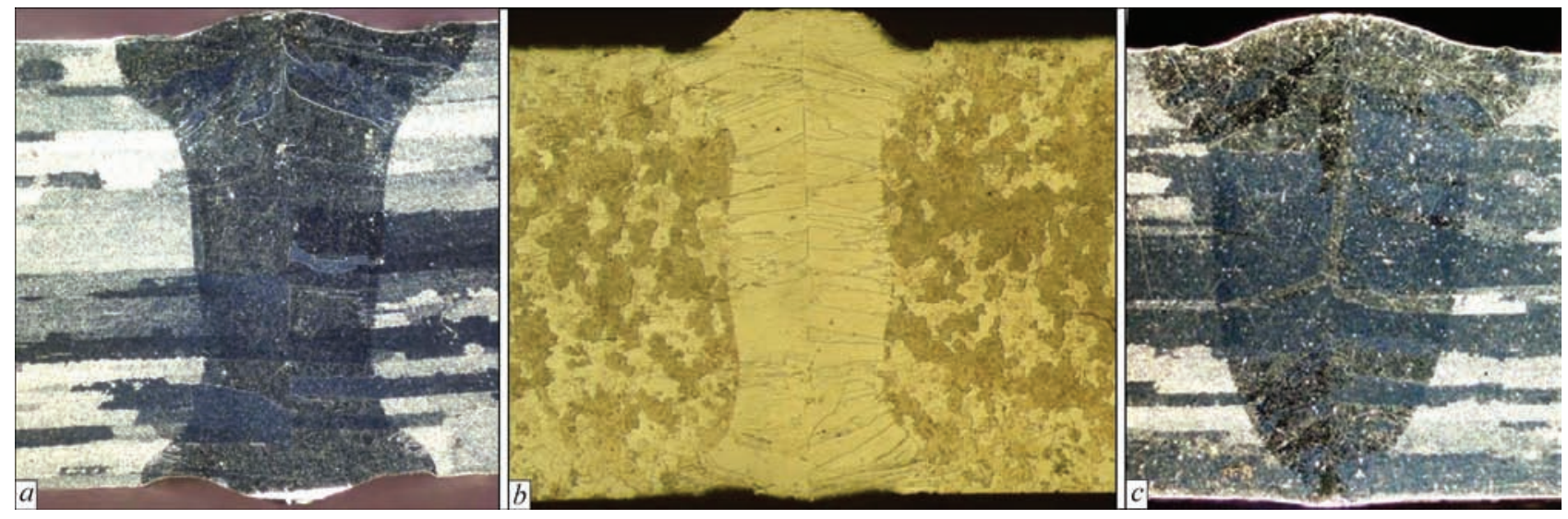

Figure 2. Macrosections $(\times 30)$ of examined welded joints from alloy InMA758: $a-\mathrm{EBW}, v_{w}=90 \mathrm{~m} / \mathrm{h}$, overrated beam power $2.8 \mathrm{~kW} ; b-\mathrm{LW}, v_{\mathrm{w}}=90 \mathrm{~m} / \mathrm{h}$, beam power $2.2 \mathrm{~kW} ; c-\mathrm{LW}, \underline{\mathrm{v}}_{\mathrm{w}}=180 \mathrm{~m} / \mathrm{h}$, beam power $2.2 \mathrm{~kW}$ 


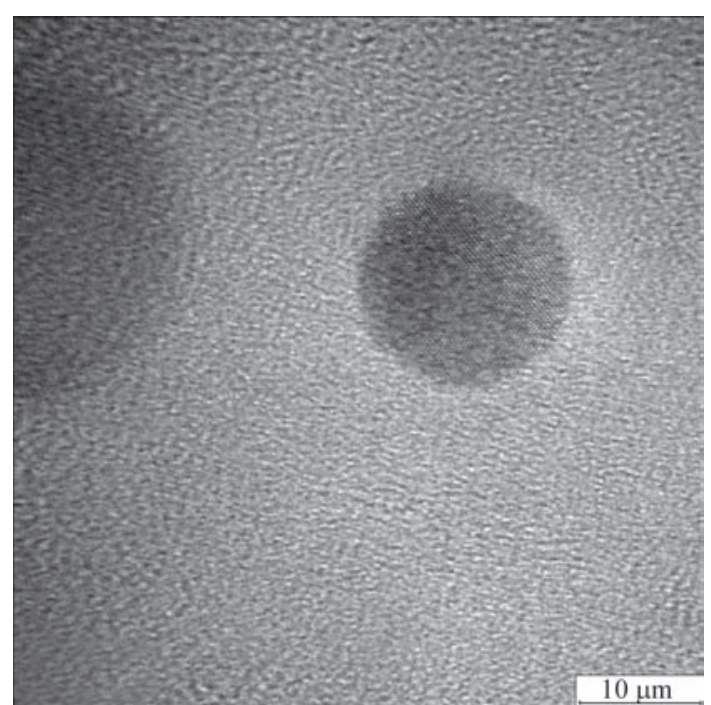

Figure 3. Transmission microscopy of initial metal of alloy InMA758 (photo was made in the Institute of Materials Science of the NAS of Ukraine)

Presence, size, distribution in weld metal, change of morphology and composition of strengthening nanoparticles were determined using Auger mi- croprobe JAMP-9500F of JEOL Company (Japan) equipped with energy-dispersion X-ray spectrometer INCAP Penta FETX3 (INCA 350 system) of Oxford Instruments Company (Great Britain). At that the particles of minimum size up to $10 \mathrm{~nm}$ were determined.

Higher accuracy on peculiarities (size, morphology, composition) of the nanoparticles can be obtained only based on the results received using transmission (Figure 3) or atomic-force microscope. However, it provokes problems with correct interpreting of the results received from some areas of the welded joint.

Taking into account indicated difficulties, quality picture of total distribution and presence of precipitations of different dispersion were evaluated following the analysis of dark-field optical images of the microstructure. They demonstrate obvious image contrast due to differences of physicomechanical properties of the strengthening particles and metal matrix (Figure 4).

Analysis of the examination results shows that structure of initial material in as-delivered condition is characterized with noticeable inhomogeneity on
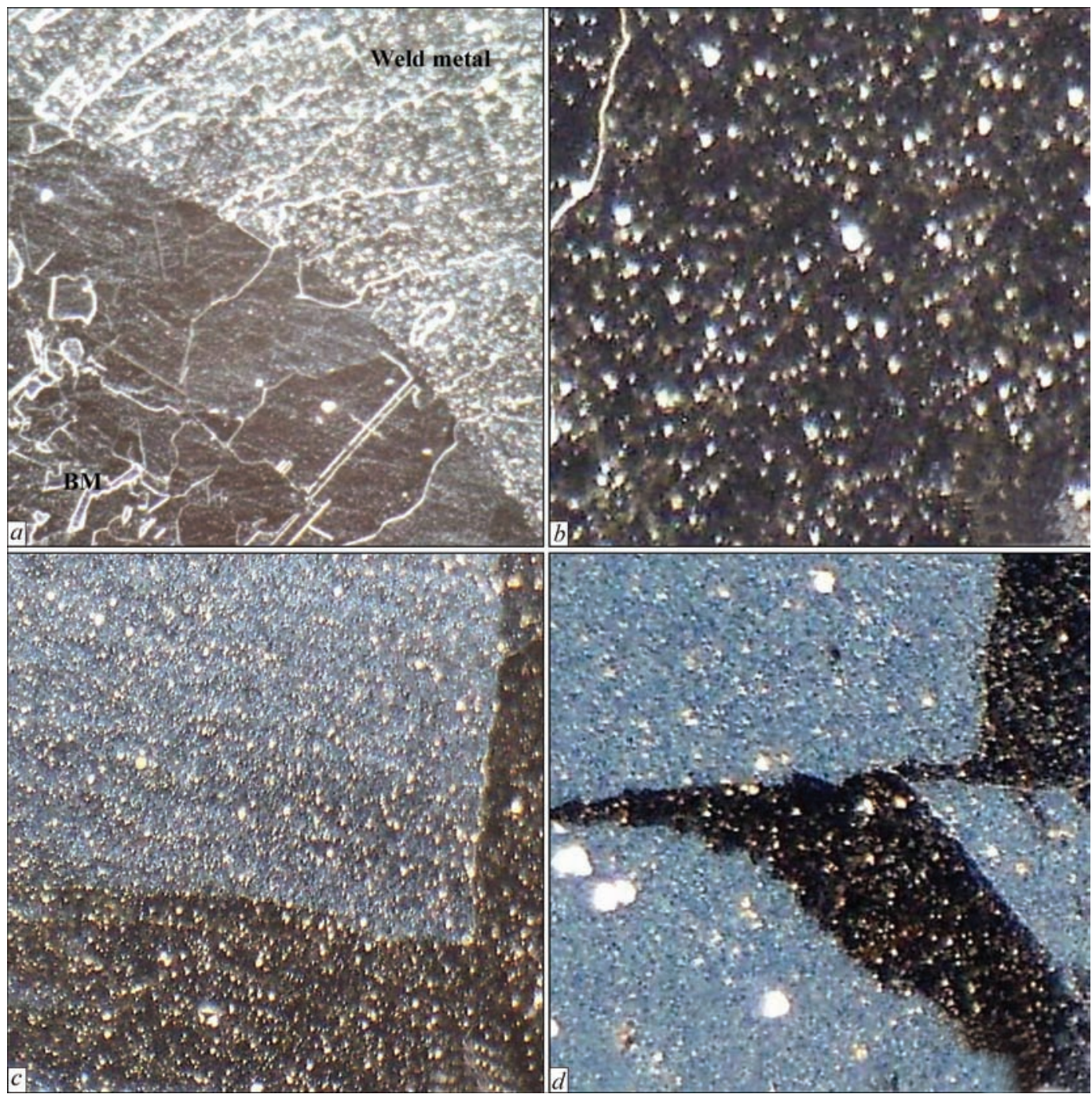

Figure 4. Microstructure $(a-\times 200 ; b-d-\times 500)$ of welds (photo in dark field): $a$ - transition area «heat affected zone-weld metal», LW, $v_{\mathrm{w}}=90 \mathrm{~m} / \mathrm{h} ; b$ - weld metal, EBW, $v_{\mathrm{w}}=90 \mathrm{~m} / \mathrm{h} ; c$ - weld metal, LW, $v_{\mathrm{w}}=90 \mathrm{~m} / \mathrm{h} ; d$ - weld metal, LW, $v_{\mathrm{w}}=180 \mathrm{~m} / \mathrm{h}$ 


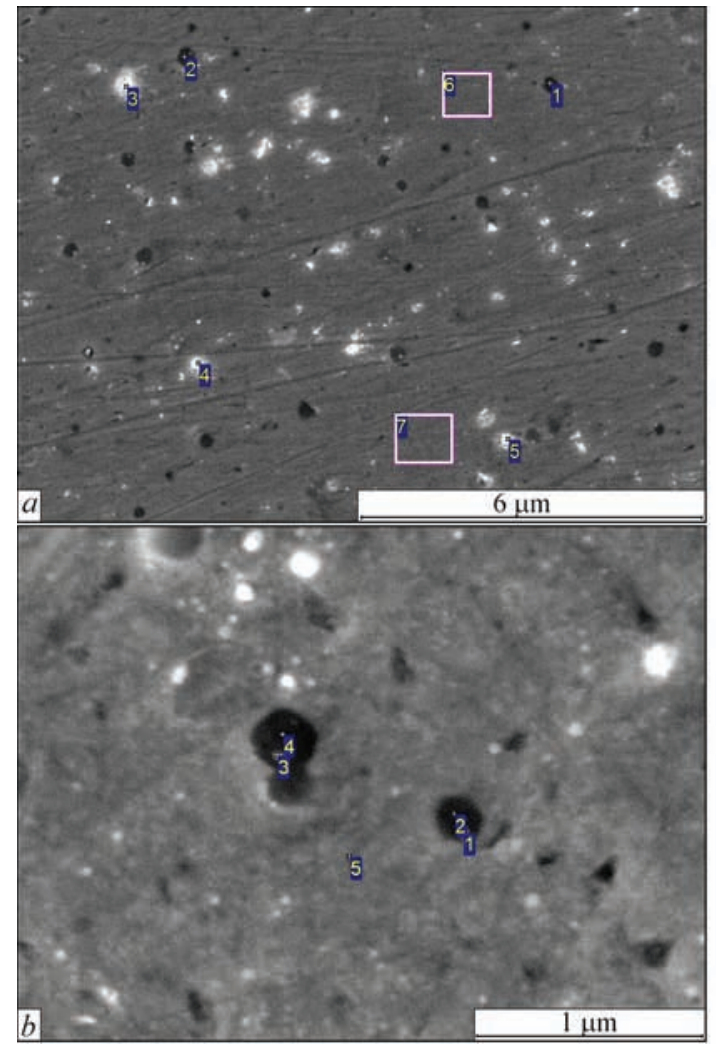

\begin{tabular}{|c|c|c|c|c|c|c|c|c|c|c|}
\hline Spectrum C & $\mathrm{N}$ & $\mathrm{O}$ & $\mathrm{Al}$ & $\mathrm{Si}$ & $\mathrm{Ti}$ & $\mathrm{Cr}$ & $\mathrm{Fe}$ & $\mathrm{Ni}$ & $\mathrm{Y}$ \\
\hline 1 & 2.74 & 32.88 & 0 & 0.84 & 0 & 29.02 & 9.94 & 0 & 23.82 & 0.77 \\
\hline 2 & 2.43 & 30.40 & 6.61 & 0.46 & 0.41 & 30.54 & 8.89 & 0 & 20.26 & 0 \\
\hline 3 & 1.78 & 0 & 27.43 & 14.02 & 0 & 0 & 16.54 & 0 & 40.23 & 0 \\
\hline 4 & 2.10 & 0 & 22.26 & 13.09 & 0.25 & 1.03 & 20.61 & 0 & 40.19 & 0.47 \\
\hline 5 & 6.57 & 0.63 & 23.44 & 13.16 & 0.35 & 0.50 & 13.37 & 0.54 & 39.76 & 1.67 \\
\hline 6 & 3.62 & 0 & 1.97 & 0.33 & 0.29 & 0 & 28.00 & 1.72 & 63.84 & 0.21 \\
\hline 7 & 1.69 & 0 & 3.49 & 0.23 & 0.11 & 0.84 & 29.04 & 0 & 64.60 & 0 \\
\hline
\end{tabular}

Figure 5. Electron image of microstructure and analysis of chemical composition, at.\%: $a$ - initial metal; $b$ - base metal

size as well as precipitation composition (Figures 4 , 5). More than 10 different types of precipitations were found. The most typical among them are:

- nanosized oxygen-containing of $\mathrm{Y}-\mathrm{O}-, \mathrm{Al}-\mathrm{O}$, $\mathrm{Y}-\mathrm{Al}-\mathrm{O}$ type make around $80 \%$ of all detected, around $30 \%$ of which are referred to precipitations of complex type $\mathrm{Y}-\mathrm{Al}-\mathrm{O}$;

- microsized nitrogen-containing of Ti-C-N, Ti-N type make approximately $20 \%$.

It should be underlined that around $25 \%$ of oxygen-containing nanoparticles are located in the center or along the surface of nitrogen-containing precipitations (Figure 5), size of the latter can make from 140 to $630 \mathrm{~nm}$. Therefore, results of their energy-dispersion analysis (EDA) often demonstrate presence of nitrogen, carbon, iron and other alloy components.

The main massif of precipitations is nanosized particles (around 15-30 nm), which mainly cause ODS-alloys specific properties [1-9] due to high specific surface energy and high resistance to dislocation displacement. Less part is microsized precipitations (around 110-290 nm), main role of which most likely comes to increase of strength according to classical theory of dispersion strengthening $[18,19]$. There are also separate precipitations of different composition of around $600-1200 \mathrm{~nm}$ size as well as conglomerates of nanosized particles of area approximately 200$4000 \mathrm{~nm}^{2}$ and more (Figure 5).
In process of welding, regardless high rates of its performance and apparent small overheating, alloy microstructure is subjected to significant changes. Size, morphology and composition of the main strengthening constituents (Figures 6-8) are changed. Virtually in all considered cases the size of oxygen-containing precipitations of $\mathrm{Y}-\mathrm{Al}-\mathrm{O}$ type rises $2-5$ times at significant decrease of size and content of $\mathrm{Y}-\mathrm{O}$ and $\mathrm{Al}-\mathrm{O}$ precipitations. Nitrogen-containing precipitations of Ti-N and Ti-C-N type are subjected to lower changes. Oxygen-containing particles of globular type, which are located inside nitrogen-containing precipitations (Figures 6-8), are found most often.

More significant changes of structure (Figure 6) are observed in the welds produced with overrated EBW heat input. As it was mentioned, the welds produced at lower rates of EBW and ArAW were eliminated from consideration due to large loss of oxides provoked by weld pool metal overheating.

LW results in increase (to $80 \%$ ) of portion of found oxide inclusions with coarse size nanoparticles up to 44-110 nm (15-24 nm in the initial metal), that, apparently, is caused by coagulation of smaller particles. Increase of microsized precipitations up to $300-510 \mathrm{~nm}$ (at $140-300 \mathrm{~nm}$ in initial metal) is noted. Portion of nitrogen-containing precipitations somewhat reduces (approximately 2-3\%). Their size rises from initial $140-290 \mathrm{~nm}$ to $270-410 \mathrm{~nm}$ and $310-410$ to $600-900 \mathrm{~nm}$ for rare microprecipitations. Increase 


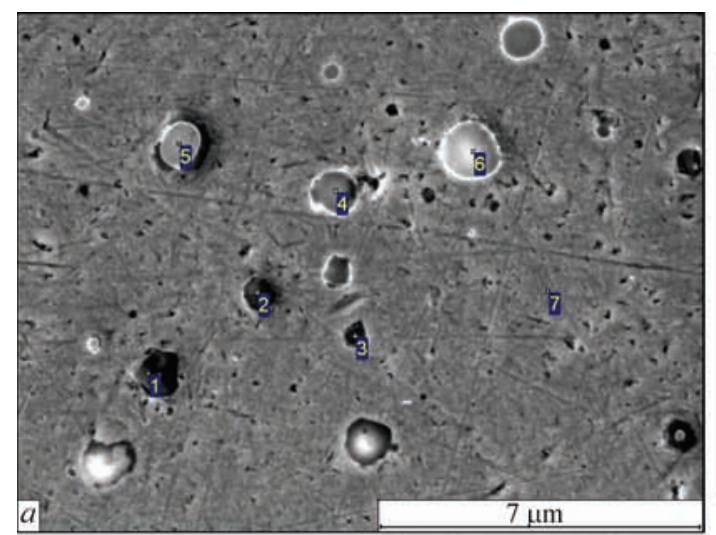

\begin{tabular}{|c|c|c|c|c|c|c|c|c|c|}
\hline Spectrum & $\mathrm{C}$ & $\mathrm{N}$ & $\mathrm{O}$ & $\mathrm{Al}$ & $\mathrm{Ti}$ & $\mathrm{Cr}$ & $\mathrm{Fe}$ & $\mathrm{Ni}$ & $\mathrm{Y}$ \\
\hline 1 & 2.25 & 47.85 & 0 & 0 & 35.02 & 9.18 & 0.37 & 5.20 & 0.14 \\
\hline 2 & 2.71 & 42.76 & 11.43 & 4.52 & 24.07 & 6.02 & 0 & 3.69 & 4.80 \\
\hline 3 & 0.54 & 0 & 55.40 & 15.48 & 1.08 & 4.10 & 0.11 & 8.04 & 15.25 \\
\hline 4 & 1.50 & 0 & 58.73 & 16.76 & 1.26 & 1.84 & 0 & 4.17 & 15.74 \\
\hline 5 & 2.45 & 0 & 59.19 & 15.70 & 5.14 & 1.28 & 0 & 1.75 & 14.48 \\
\hline 6 & 2.99 & 0 & 60.02 & 16.95 & 1.10 & 0.65 & 0 & 1.38 & 16.92 \\
\hline 7 & 2.50 & 0 & 0 & 0.71 & 0.37 & 28.78 & 0.73 & 66.67 & 0.23 \\
\hline
\end{tabular}

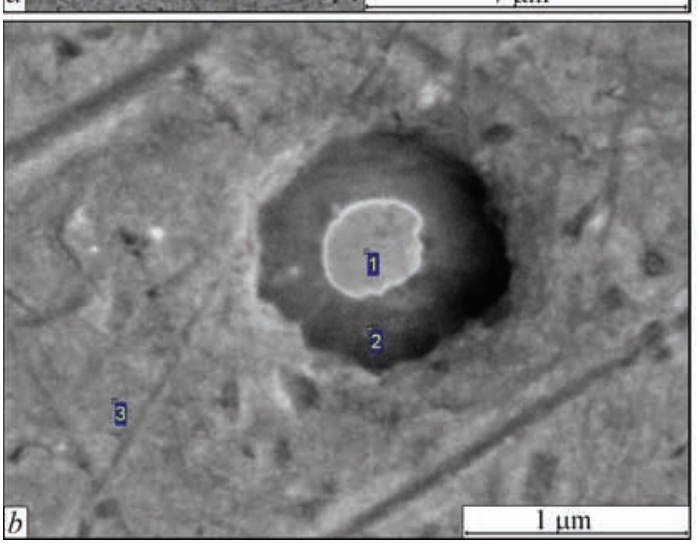

\begin{tabular}{|c|c|c|c|c|c|c|c|c|c|}
\hline Spectrum & $\mathrm{C}$ & $\mathrm{N}$ & $\mathrm{O}$ & $\mathrm{Al}$ & $\mathrm{Ti}$ & $\mathrm{Cr}$ & $\mathrm{Fe}$ & $\mathrm{Ni}$ & $\mathrm{Y}$ \\
\hline 1 & 2.68 & 5.97 & 53.56 & 16.70 & 2.56 & 0.92 & 0.50 & 1.28 & 15.83 \\
\hline 2 & 2.38 & 35.66 & 11.74 & 4.08 & 27.86 & 7.13 & 0 & 8.47 & 2.68 \\
\hline 3 & 2.91 & 0.47 & 0 & 0.11 & 0.48 & 29.67 & 0 & 66.12 & 0.24 \\
\hline
\end{tabular}

Figure 6. Electron image of microstructure and analysis of chemical composition (at.\%) of weld metal $(a, b)$ produced at EBW, $v_{\mathrm{w}}=$ $=90 \mathrm{~m} / \mathrm{h}$

of precipitation size is already noticeable on optical images in the dark field (Figure 4).

LW provokes somewhat smaller level of rise of precipitation size (Figures 7,8 ) that is, apparently, caused by increase of specific power and additional cooling due to shielding gas blowing. Thus, there is increase of size of oxygen-containing nanoparticles to 24-92 nm (Figure 7) and microsized precipitations

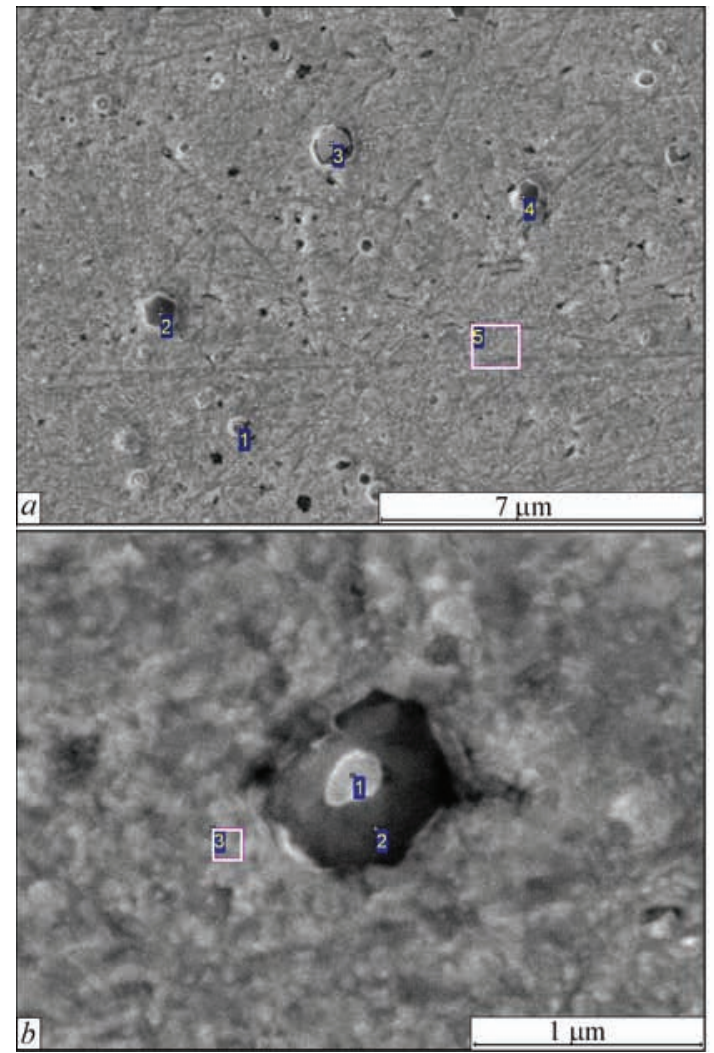

\begin{tabular}{|c|c|c|c|c|c|c|c|c|c|}
\hline Spectrum & $\mathrm{C}$ & $\mathrm{N}$ & $\mathrm{O}$ & $\mathrm{Al}$ & $\mathrm{Ti}$ & $\mathrm{Cr}$ & $\mathrm{Fe}$ & $\mathrm{Ni}$ & $\mathrm{Y}$ \\
\hline 1 & 3.16 & 0 & 24.23 & 6.45 & 4.97 & 18.10 & 0.77 & 35.06 & 7.27 \\
\hline 2 & 3.05 & 41.50 & 0 & 0.10 & 29.61 & 10.40 & 0.85 & 14.37 & 0.12 \\
\hline 3 & 1.30 & 0 & 59.10 & 13.80 & 2.73 & 1.83 & 0 & 3.85 & 17.39 \\
\hline 4 & 3.35 & 17.83 & 1.35 & 0 & 14.28 & 21.77 & 0 & 41.42 & 0 \\
\hline 5 & 2.89 & 0 & 0.16 & 0.46 & 0.42 & 28.94 & 0 & 67.14 & 0 \\
\hline
\end{tabular}

\begin{tabular}{|c|c|c|c|c|c|c|c|c|c|}
\hline Spectrum & $\mathrm{C}$ & $\mathrm{N}$ & $\mathrm{O}$ & $\mathrm{Al}$ & $\mathrm{Ti}$ & $\mathrm{Cr}$ & $\mathrm{Fe}$ & $\mathrm{Ni}$ & $\mathrm{Y}$ \\
\hline 1 & 1.55 & 5.50 & 53.20 & 17.35 & 2.33 & 1.17 & 0.49 & 2.19 & 16.24 \\
\hline 2 & 2.83 & 27.79 & 24.36 & 8.50 & 18.09 & 5.71 & 0 & 4.91 & 7.82 \\
\hline 3 & 4.80 & 2.71 & 0 & 0.48 & 0.46 & 26.25 & 0.98 & 63.92 & 0.40 \\
\hline
\end{tabular}

Figure 7. Electron image of microstructure and analysis of chemical composition (at.\%) of weld metal ( $a, b)$ produced at LW, $v_{\mathrm{w}}=90 \mathrm{~m} / \mathrm{h}$ 
SCIENTIFIC AND TECHNICAL

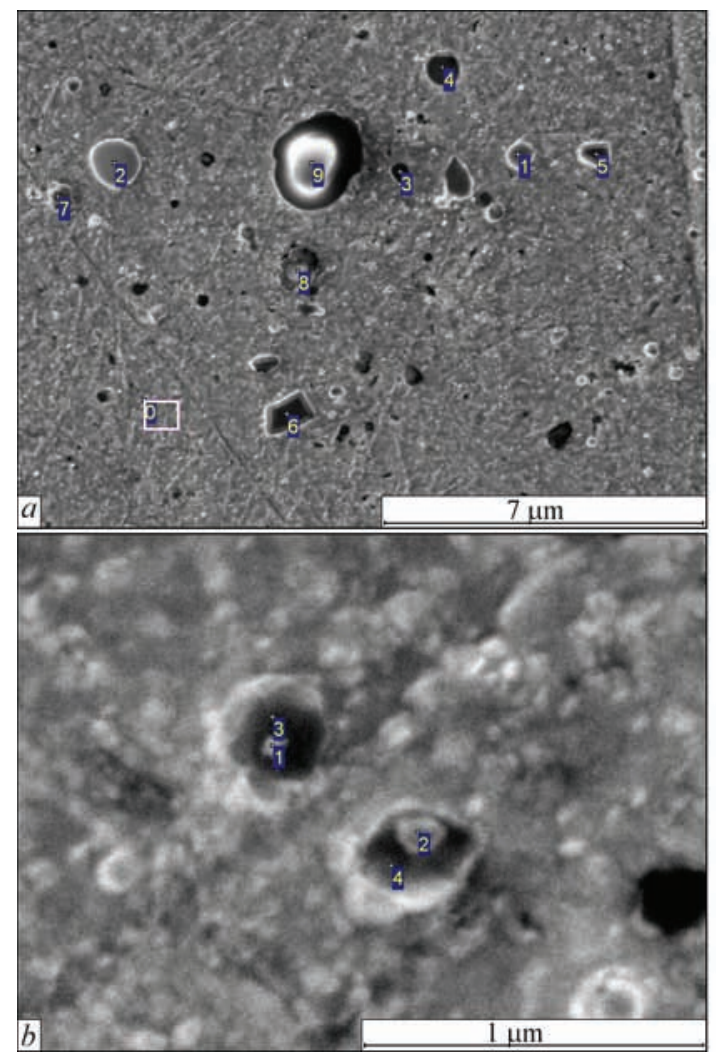

\begin{tabular}{|c|c|c|c|c|c|c|c|c|c|}
\hline Spectrum & $\mathrm{C}$ & $\mathrm{N}$ & $\mathrm{O}$ & $\mathrm{Al}$ & $\mathrm{Ti}$ & $\mathrm{Cr}$ & $\mathrm{Fe}$ & $\mathrm{Ni}$ & $\mathrm{Y}$ \\
\hline 1 & 0.89 & 0 & 13.20 & 7.39 & 1.71 & 18.29 & 0.24 & 40.04 & 18.23 \\
\hline 2 & 0.95 & 0 & 26.00 & 10.08 & 3.14 & 4.79 & 1.04 & 6.96 & 47.05 \\
\hline 3 & 1.38 & 0 & 24.69 & 13.23 & 2.48 & 5.31 & 0.19 & 18.4 & 34.25 \\
\hline 4 & 0.92 & 0 & 30.21 & 16.80 & 1.89 & 3.91 & 0 & 9.75 & 36.40 \\
\hline 5 & 0.84 & 0.48 & 16.80 & 10.22 & 4.34 & 18.22 & 0 & 29.54 & 19.56 \\
\hline 6 & 0.69 & 0 & 27.45 & 27.45 & 4.40 & 2.92 & 0.59 & 8.50 & 40.35 \\
\hline 7 & 1.01 & 8.96 & 3.68 & 3.68 & 19.58 & 20.48 & 1.21 & 37.54 & 5.56 \\
\hline 8 & 0.82 & 0 & 26.90 & 26.90 & 5.85 & 3.93 & 0 & 9.10 & 42.37 \\
\hline 9 & 0.83 & 0 & 30.82 & 30.82 & 2.53 & 1.63 & 0 & 1.87 & 45.22 \\
\hline 0 & 1.12 & 1.32 & 0 & 0 & 0 & 28.71 & 1.51 & 67.15 & 0 \\
\hline
\end{tabular}

Figure 8. Electron image of microstructure and analysis of chemical composition (at.\%) of weld metal $(a, b)$ produced at LW, $v_{\mathrm{w}}=$ $=180 \mathrm{~m} / \mathrm{h}$

to $180-360 \mathrm{~nm}$ in the welds made at $90 \mathrm{~m} / \mathrm{h}$ welding rate. Therefore, rise of size of nanoparticles to 21-70 and $140-600 \mathrm{~nm}$ for microsized ones takes place in the welds produced by $\mathrm{LW}$ at $180 \mathrm{~m} / \mathrm{h}$ rate (Figure 8). Changes of nitrogen-containing precipitations are less noticeable.

As can be seen, the difference in change of precipitation sizes in the welds, made at 90 and $180 \mathrm{~m} / \mathrm{h}$ rate is less obvious that indicates approximately similar level of their overheating.

At that, general for all considered cases is transformation of simple oxygen-containing phases of $\mathrm{Y}-\mathrm{O}$ type into more complex $\mathrm{Y}-\mathrm{Al}-\mathrm{O}$ precipitations.
It should be noted that changes that takes place at different methods and modes of welding are less noticeable in comparison with transfer from base to weld metal. Changes in the structure, which take place as a result of welding, as it was mentioned earlier, are determined by value of weld pool metal overheating. The latter depends not only on effective power of heat source, level of its concentration, welding rate, but to significant extent on nature of heat transfer, which is determined by relationship of welding mode parameters. Thus, there is obvious difference in formation of EBW and LW weld metal structure at similar welding rate, but various effective powers and heat input nature.

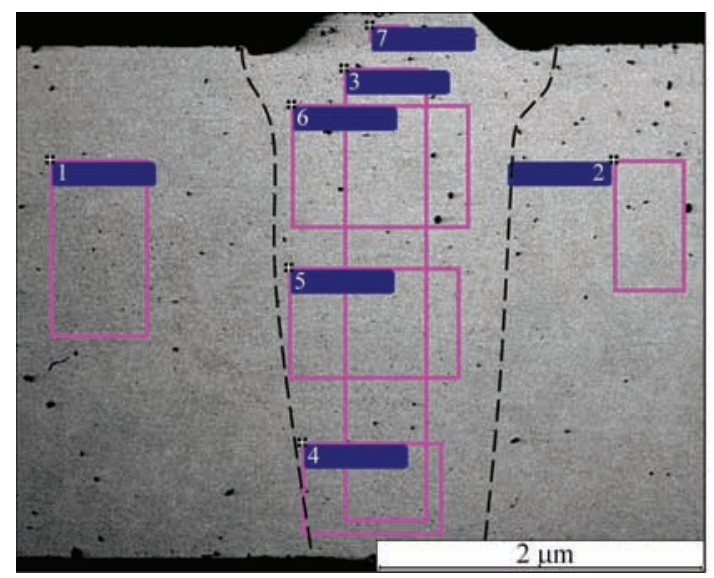

\begin{tabular}{|c|c|c|c|c|c|c|}
\hline Spectrum & $\mathrm{O}$ & $\mathrm{Al}$ & $\mathrm{Ti}$ & $\mathrm{Cr}$ & $\mathrm{Ni}$ & $\mathrm{Y}$ \\
\hline 1 & & 0.41 & 0.59 & 31.73 & 66.7 & 0.33 \\
\hline 2 & 1.66 & 0.4 & 0.52 & 30.96 & 66.46 & \\
\hline 3 & & 0.44 & 0.51 & 31.93 & 66.88 & 0.24 \\
\hline 4 & & 0.49 & 0.52 & 32.34 & 66.37 & 0.28 \\
\hline 5 & & 0.5 & 0.5 & 31.92 & 66.75 & 0.34 \\
\hline 6 & & 0.46 & 0.51 & 31.55 & 66.92 & 0.28 \\
\hline 7 & & 0.42 & 0.53 & 31.38 & 67.20 & 0.46 \\
\hline $\max$ & 1.66 & 0.5 & 0.59 & 32.34 & 67.20 & 0.46 \\
\hline $\min$ & 0 & 0.4 & 0.5 & 30.96 & 66.37 & 0 \\
\hline
\end{tabular}

Figure 9. Macrosection and chemical composition (at.\%) of separate areas of welded joint of alloy MA758 produced at EBW, $v_{\mathrm{w}}=$ $=150 \mathrm{~m} / \mathrm{h}$ 
At the same time, difference of nanodispersion of strengthening particles in the structure of weld metal produced by LW at different rates, but at somewhat different nature of heat input is less noticeable.

It should also be noted that selection of method, technological means and modes of welding determine as well uniformity of particle distribution on weld section. At low welding rate there is loss of significant portion of nanoparticles by the weld as well as their very nonuniform distribution along its section. In welding at increased rates more uniform distribution of the particles is reached (Figures 6-8), however, in this case there is some rise of their concentration in the weld upper part (Figure 9) due to removal of forming nanoparticles by molten metal flow.

Taking into account examination results it can be concluded that final recommendations on procedure of fusion welding of ODS-alloys can be made after setting a compromise between the conditions of formation of acceptable quality welds and limitations of nanostructure degradation as well as in evaluation of mechanical properties change.

\section{Conclusions}

1. It is determined that nickel ODS-alloy Inconel MA758, produced by mechanical alloying method, is characterized by presence of more than ten types of nanosized (15-100 nm) and microsized (140-610 nm) oxygen- and nitrogen-containing precipitations, noticeable chemical and structural inhomogeneity.

2. Presence of oxides in ODS-alloys to significant extent complicates quality formation of welds in fusion welding.

3. Obvious degradation of initial nanodispersed structure takes place in welding of ODS-alloys. Complete or partial loss of oxide strengthening nanoparticles in weld metal, their significant coagulation, change of morphology and chemical composition as well as formation of new phase precipitations is observed depending on method, conditions and modes of welding.

4. Level of structure degradation is mainly determined by value of weld pool metal overheating, which depends essentially on specific power of heat source, welding rate, nature of heat input and cooling in process of welding.

5. Technologically positive result can be reached due to optimization of heat input in weld pool by means of increase of welding rate and concentration of heat source power at minimal margin of power and its controlled distribution on weld pool section.

1. Gessinger, G.Kh. (1988) Powder metallurgy of high-temperature alloys. Chelyabinsk, Metallurgiya, Chelyab. Div. [in Russian].

2. Valiev, F.Z., Aleksandrov, I.V. (2007) Volumetric nanostructured metallic materials: Production, structure and properties. Moscow, IKTs Akademkniga [in Russian].

3. Chebryakova, E.V. (2011) Peculiarities of mechanism of strengthening of metal matrices with nanoparticles of refractory compounds. In: Proc. of All-Russian Conf. on Nanomaterials NANO 2011. Moscow, IMET RAN [in Russian].

4. Gusev, A.I. (1998) Effect of nanostructural state in compact metals and joints. Uspekhi Fiz. Nauk, 168, 29-58 [in Russian].

5. Soni, P.R. (2000) Mechanical alloying: Fundamentals and applications. Cambridge, Cambridge Int. Sci. Publ.

6. He, X.D., Xin, Y., Li, M.W., Sun, Y. (2009) Microstructure and mechanical properties of ODS-Ni-based superalloy foil produced by EB-PVD. J. of Alloys and Compounds, 467(12), 347.

7. Gleiter, H. (2000) Nanostructured materials. Basic concepts and microstructure. Acta Mater., 48(1), 1-29.

8. Andrievsky, R.A., Glezer, A.M. (1999) Size effects in nanocrystalline materials. Peculiarities of structure. Fizika Metallov i Metallovedenie, 88(1), 50-73 [in Russian].

9. Rebinder, P.A. (1958) Physicochemical mechanics. Moscow [in Russian].

10. Janko, B. (1986) High-temperature alloys for gas turbines and other application. Brussels, D. Ridee.

11. Kondrik, A.I., Kovtun, G.P., Datsenko, O.A. et al. (2008) Modern materials for thermonuclear power engineering. Kharkov, NNTsKhPTI [in Russian].

12. Azerenkov, N.A., Kovtun, G.P., Litovchenko, S.V. (2009) Nanotekhnologies and nanomaterials in nuclear power engineering. In: Proc. of Int. Scient. Conf. on Physicochemical Principles of Formation and Modification of Micro- and Nanostructures. FMMN, Zbirnyk Nauk. Prats. Kharkiv, NFTTsMON ta NANU, 2009, 152-157.

13. Kovtun, G.P., Verevkin, A.A. (2010) Nanomaterials: Technologies and materials science (Review). Kharkov, NNTs KhPTI [in Russian].

14. Howard, S.M., Jasthi, DB, K., Arbegast, W.J. et al. (2004) Friction stir welding of MA957 oxide dispersion strengthened ferritic steel. In: Fusion materials semiannual progress report for the period ending. December 31, 55-60.

15. Hemilton, M.L. et al. (2000) Fabrication technology for ODS alloy MA957, PNL-13165.

16. Shinozaki, K et al. (1997) Metallurgical and mechanical properties of ODS alloy MS956 friction welds. Welding J., 76(8), 289-299.

17. Feng, Z., Ren, W. (2006) Initial development in joining of ODS alloys using friction stir welding. Report No. ORNL/ GEN4LTR-06-021.

18. Portnoj, K.I., Babich, V.N. (1974) Dispersion-hardened materials. Moscow, Metallurgiya [in Russian].

19. Kelly, A., Nicholson, R. (1966) Dispersion hardening. Moscow, Metallurgiya [in Russian].

Received 12.04.2018 


\title{
EFFECT OF LIQUID GLASS COMPOSITION AND STRUCTURE ON THE STRENGTH OF LOW-HYDROGEN ELECTRODE COATINGS
}

\author{
A.E. MARCHENKO ${ }^{1}$, V.V. TRACHEVSKY ${ }^{2}$ and N.V. SKORINA ${ }^{1}$ \\ ${ }^{1}$ E.O. Paton Electric Welding Institute of the NAS of Ukraine \\ 11 Kazimir Malevich Str., 03150, Kyiv, Ukraine. E-mail: office@paton.kiev.ua \\ ${ }^{2}$ Technical Center of the NAS of Ukraine \\ 13 Pokrovskaya Str., 04070, Kyiv, Ukraine. E-mail: tracev@imp.kiev.ua
}

\begin{abstract}
The paper presents the results of investigations of the strength of coatings of low-hydrogen electrodes, baked at 200, 300 and $400^{\circ} \mathrm{C}$, depending on the composition of liquid $\mathrm{Li}$-, Na- and K-glasses, as well as their binary mixtures. Investigation results were interpreted from the viewpoint of evolution of silicon-oxygen structure of liquid glasses under the conditions of changing kind and ratio of cations-modifiers, as well as the level of water content, related to the parameters of electrode heat treatment. Diagnostics of structural-functional self-organization of silicon-oxygen anions (SOA) in the liquid glass composition was performed with application of the data of nuclear magnetic resonance (NMR). $\mathrm{NMR}^{29} \mathrm{Si}$ spectrum was used. The generalized results were considered in terms of dominance of polycondensation mechanism. A correlation was established between the values of coating strength and ratio of bridge $\mathrm{Q}^{4}, \mathrm{Q}^{3}, \mathrm{Q}^{2}$ and non-bridge $\mathrm{Q}^{1}$ connectivities in SOA structure. 8 Ref., 4 Tables, 12 Figures.
\end{abstract}

Ke y words : arc welding, welding electrodes, manufacturing technology, liquid glass, liquid glass structure, application of NMR spectroscopy method

Searching for methods to improve the mechanical strength of coatings of low-hydrogen electrodes is an urgent engineering problem:

- violation of the continuity of coatings during their transportation from the manufacturer to the user is the cause for an essential degradation of the quality of electrodes as industrial products;

- spalling and cracks arising in the low-strength coating, cause formation of pores, undercuts and other critical defects in welds, resulting in degradation of their quality and lowering of operational reliability of welded structures;

- low strength of coatings essentially limits the possibilities for improvement of metallurgical characteristics of electrodes, such, in particular, as reaching a low and ultra-low content of hydrogen in the deposited metal, as well as reaching the specified resistance of the coating to absorption of atmospheric moisture. This can be achieved by deep dehydration of the coating, as well as application of liquid glasses, the dry residue of which is non-hygroscopic, that, in its turn is associated with the need to provide its strength.

In view of the above problems, the levels of requirements to coating strength, similar to other quality characteristics of electrode products, cannot be established. Demand practically continuously tightens these requirements. The scientific base underlying development of the respective compositions of electrode coatings and their manufacture technology, should be also improved, accordingly.

Thus, it is necessary to understand the nature of strength of electrode coatings, clarify the causes for its evolution at the change of material composition and dehydration of liquid glass - the coating binder - at heat treatment of electrodes, as well as find effective techniques, eliminating manifestation of the above drawback.

Electrode heat treatment is usually performed in two stages (Figure 1): low-temperature (air drying or

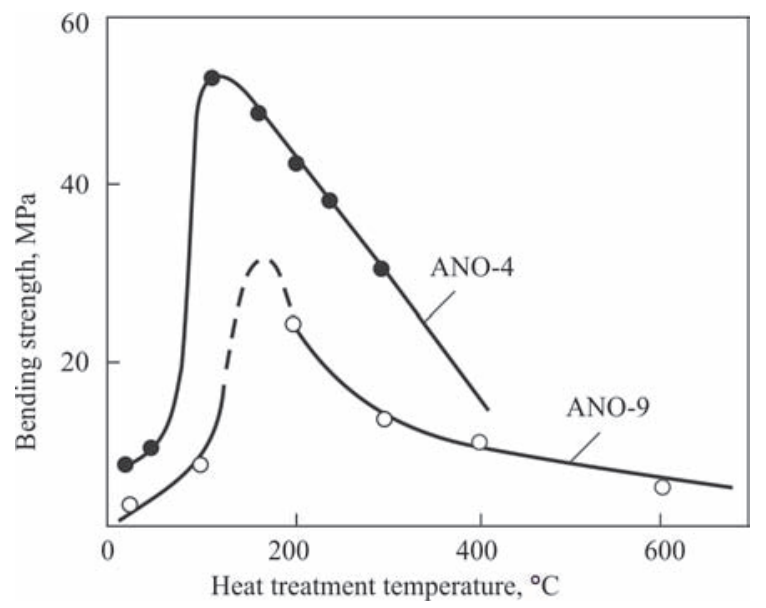

Figure 1. Dependence of strength of cylindrical samples, extruded from covering of electrodes of ANO-4 and ANO-9 grades on heat treatment temperatures [1] 


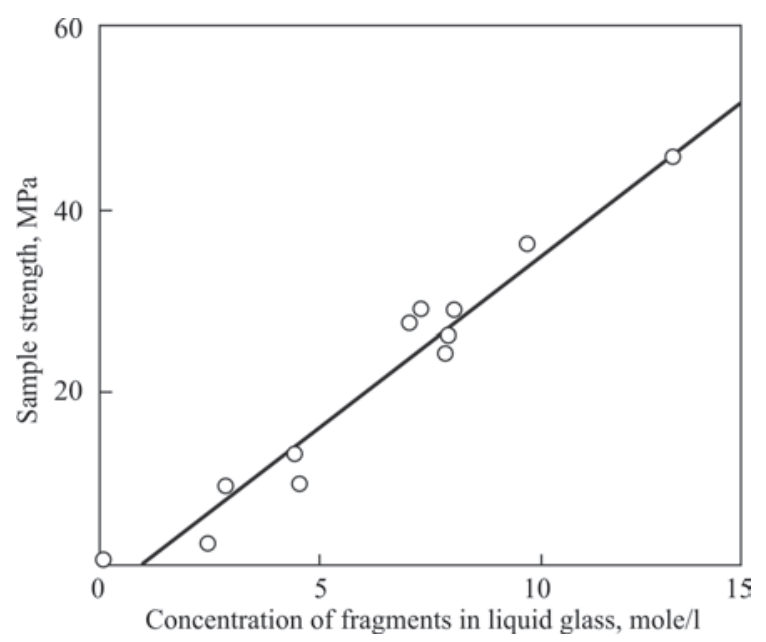

Figure 2. Dependence of strength of silicate stone on total concentration of $\equiv \mathrm{SiO}^{-}+\equiv \mathrm{SiOH}$ fragments in liquid glass (filler is quartz flour) [2]

heating of electrodes up to the temperature of 140 $160^{\circ} \mathrm{C}$ ) and high-temperature (heating and soaking at $200^{\circ} \mathrm{C}$ for rutile and at $400{ }^{\circ} \mathrm{C}$ for low-hydrogen electrodes). At the first stage of the process, the coating acquires the specified strength and water resistance. The second stage is introduced with the purpose of achievement of the degree of dehydration, which is required to lower the hydrogen content in the deposited metal. However, coating strength at this stage is reduced considerably.

This can be due to dehydration of hydrated forms of silicon-oxygen anions (SOA) in the composition of liquid glass binder, the structure of which determines their binding properties.

The essence of the processes of strength formation proceeding in the coating during the low-temperature stage, can be presented in the case of liquid glass cements - binding compositions of alkaline activation, the hardness of which is determined by molecular distribution of liquid glass components [2]. Formation of silicon-oxygen frame, binding the filler particles into a strong «silicate stone», occurs due to connection of

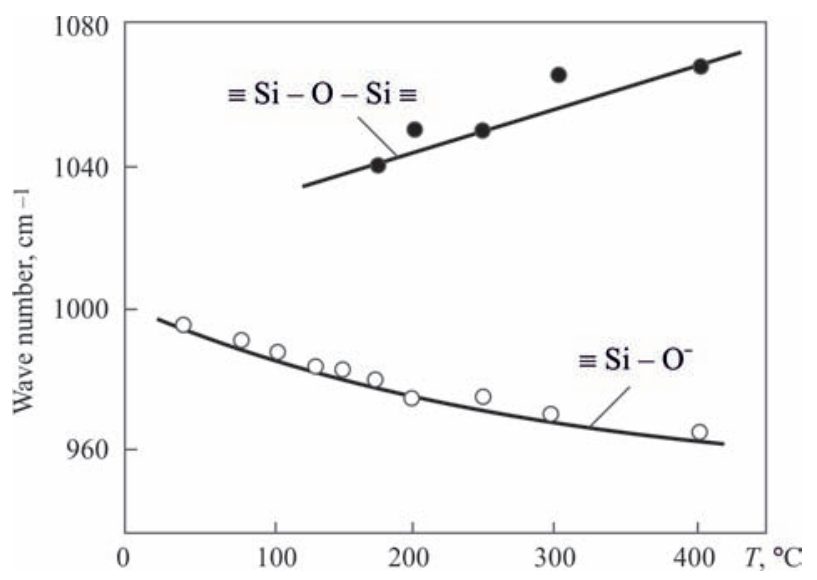

Figure 3. Effect of temperature of sodium hydrosilicate $\mathrm{Na}_{2} \mathrm{O} \cdot 2.33 \mathrm{SiO}_{2} \cdot 6 \mathrm{H}_{2} \mathrm{O}$ on SOA structure [5] polymer fragments of different dimensions. At dehydration, it is necessary to take into account water, both that initially introduced into the system as a solvent, and appearing at structure formation due to intermolecular and interfragment condensation.

Additives in the form of calcium silicate powders are used in classic liquid-glass cements to increase the degree of structuring [3]. Hardening of electrode coverings is promoted by marble powder - coating ingredient, which interacts with liquid glass through the reactions of ion exchange and substitution [4].

At application of glass with module $\mathrm{M}<2.5$, in the structure of which $\mathrm{Q}^{1}$ connectivities prevail, the process of «silicate stone» formation is presented by reactions of condensation of fragments, containing $\equiv \mathrm{SiO}^{-}$and $\equiv \mathrm{SiOH}$ groups:

$$
\begin{aligned}
\equiv \mathrm{Si}-\mathrm{O}^{-}+\equiv \mathrm{SiOH} \leftrightarrow & \equiv \mathrm{Si}-\mathrm{O}-\mathrm{Si} \equiv+\mathrm{OH}^{-}, \\
& \equiv \mathrm{Si}-\mathrm{OH}+\mathrm{OH}^{-} \leftrightarrow \equiv \mathrm{Si}-\mathrm{O}^{-}+\mathrm{H}_{2} \mathrm{O},
\end{aligned}
$$

the equilibrium of which is shifted in the direction opposite to dissolution of the silicate block. Strength acquired by «silicate stone» during running of reactions (1) and (2) is proportional to total content of reaction-capable $\equiv \mathrm{SiO}^{-}$and $\equiv \mathrm{SiOH}$ groups (Figure 2).

In liquid glasses with silicate module $2.5<\mathrm{M}<$ $<3.0$ reaction-capable silicon-oxygen derivatives with $\mathrm{Q}^{2}$ and $\mathrm{Q}^{3}$ connectivities prevail. They have one or two non-bridge bonds. Reactivity of the above SOA groups, moderate in terms of the level, complexity and degree of increase of the stone strength, is compensated by their concentration.

Liquid glasses with $\mathrm{M}>3.0$, containing predominantly $\mathrm{Q}^{4}$ connectivities, have weak binding properties, and they are not used in liquid-glass cements for these purposes. Degradation of binding capacity of alkaline hydrogel under the influence of $\mathrm{Q}^{4}$ connectivity should be regarded as the cause for lowering of the coating strength during the second stage of electrode heat treatment, when accumulation of the respective derivatives takes place.

SOA polycondensation is accompanied by a deeper degradation of the matrix structure and lowering of binding capacity of alkaline hydrogel. Concentration of SOA with $\mathrm{Q}^{4}$ connectivity in the structure can reach critical values and can cause a sharp decrease in coating strength.

The negative, from this viewpoint, degradation of SOA structure with accumulation of $\mathrm{Q}^{4}$ connectivity in it, was experimentally confirmed.

Figure 3 gives the obtained by IR-spectroscopy method data on the fractions of rigid $(\equiv \mathrm{Si}-\mathrm{O}-\mathrm{Si} \equiv)$ and elastic $\left(\equiv \mathrm{S}-\mathrm{O}^{-}\right)$forms of connectivities in the structure of SOA, precipitated from liquid glass of sodium hydrosilicates $\mathrm{Na}_{2} \mathrm{O} \cdot 2.33 \mathrm{SiO}_{2} \cdot 6 \mathrm{H}_{2} \mathrm{O}$, depending on dehy- 
Table 1. Chemical composition, density and viscosity of liquid Li-, Na- and K-glasses [6]

\begin{tabular}{|c|c|c|c|c|c|c|c|}
\hline \multirow{2}{*}{ Glass type } & \multirow{2}{*}{ Module } & \multicolumn{4}{|c|}{ Weight fraction, \% } & \multicolumn{2}{c|}{ Steel properties } \\
\cline { 3 - 8 } & & $\mathrm{SiO}_{2}$ & $\mathrm{Li}_{2} \mathrm{O}$ & $\mathrm{Na}_{2} \mathrm{O}$ & $\mathrm{K}_{2} \mathrm{O}$ & $\rho, \mathrm{kg} \cdot \mathrm{m}^{-3}$ & $\eta, \mathrm{mPa} \cdot \mathrm{s}$ \\
\hline $\mathrm{Li}$ & 2.77 & 25.52 & 4.60 & - & - & 1313 & 325 \\
\hline $\mathrm{Na}$ & 3.09 & 28.54 & - & 8.40 & 1.70 & 1433 & 325 \\
\hline $\mathrm{K}$ & 3.67 & 26.37 & - & 1.66 & 8.93 & 1422 & 360 \\
\hline
\end{tabular}

dration temperature. One can see that increase of dehydration temperature is indeed accompanied by SOA polymerization that results in enrichment of their structure by rigid and brittle elements due to reduction of the fraction of elements with elastic bonds in it.

Object and procedure of investigations. Coatings of test low-hydrogen electrodes, based on mono-alkaline (Li, Na, K) and binary (Li, Na-, Li, K- and $\mathrm{Na}, \mathrm{K}-$ ) liquid glasses with different ratio of alkaline components were selected for study. Binary mixtures were prepared by applying mono-alkaline liquid glasses (Table 1). Lithium glasses were synthesized by wet method, and sodium and potassium ones - by autoclave dissolution of silicate lumps of commercial quality.

Material composition, density $\rho$, viscosity $\eta$, preparation methods, as well as the results of studying the features of binary glass structure with application of NMR-spectroscopy on ${ }^{29}$ Si nuclei are described in [6].

Structure of liquid glasses was presented as a combination of the fraction of $\left(\mathrm{Q}^{4}, \mathrm{Q}^{3}, \mathrm{Q}^{2}\right.$ and $\left.\mathrm{Q}^{1}\right)$ connectivities of different complexity in SOA chains and frame, which was determined by the values of integral intensities of signals of ${ }^{29} \mathrm{Si}$ atom nuclei with characteristic values of chemical shifts, measured at room temperature in the spectrometer of AVANSE 400 model of BRUKER Company, Germany [6].

As one can see (Table 1), mono-alkaline Li-, Na-, and K- liquid glasses were used to prepare the coverings, designed for assessment of coating strength, with the same consistency as in [6].

Unlike them, binary glasses were preliminarily brought to the level of viscosity of initial mono-alkaline glasses, by dilution by small water additives, with the aim of leveling the synergetic effect. In liquid $\mathrm{Li}$, K-glasses, containing from 16.3 up to 50.0 wt.\% of potassium component, the synergetic viscosity surge reached $20800 \mathrm{mPa}$ 's in the initial condition. Therefore, the degree of their dilution is much greater than that of the other glasses.

Covering with $24 \%$ fraction of liquid glass was prepared in the intensive mixer. Capillary plastometer OB 1435 was used to form from the covering the samples of a cylindrical shape of $4 \mathrm{~mm}$ diameter and 40 $50 \mathrm{~mm}$ length, designed for strength assessment. The consistency of the absolute majority of the coverings allowed producing extrudate of the required quality.
Cracks were found in extrudate billets from four $\mathrm{Li}$, Na-coverings and two Li, K-coverings, differing by a more rigid consistency. In this case, extrudate samples for strength testing were taken from sections not affected by cracks.

After drying in air for one day the cylindrical samples were soaked in the furnace at $T=150{ }^{\circ} \mathrm{C}$, and then were baked for one hour stage-by-stage at the temperature of 200,300 and $400{ }^{\circ} \mathrm{C}$.

Strength of samples was evaluated after cooling to room temperature by the method of three-point bending with application of spring autoplastometer OB 2059. Its standard indenter with conical profile was replaced by a wedge-shaped die for the duration of the tests. The block-diagram of the device for the above tests is presented in Figure 4.

Testing samples of exactly the described configuration allowed observing the change of strength during dehydration of coating material in the pure form without superposition of contributions from thermosetting, thermoelastic (coefficient) and thermal (gradient) stresses, usually arising in coatings deposited on the rods [7].

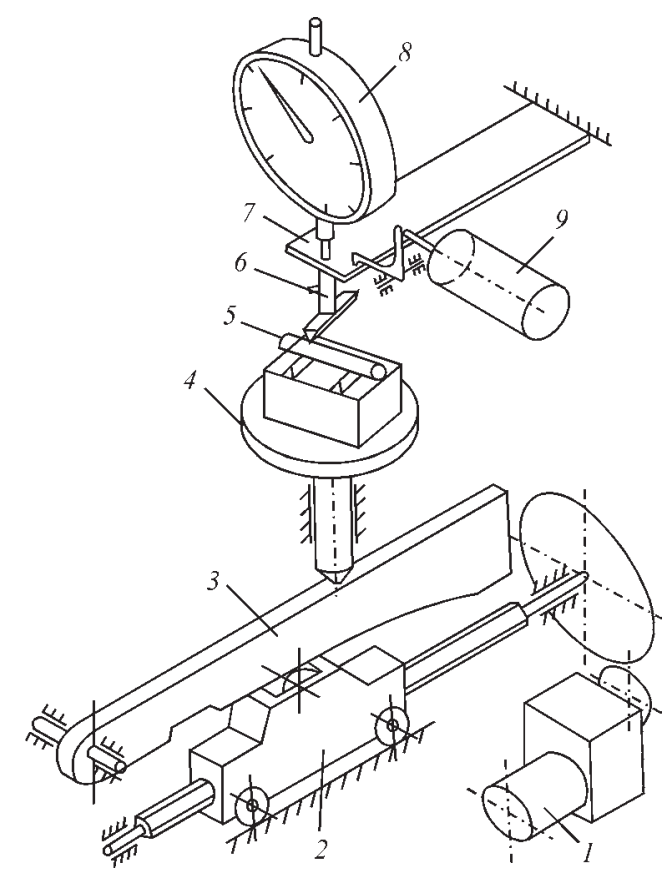

Figure 4. Block diagram of the device based on autoplastometer OB 2059, for determination of strength of ECM samples: 1 electric drive, 2 - carriage; 3 - guide block; 4 - worktable; 5 - sample; 6 - wedge indenter; 7 - dynamometer; 8 - clocktype indicator of displacement; 9 - self-recorder 
Table 2. Characteristics of the structure of SOA in mono-alkaline liquid glasses and strength of ECM samples prepared from them

\begin{tabular}{|c|c|c|c|c|c|c|c|c|}
\hline \multirow{2}{*}{ Kind of glass } & \multirow{2}{*}{ Viscosity, $\mathrm{mPa} \cdot \mathrm{s}$} & \multicolumn{4}{|c|}{ Fraction of connectivities in liquid glass structure, $\%$} & \multicolumn{3}{|c|}{$\begin{array}{c}\text { ECM strength*, } \\
\text { ture, }{ }^{\circ} \mathrm{C}\end{array}$} \\
\hline & & $\mathrm{Q}^{1}$ & $\mathrm{Q}^{2}$ & $\mathrm{Q}^{3}$ & $\mathrm{Q}^{4}$ & 200 & 300 & 400 \\
\hline $\mathrm{Li}_{2} \mathrm{O} \cdot 2.77 \mathrm{SiO}_{2}$ & 325 & 11.2 & 24.0 & 38.3 & 26.5 & 31.5 & 21.0 & 20.5 \\
\hline $\mathrm{Na}_{2} \mathrm{O} \cdot 3.09 \mathrm{SiO}_{2}$ & 325 & 13.0 & 32.9 & 38.1 & 16.0 & 60.0 & 47.5 & 37.0 \\
\hline $\mathrm{K}_{2} \mathrm{O} \cdot 3.67 \mathrm{SiO}_{2}$ & 360 & 10.1 & 34.7 & 41.7 & 13.5 & 50.0 & 47.0 & 44.0 \\
\hline
\end{tabular}

Strength of samples, made with liquid Li-, Naand K-glasses. Table 2 gives the structural characteristics of mono-alkaline liquid glasses, $\mathrm{Q}^{\mathrm{n}}$, and strength characteristics of samples of electrode coating material (ECM) made on their base.

From the data of Table 2 it follows that ECM strength level during dehydration is determined both by chemical composition of liquid glasses, and degree of moisture removal achieved during electrode heat treatment.

Higher strength of samples on sodium silicate base than that of its lithium analogs, is attributable, primarily, to a smaller fraction of rigid connectivities $\mathrm{Q}^{4}$ and at the same time greater fraction of elastic connectivities $\mathrm{Q}^{2}$ in the glass (content of $\mathrm{Q}^{3}$ structural elements in liquid glasses, which are the base of the compared ECM samples, is the same).

At transition from ECM Na-liquid glass matrix to K-matrix the fraction of bridge connectivities $\mathrm{Q}^{4}$ decreases in it and that of elastic $\mathrm{Q}^{2}$ and $\mathrm{Q}^{3}$ increases equivalently. Nonetheless, in terms of coating strength, such a replacement turned out to be beneficial only at increase of sample baking temperature up to $400{ }^{\circ} \mathrm{C}$.

The observed effect is certainly related to that the hydroxyl groups are preserved in potassium glass SOA structure up to a higher temperature than that in Li- and Na-glasses [8]. Accordingly, resynthesis of silanol fragments, which are usually broken up by reaction-capable hydroxide ions during dissolution of the silicate lump in an aqueous media, is usually delayed.

NMRS method visualizes the final patterns of the ratio of connectivities in SOA structure under the combined impact of hydroxyl ions and cations-modifiers of hydrosilicate. With increase of electrode baking temperature, the embrittling role of resynthesized structures in lowering of coating strength can become a decisive one.

Influence of combined glasses on ECM strength. Results of determination of the strength of samples of ECM based on binary liquid glasses are given in Figure 5.

As one can see the interconnection between the composition of binary alkaline hydrosilicates in the space between the coating ingredient grains and depth of their dehydroxylation during electrode heat treatment and ECM strength is ambiguous.

This applies both to the nature and degree of the above influence.

1. Substitution of Li-cations-modifiers having a higher energy potential, compared to $\mathrm{Na}^{+}$or $\mathrm{K}^{+}$(they are characterized by smaller $\mathrm{Z} / \mathrm{r}$ values) in the composition of liquid Li, Na- and Li, K-glasses, is accompanied by a considerable increase of the strength of ECM samples in the entire range of baking temperatures (dotted lines). The higher the baking temperature, the lower the total level and degree of increase of sample strength. At the same time, the nature of change of the strength of ECM samples, based on liquid $\mathrm{Na}, \mathrm{K}$-glasses with different ratio of $\mathrm{Na}$ - and $\mathrm{K}$-components in the mixtures, depends on the conditions of sample heat treatment. So, the strength of samples, baked at $200{ }^{\circ} \mathrm{C}$, decreases, and that of samples baked at $300{ }^{\circ} \mathrm{C}$, remains at an approximately constant level. However, in the case of samples baked at $400{ }^{\circ} \mathrm{C}$, it increases at increase of the fraction of $\mathrm{K}$-component in the mixture.

2. In the range between the extreme values, the sample strength changes non-monotonically, depending on the fraction of the substitution component in binary binder. It deviates from the additive value, both to the lesser (in the left part of the diagram) and to the greater (in the right part of the diagram) level.

Minimums of strength are expressed to the greatest extent in Li, K-compositions, their depth somewhat decreasing with increase of the degree of sample dehydration, resulting from increase of their baking temperature.

The observed initial minimal values of strength are expressed to the smallest degree in Li, Na-compositions. In $\mathrm{Na}$,K compositions the left, weak minimum of strength, is observed in samples, dehydrated at $300{ }^{\circ} \mathrm{C}$; with increase of the degree of dehydration the depth of the minimum somewhat increases.

3. Degree of singularity of maximums of strength values in the right part of the diagrams also depends on the combination of the applied liquid glasses and temperature of ECM sample heat treatment. In $\mathrm{Na}$, 

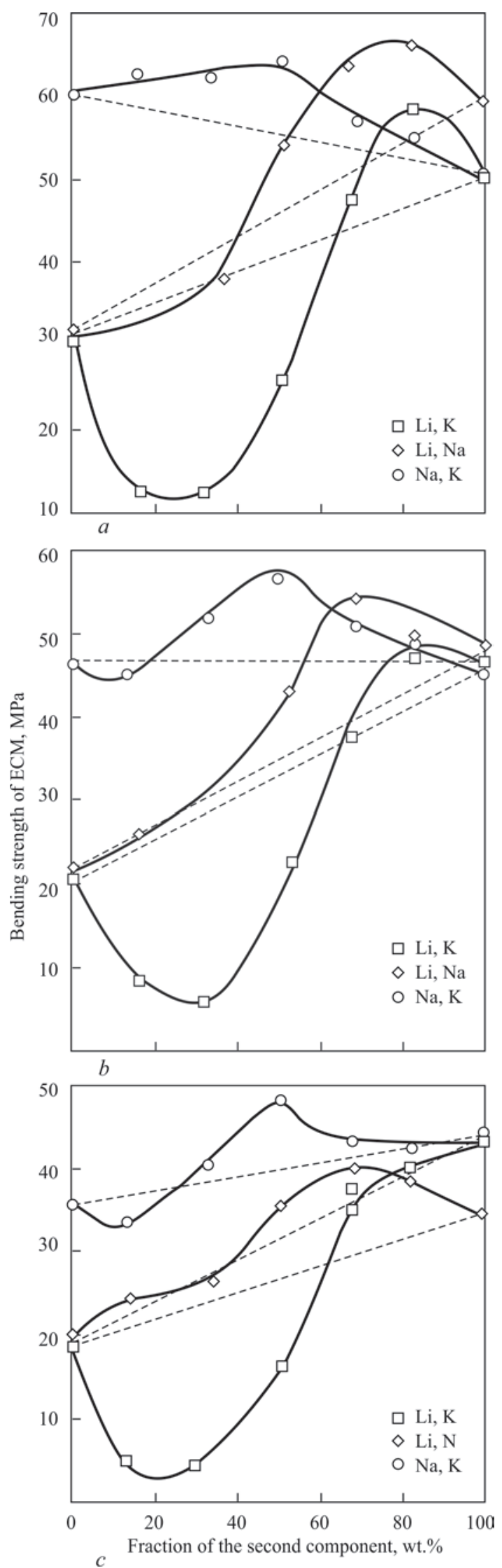

Figure 5. Influence of the composition of binary liquid Li, Na-, $\mathrm{Li}, \mathrm{K}-$ and $\mathrm{Na}, \mathrm{K}$-glasses on the strength of ECM samples, baked at $200(a), 300(b)$ and $400{ }^{\circ} \mathrm{C}(c)$
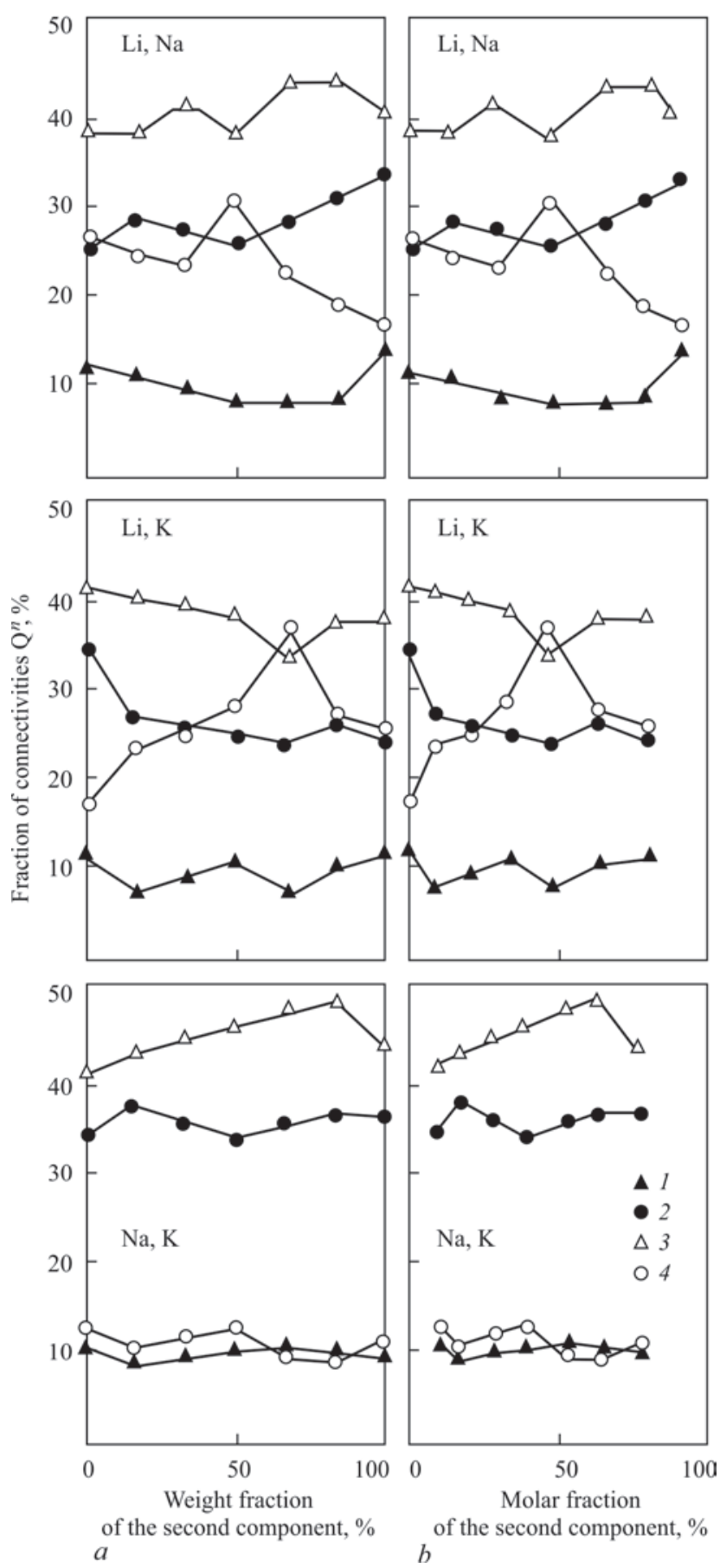

Figure 6. Evolution of $\mathrm{NMR}^{29} \mathrm{Si}$ parameters of combined liquid $\mathrm{Li}, \mathrm{Na}-$, $\mathrm{Li}, \mathrm{K}-$ and $\mathrm{Na}, \mathrm{K}$-glasses, depending on weight $(a)$ and molar $(b)$ ratio of mono-alkaline components included into them $\left(1-\mathrm{Q}^{1} ; 2-\mathrm{Q}^{2} ; 3-\mathrm{Q}^{3} ; 4-\mathrm{Q}^{4}\right)$

$\mathrm{K}$-series of samples the strength values in the maximum rise with $T_{\mathrm{b}}$ increase, in $\mathrm{Li}$, Na they decrease and are blurred, and in $\mathrm{Li}, \mathrm{K}$ they completely degenerate.

The above configuration features of strength diagrams of electrode compositions based on binary liquid glasses, can be attributed to availability of a wide range of structural forms of silicates, which are formed in the final silicon-oxygen matrix and determine the composition strength, as well as the complexity and diversity of the processes, i.e. presence 
of several directions of mutual transformation of the above forms.

Features of structural-functional transformations, due to variation of the composition of binary liquid glasses. Using the $\mathrm{NMR}^{29} \mathrm{Si}$ spectroscopy data given in a generalized form in Figure 6, we will consider, first of all, how the ratio of structural forms of silicates in binary liquid $\mathrm{Li}, \mathrm{Na}-, \mathrm{Li}, \mathrm{K}-$ and $\mathrm{Na}$, K-glasses changes.

So, in the structure of liquid Li,Na-glasses the fraction of connectivities $\mathrm{Q}^{3}$, compared to other kinds of the considered binary liquid glasses, is maximum, and is on the level of $40 \%$, irrespective of the ratio of the lithium and sodium components.

Judging by the stoichiometry, the following exchange reactions can run in structural transformations of this group of liquid glasses:

$$
\begin{aligned}
& 2 \mathrm{Q}^{4} \leftrightarrow \mathrm{Q}^{3}+\mathrm{Q}^{2} \\
& 2 \mathrm{Q}^{2} \leftrightarrow \mathrm{Q}^{3}+\mathrm{Q}^{4}
\end{aligned}
$$

With increase of the fraction of the sodium component in the mixture, the concentration of $\mathrm{Q}^{2}$ structural units rises monotonically (from 25 up to $35 \%$ ), and $\mathrm{Q}^{4}$ decreases from 25 to $18 \%$, respectively.

For a mixture with equal fractions of $\mathrm{Li}$ - and Na-components (mass and molecular) the content of $\mathrm{Q}^{4}$ structural units reaches the maximum value, and stoichiometry of equation (3) is fulfilled with maximum accuracy. The same applies to equation (4) for mixtures, containing 16.3 and $83.7 \%$ of sodium component.

In liquid $\mathrm{Li}, \mathrm{K}$-glasses at almost constant content of $\mathrm{Q}^{1}$ (on the level of about $10 \%$ ) and $\mathrm{Q}^{3}$ (on the level of $40 \%$ ) the fraction of $\mathrm{Q}^{2}$ connectivities decreases with the mixture enrichment in potassium component from 35 up to $25 \%$.

Here, the fraction of $\mathrm{Q}^{4}$ connectivities first rises nonmonotonically from 15 up to $25 \%$, and then goes through a maximum equal to $38 \%$, at $68 \%$ weight fraction of $\mathrm{K}_{2} \mathrm{O}$ in the mixture.

In some $\mathrm{NMR}^{29} \mathrm{Si}$ spectra of this group of liquid glass samples, indications of stoichiometric running, according to equations (3)-(5), of exchange reactions between SOA structural elements, were also revealed.

So, it follows from Figure 6 that, similar to the previous series of experiments, the maximum fraction of $\mathrm{Q}^{4}$ structural units was registered in the mixtures of glasses with molar ratio $\mathrm{K}_{2} \mathrm{O} / \mathrm{Li}_{2} \mathrm{O}=50 / 50$. The highest value of weighted average of connectivity $\mathrm{Q}^{\mathrm{m}}$ corresponds to it. Interactions according to equations (3)-(5), for mixtures with the second component fraction of 50.0; 83.7; and 66.7 wt.\%, respectively, turned out to be close to stoichiometricity.

$$
2 \mathrm{Q}^{3} \leftrightarrow \mathrm{Q}^{2}+\mathrm{Q}^{4}
$$

$$
2 \mathrm{Q}^{2} \leftrightarrow \mathrm{Q}^{1}+\mathrm{Q}^{3}
$$

Alongside that it was found that exchange reactions with participation of lower forms of connectivity $\mathrm{Q}^{1}$ and $\mathrm{Q}^{2}$, proceed in the composition of lithium glass and in the majority of the studied binary mixtures with sodium and potassium components. These reactions can be presented by equation (6).

Constant (on the level of 10 and $12 \%$ ) $\mathrm{Q}^{1}$ and $\mathrm{Q}^{4}$ contents are registered in liquid $\mathrm{Na}, \mathrm{K}$-glasses, and $\mathrm{Q}^{2}$ and $\mathrm{Q}^{3}$ connectivities have a decisive influence on their properties. The fraction of the first of them does not depend on the mixture composition, and remains on the level of about $35 \%$, and the fraction of the second one rises linearly from 40 up to $48 \%$ with increase of the content of potassium component in the mixture. Then it drops to the level characteristic for the initial potassium component.

The degree of correspondence to the stoichiometricity on the level of $80 \%$ was revealed for interactions, which are described by equations (4) and (6).

Comparing the data of Figures 5 and 6, it can be assumed that the highest level of strength of dehydrated coverings, based on liquid Na, K-glasses, is associated with the low total fraction of $\mathrm{Q}^{4}$ connectivities. The total fraction of $\mathrm{Q}^{2}+\mathrm{Q}^{3}$ connectivities is weakly dependent on $\mathrm{K}_{2} \mathrm{O} / \mathrm{Na}_{2} \mathrm{O}$ ratio in the glass mixture. Accordingly, strength of the coating, which is determined by $\left(\mathrm{Q}^{2}+\mathrm{Q}^{3}\right)$ characteristic, also changes only slightly. In Figure 5, the dotted line marks the overall tendency of $\sigma_{\mathrm{ch}}$ change, under the influence of the second component in the mixture: it decreases $\left(T_{\mathrm{b}}=200^{\circ} \mathrm{C}\right)$, remains unchanged $\left(300^{\circ} \mathrm{C}\right.$ ) or increases $\left(400^{\circ} \mathrm{C}\right.$ ) with $T_{\mathrm{b}}$ increase, and is determined, most probably, by the features of dehydration of hydrosilicate matrix in the presence of the potassium component.

The level of strength of the coverings, based on liquid $\mathrm{Li}$, Na-glasses, is lower than that in the previous series, as a result of the lower total fraction of $\left(\mathrm{Q}^{2}+\mathrm{Q}^{3}\right)$ connectivities in liquid glass. Relatively more significant increase in strength is attributable to greater total fraction of $\left(\mathrm{Q}^{2}+\mathrm{Q}^{3}\right)$ connectivities due to equivalent reduction of the fraction of $\mathrm{Q}^{4}$-type connectivities in liquid glass.

The lowest strength values of dehydrated coverings are observed in the series of experiments with $\mathrm{Li}$, K-glasses, particularly those based on mixtures with a low content of the second component.

Features of molecular-weight distribution of SOA elements. Let us consider the interrelation between the weighted average value $\mathrm{Q}^{\mathrm{m}}=\sum x_{i} \mathrm{Q}_{i}^{\mathrm{n}}$ and molecular-weight distribution of SOA elements in the studied alkaline-silicate systems, where $\mathrm{Q}_{i}^{\mathrm{n}}$ is the cur- 
rent value of $\mathrm{Q}^{\mathrm{n}}$, and $x_{i}$ is their fraction in the total number of connectivities.

It follows from Figure 7 that the strength of ECM samples is inversely proportional to the negative value of structural characteristic $\mathrm{Q}^{\mathrm{m}}$. Strength values are stratified into 4 groups, shifted relative to each other along the abscissa axis. The first, the largest group, designated by index 1 , is mostly represented by samples of $\mathrm{Li}, \mathrm{Na}-, \mathrm{Li}, \mathrm{K}$ - and $\mathrm{Na}, \mathrm{K}$-series. The other form a small group II, as well as isolated III and IV groups. Assessment of the material and molecular-weight compositions of liquid glasses, as well as the value of strength of dehydrated coverings based on them, is given in Table 3.

Maximum value of strength (50 MPa) was achieved on the sample of $\mathrm{Na}, \mathrm{K}-16$ coating in group II. It is stated above that this sample is based on liquid glass with $50 \mathrm{wt} . \%$ of the potassium component. Its structure is presented as follows: $10 \%$ contribution of $\mathrm{Q}^{4}$ connectivities, and the fraction of $\mathrm{Q}^{3}$ and $\mathrm{Q}^{2}$ connectivities reaches 45 and $35 \%$, respectively. Deviation of the ratio of alkaline components from the optimum value only slightly affects the strength of coatings of this group, and has little effect on the ratio of structural formations in the composition of liquid glass SOA. The value of coating strength rarely drops below $35 \mathrm{MPa}$.

Minimum values of strength (2.5-5.0 MPa) were found in $\mathrm{Li}, \mathrm{K}-12$ and $\mathrm{Li}, \mathrm{K}-13$ samples from group I, based on liquid Li, K-glasses, in the composition of which the fraction of the potassium component changes in the range of $10-25 \%$ of the mixture. In the structural distribution of SOA of these glasses $\mathrm{Q}^{3}$ connectivities account for $40 \%$, and $\mathrm{Q}^{2}$ and $\mathrm{Q}^{4}$ con-

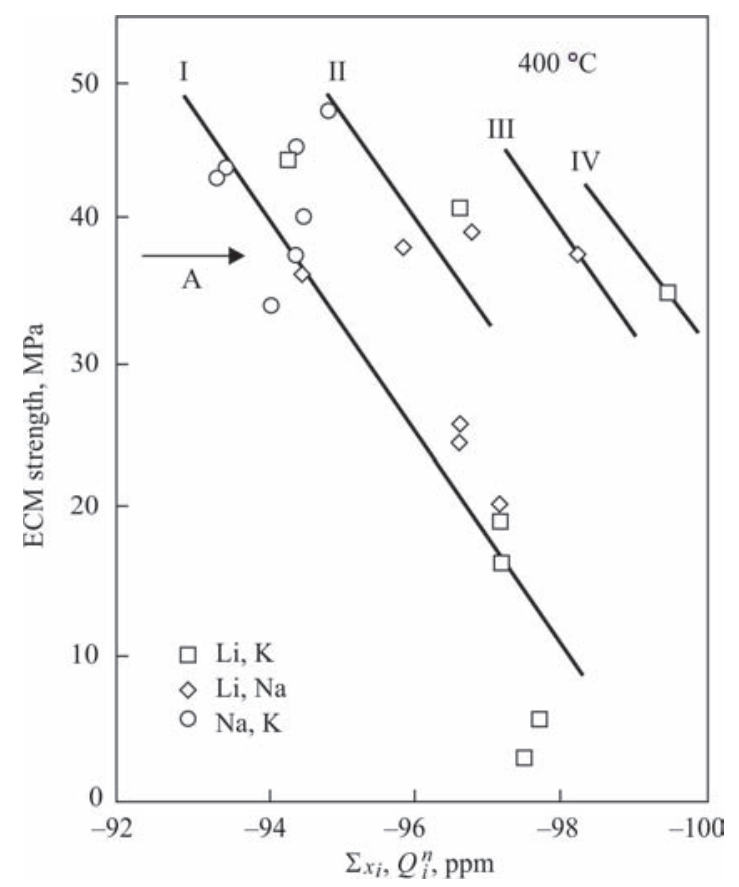

Figure 7. Interrelation of strength of ECM samples made from binary liquid Li, Na-, Li, K- and Na, K-glasses and weighted average values of connectivities in SOA structure (for designations see the text)

nectivities are equal to $25 \%$ each. This result is notable for the following reasons:

- above-mentioned strength is 4-8 times lower than that of samples based on the mono-alkaline lithium liquid glass;

- fraction of $\mathrm{Q}^{4}$ connectivities in SOA structure is almost the same, as in the case of the lithium glass (about $25 \%$ ). The largest total fraction of connectivities $\left(\mathrm{Q}^{3}+\mathrm{Q}^{4} \approx 65 \%\right.$ ), was revealed in the composition of exactly those binary liquid Li, K-glasses, which provide the lowest coating strength;

Table 3. Interrelation of strength of ECM samples with structural characteristics of SOA of binary liquid glasses (I-IV groups)

\begin{tabular}{|c|c|c|c|c|c|c|c|c|}
\hline \multirow{2}{*}{ Test index } & \multirow{2}{*}{ Test group } & \multirow{2}{*}{ Liquid glass composition } & \multicolumn{4}{|c|}{ Fraction of connectivities, \% } & \multirow{2}{*}{$\mathrm{Q}^{\mathrm{m}}, \mathrm{ppm}$} & \multirow{2}{*}{$\sigma_{\mathrm{i}}, \mathrm{MPa}$} \\
\hline & & & $\mathrm{Q}^{1}$ & $\mathrm{Q}^{2}$ & $\mathrm{Q}^{3}$ & $\mathrm{Q}^{4}$ & & \\
\hline Na, K-15 & \multirow{7}{*}{ I } & $0.48 \mathrm{Na}_{2} \mathrm{O} \cdot 0.52 \mathrm{~K}_{2} \mathrm{O} \cdot 3.40 \mathrm{SiO}_{2}$ & 10.3 & 34.4 & 47.0 & 9.0 & 93.5 & 42.8 \\
\hline $\mathrm{Na}$ & & $0.88 \mathrm{Na}_{2} \mathrm{O} \cdot 0.12 \mathrm{~K}_{2} \mathrm{O} \cdot 3.10 \mathrm{SiO}_{2}$ & 13.1 & 32.9 & 38.1 & 16.0 & 94.5 & 36.9 \\
\hline Li, Na-8 & & $0.85 \mathrm{Na}_{2} \mathrm{O} \cdot 0.52 \mathrm{Li}_{2} \mathrm{O} \cdot 2.83 \mathrm{SiO}_{2}$ & 11.0 & 27.8 & 37.8 & 23.4 & 96.7 & 23.8 \\
\hline $\mathrm{Li}$ & & $\mathrm{Li}_{2} \mathrm{O} \cdot 2.77 \mathrm{SiO}_{2}$ & 11.2 & 24.0 & 38.3 & 26.5 & 97.3 & 20.4 \\
\hline $\mathrm{Li}, \mathrm{K}-11$ & & $0.65 \mathrm{Li}_{2} \mathrm{O} \cdot 0.35 \mathrm{~K}_{2} \mathrm{O} \cdot 3.13 \mathrm{SiO}_{2}$ & 10.6 & 24.1 & 38.4 & 26.9 & 97.3 & 16.3 \\
\hline Li, K-13 & & $0.89 \mathrm{Li}_{2} \mathrm{O} \cdot 0.11 \mathrm{~K}_{2} \mathrm{O} \cdot 2.90 \mathrm{SiO}_{2}$ & 7.0 & 25.1 & 40.5 & 27.3 & 97.9 & 4.6 \\
\hline Li, K-12 & & $0.78 \mathrm{Li}_{2} \mathrm{O} \cdot 0.22 \mathrm{~K}_{2} \mathrm{O} \cdot 3.00 \mathrm{SiO}_{2}$ & 8.5 & 25.1 & 40.0 & 26.4 & 97.6 & 2.9 \\
\hline $\mathrm{Na}, \mathrm{K}-16$ & \multirow{4}{*}{ II } & $0.59 \mathrm{Na}_{2} \mathrm{O} \times 0.41 \mathrm{~K}_{2} \mathrm{O} \times 3.31 \mathrm{SiO}_{2}$ & 9.6 & 32.4 & 45.3 & 12.6 & 94.7 & 49.8 \\
\hline Li, Na-5 & & $0.36 \mathrm{Li}_{2} \mathrm{O} \cdot 0.64 \mathrm{Na}_{2} \mathrm{O} \cdot 3.00 \mathrm{SiO}_{2}$ & 7.5 & 27.2 & 43.3 & 22.0 & 97.0 & 39.2 \\
\hline Li, K-9 & & $0.37 \mathrm{Li}_{2} \mathrm{O} \cdot 0.53 \mathrm{~K}_{2} \mathrm{O} \cdot 3.42 \mathrm{SiO}_{2}$ & 10.5 & 26.7 & 37.8 & 25.0 & 96.8 & 41.3 \\
\hline Li, Na-6 & & $0.53 \mathrm{Li}_{2} \mathrm{O} \cdot 0.47 \mathrm{Na}_{2} \mathrm{O} \cdot 2.94 \mathrm{SiO}_{2}$ & 7.2 & 25.1 & 36.9 & 30.8 & 98.3 & 37.0 \\
\hline Li, Na-5 & III & $0.36 \mathrm{Li}_{2} \mathrm{O} \cdot 0.64 \mathrm{Na}_{2} \mathrm{O} \cdot 3.00 \mathrm{SiO}_{2}$ & 7.5 & 27.2 & 43.3 & 22.0 & 98.0 & 39.6 \\
\hline Li, K-10 & IV & $0.52 \mathrm{Li}_{2} \mathrm{O} \cdot 0.0 .48 \mathrm{~K}_{2} \mathrm{O} \cdot 3.27 \mathrm{SiO}_{2}$ & 6.6 & 23.5 & 33.0 & 36.9 & 99.5 & 35.5 \\
\hline
\end{tabular}



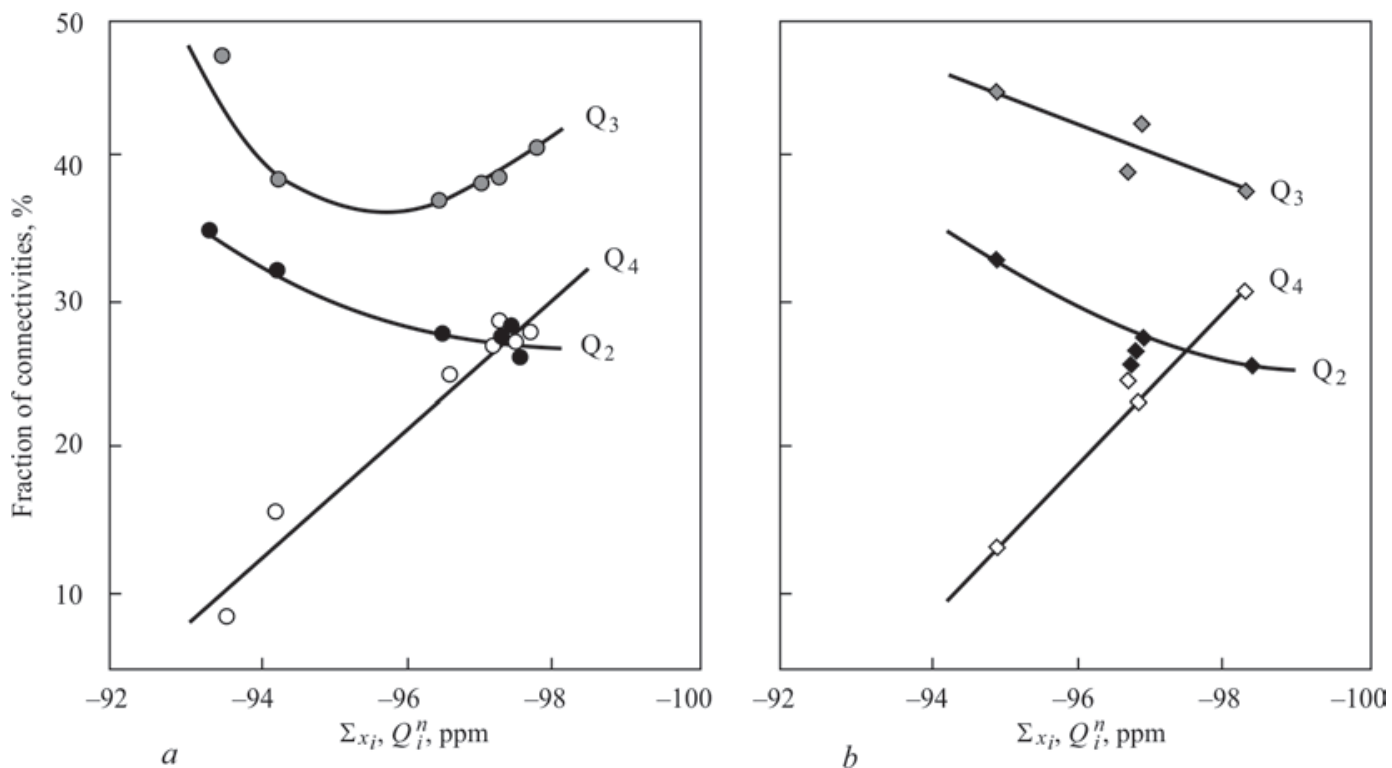

Figure 8. Distribution of chemical shifts $\mathrm{Q}^{\mathrm{n}}$ in liquid glasses, used for producing coatings in test groups designated by indexes I (a) and II (b) (see Table 3)

- fraction of $\mathrm{Q}^{4}$ connectivities in SOA structure reaches 30 and $37 \%$, respectively, in the structure of some combinations of lithium glass with potassium and sodium liquid glasses (for instance, $\mathrm{Li}, \mathrm{Na}-6$ and $\mathrm{Li}, \mathrm{K}-10$ experiments). Here, the total fraction of connectivities $\left(\mathrm{Q}^{3}+\mathrm{Q}^{4}\right)$ reaches 65-70\%. In mono-alkaline liquid glasses such a significant prevalence of spatially-diverse structural connectivities over the non-bridge ones, does not occur at all [2]. Therefore, their formation is the result of simultaneous multisite interaction of binary mixture components. Despite that, the strength of the above-mentioned ECM samples does not drop below the values of $35 \mathrm{MPa}$.

Thus, increase of the fraction of complex forms of connectivities should be regarded as the main cause behind lowering of coating strength (in group I it rises three times, reaching the value of $27 \%$, in series II -2.5 times, reaching the value of $30.8 \%$ ). This is due to reduction of the total fraction of connectivities $\left(\mathrm{Q}^{2}+\mathrm{Q}^{3}\right)$. As follows from Figure 8, this transformation of SOA structures proceeds differently in the compared groups.

In group I, in which the initial $\mathrm{Q}^{\mathrm{m}}$ value is lower, and the fraction of bridge connectivities is higher, than in group II, increase of $\mathrm{Q}^{4}$ contribution occurs due

to lowering of the total content of $\left(\mathrm{Q}^{2}+\mathrm{Q}^{3}\right)$ groups. However, at $\mathrm{Q}^{\mathrm{m}}$ with $\delta<-96 \mathrm{ppm}$, the change of $\mathrm{Q}^{2}$ fraction becomes smoother, and lowering of $\mathrm{Q}^{3}$ content is replaced by its significant increase, resulting in the total fraction of connectivities $\left(\mathrm{Q}^{3}+\mathrm{Q}^{4}\right)$ reaching $70 \%$. This, most probably, is what provokes the catastrophic drop of the strength of samples of Li,K-series with 11,12 and 13 indices.

Structure of liquid glasses in samples of group II changes more smoothly. The overall increase of the number of $\mathrm{Q}^{4}$ connectivities is completely compensated by total decrease of the fraction of more elastic kinds $\mathrm{Q}^{2}$ and $\mathrm{Q}^{3}$.

Synchronous change of the ratio of connectivities occurs at formation of the structure of $\mathrm{Li}, \mathrm{Na}-5$ and $\mathrm{Li}$, K-10 samples (see Table 3).

Another variant of interrelation of SOA structure with ECM strength was revealed: similar to test series designated by II-IV indices, degradation of hydrosilicate binder due to increase of $\mathrm{Q}^{4}$ connectivities is damped by the change of the quantity of $\mathrm{Q}^{2}$ and $\mathrm{Q}^{3}$ connectivities (Table 4; Figure 9).

Here, the fraction of elastic $Q^{2}$ connectivities decreases continuously, and that of the less elastic one $\mathrm{Q}^{3}$ is reduced after it has reached, in the sum with

Table 4. Strength of ECM samples of group A

\begin{tabular}{|c|c|c|c|c|c|c|c|}
\hline \multirow{2}{*}{ Test index } & \multirow{2}{*}{ Liquid glass composition } & \multicolumn{4}{|c|}{ Fraction of connectivities, \% } & \multirow{2}{*}{$\mathrm{Q}^{\mathrm{m}}, \mathrm{ppm}$} & \multirow{2}{*}{$\sigma_{\mathrm{i}}, \mathrm{MPa}$} \\
\hline & & $\mathrm{Q}^{1}$ & $\mathrm{Q}^{2}$ & $\mathrm{Q}^{3}$ & $\mathrm{Q}^{4}$ & & \\
\hline $\mathrm{Na}$ & $0.88 \mathrm{Na}_{2} \mathrm{O} \cdot 0.12 \mathrm{~K}_{2} \mathrm{O} \cdot 3.10 \mathrm{SiO}_{2}$ & 13.1 & 32.9 & 38.1 & 16.0 & 94.5 & 36.9 \\
\hline Li, Na-4 & $0.19 \mathrm{Li}_{2} \mathrm{O} \cdot 0.81 \mathrm{Na}_{2} \mathrm{O} \cdot 3.05 \mathrm{SiO}_{2}$ & 7.9 & 30.3 & 43.4 & 18.4 & 96.1 & 38.7 \\
\hline Li, Na-5 & $0.36 \mathrm{Li}_{2} \mathrm{O} \cdot 0.64 \mathrm{Na}_{2} \mathrm{O} \cdot 3.00 \mathrm{SiO}_{2}$ & 7.5 & 27.2 & 43.3 & 22.0 & 97.0 & 39.2 \\
\hline Li, Na-6 & $0.53 \mathrm{Li}_{2} \mathrm{O} \cdot 0.47 \mathrm{Na}_{2} \mathrm{O} \cdot 2.94 \mathrm{SiO}_{2}$ & 7.2 & 25.1 & 36.9 & 30.8 & 98.3 & 37.0 \\
\hline Li, K-10 & $0.52 \mathrm{Li}_{2} \mathrm{O} \cdot 0.48 \mathrm{~K}_{2} \mathrm{O} \cdot 3.27 \mathrm{SiO}_{2}$ & 6.6 & 23.5 & 33.0 & 36.9 & 99.5 & 35.5 \\
\hline
\end{tabular}




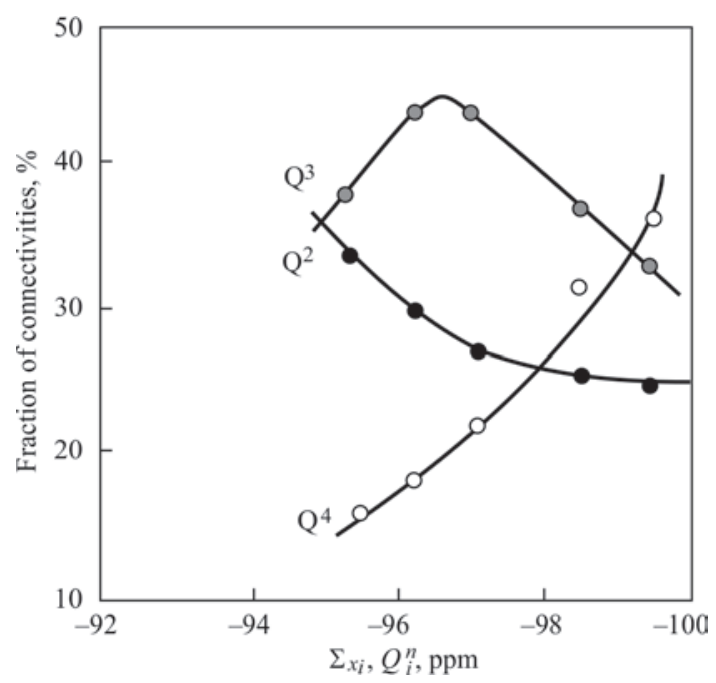

Figure 9. Distribution of connectivities $\mathrm{Q}^{\mathrm{n}}$ in liquid glasses of test group designated by A index (see Table 4)

$\mathrm{Q}^{4}$ connectivity, a critical value in terms of coating strength.

The interrelation between material composition, degree of dehydroxylation of alkaline-silicate binder and SOA molecular-weight distribution, as well as coating strength. Mechanical strength of electrode coating forms under the conditions of joint action of cations-modifiers and hydroxide-ions in the liquid glass composition on SOA structure. Cation ratio is determined by liquid glass composition. It can improve or degrade the SOA structure in the liquid glass, and, therefore, increase or decrease the coating strength. Hydroxide-ion concentration is determined by the degree of SOA dehydration at electrode heat treatment. Alongside temperature, it is also influenced by SOA water retention capacity, which, in its turn, depends on their structure, determined by the ratio of cations-modifiers in their composition. At baking temperatures, characteristic for manufacturing low-hydrogen electrodes, degradation of coating strength usually prevails.

The cumulative effect of cations-modifiers present in the composition of alkaline hydrosilicates, on the one hand, and degree of their dehydroxilation at electrode baking, on the other hand, on SOA structure and coating strength, can be separated, by applying instead of the moisture content of the coating, which was not yet studied in this work, its «Siverts equivalent» in the form of hydrogen content in the deposited metal.

Figure 10 gives the results of comparison of the content of diffusible hydrogen in the metal, deposited with electrodes based on liquid $\mathrm{Na}, \mathrm{K}-, \mathrm{Li}, \mathrm{Na}-$ and Li, K-glasses.

One can see from the data of Figure 10 that hydrogen content in the deposited metal changes in the ranges from 5.7 up to $7.7 \mathrm{ml} / 100 \mathrm{~g}$ of deposited met-

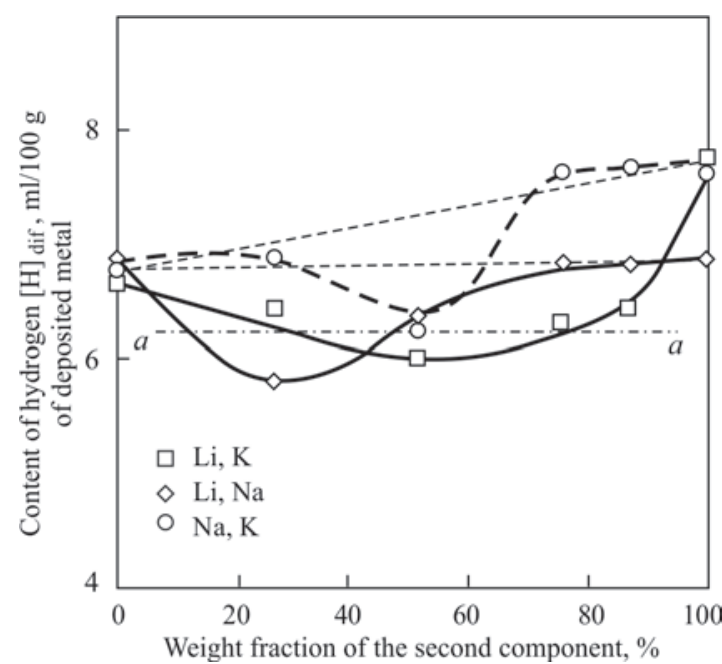

Figure 10. Comparison of hydrogen content in the metal deposited with electrodes based on liquid Li, Na-, Li, K- and Na, K-glasses (electrode baking temperature of $400^{\circ} \mathrm{C}$ )

al, depending on the composition of the studied liquid-glass binders of electrode coating. The observed lowering (in the minimum) is similar for all the series of glasses, whereas the position and extent of the extremum along the concentration axis changes significantly for all the samples at transition from series to series, and the curves representing the change of hydrogen content in the deposited metal, intersect in the point corresponding to equal weight fractions of the components of binary mixtures. For Li, Na-series of samples the point of intersection of the curves becomes close to, and for $\mathrm{Na}, \mathrm{K}$ and $\mathrm{Li}, \mathrm{K}$-series it exactly corresponds to $[\mathrm{H}]$ minimum, recalculated to deposited metal.

As follows from Figure 7, the strength of ECM samples based on liquid $\mathrm{Na}, \mathrm{K}-16, \mathrm{Li}, \mathrm{Na}-6$ and $\mathrm{Li}$, $\mathrm{K}-11$ glasses changes from 16 to $50 \mathrm{MPa}$, i.e. 3 times. Considering the same content of hydrogen in the de-

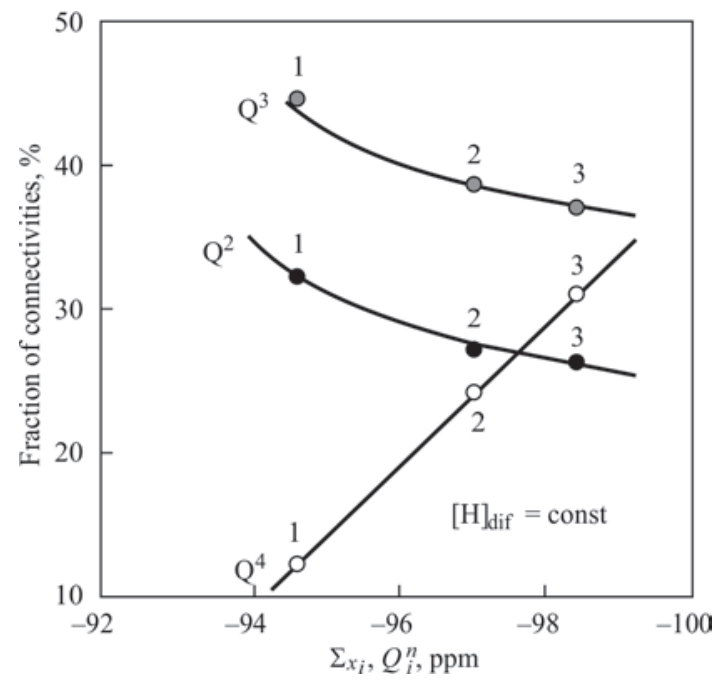

Figure 11. Distribution of connectivities $\mathrm{Q}_{i}^{\mathrm{n}}$ in liquid glasses, used for producing ECM with indexes Na, K-16 (1), Li, Na-6 (2) and Li, K-11 (3) 


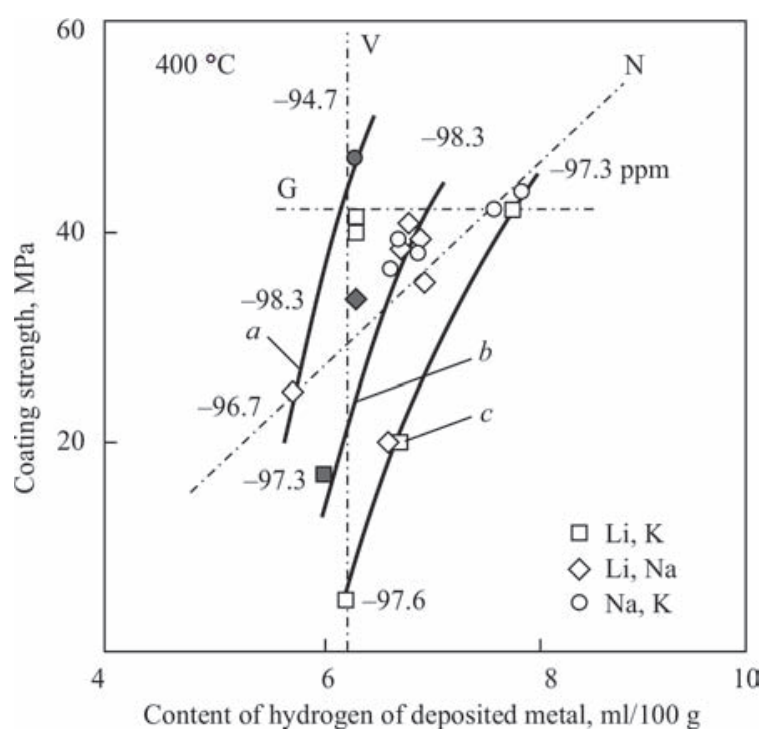

Figure 12. Interrelation of strength of low-hydrogen electrode coatings, based on liquid $\mathrm{Na}, \mathrm{K}-, \mathrm{Li}, \mathrm{Na}-$ and $\mathrm{Li}$, K-glasses, with hydrogen equivalent of their moisture content; electrode baking temperature of $440{ }^{\circ} \mathrm{C}$ (for designations see the text)

posited metal, we can assume that moisture content of initial electrode coatings remains unchanged. Therefore, three times change of ECM strength is due to the dynamics of structural components of SOA of binder composition under the influence of cations-modifiers. This is confirmed by the data in Figure 11.

The sample of Na,K-16 coating is the most dehydrated. Nonetheless, it is the strongest one in $\mathrm{Na}$, K-series. This is indicative of the fact that lowering of the strength of ECM structure during dehydration of binary binder can be compensated by such a transformation of SOA structure under the impact of the change of the ratio of alkaline modifiers content, which will be favourable for strength formation. For one composition of the binder, the above transformation partially, and for another - completely compensates, and for the third one it even exceeds the lowering of strength, due to dehydration of the alkaline silicate binder.

Figure 12 shows the dependence of the strength of ECM samples based on liquid Na, K-, Li, Na- and $\mathrm{Li}, \mathrm{K}$-glasses, on hydrogen content in the deposited metal.

One can see here that the figurative points, expressing $\sigma_{\mathrm{ch}}$ value, were stratified into three layers, designated by indices $a, b, c$, that are supposedly associated with the change of average weighted value of $\mathrm{Q}^{\mathrm{m}}$, which is caused by degradation of SOA structure: the larger $\mathrm{Q}^{\mathrm{m}}$, the greater the shifting of the respective curve along the abscissa axis. Symbols V, G and $\mathrm{N}$ designate the results of experiments located along the straight lines, oriented normal, in parallel and obliquely relative to the abscissa axis.
Results of tests oriented along the vertical, characterize the strength of coating samples with the same moisture level. Therefore, their strength is determined exclusively by the ratio of contributions of connectivities, dependent on SOA chemical composition and structure. They include also the above-considered $\mathrm{Na}$, K-16, Li, Na-6 and Li, K-11 samples, which are designated by shaded points in Figure 12. In their structure the fraction of $\mathrm{Q}^{4}$ connectivities grows in proportion to decrease of both the angle of inclination of a curve, characterizing the yield of connectivities $\left(Q^{3}+Q^{2}\right)$, in Figure 11, and ECM strength. The same pattern is found in experiments with the other samples of this group.

In samples located along the horizontal, $\sigma_{\mathrm{ch}}=$ $=$ const. Therefore, decrease (increase) of strength, determined by increase (decrease) of their moisture level, is completely compensated by the correcting change of SOA structure, associated with the impact of the ratio of cations, determining the formation of strength. Numbers near $\sigma_{\mathrm{ch}}=f([\mathrm{H}])$ curves express the nature of change of $\mathrm{Q}^{\mathrm{m}}$ characteristic.

Dependencies shown by $a, b, c$ and $\mathrm{N}$ lines, characterize the resultant of the parameters of the change of SOA structure and $\sigma_{c h}$, connected with the dynamics of chemical composition and simultaneous dehydration of liquid glass in the range between V and G values.

\section{Conclusions}

1. Strength of electrode coatings, similar to other kinds of filled compositions, which are the objects of silicate technologies, is determined by binding properties of the hydrosilicate matrix. The above parameter depends on the material and structural composition of the liquid glass used as the binder, as well as the degree of its dehydration at electrode heat treatment. Here, the composition of alkaline hydrosilicate matrices of electrode coatings, interrelated with the change of structure and water retention capacity of the hydrosilicate binder, determines the features of formation of the coating strength, while electrode heat treatment leads to degradation of the structure and lowering of the strength of coatings as a result of dehydration.

2. Maximum high level of coating strength is provided by the systems of combined liquid sodium-potassium glasses, in the structure of which the fraction of rigid and brittle silicon-oxygen (bridge) connectivities seldom exceeds $10 \%$, and the base of the structural matrix (about $80 \%$ ) is usually made up by elastic connectivities $\left(\mathrm{Q}^{2}+\mathrm{Q}^{3}\right)$.

3. The lowest level of coating strength is observed at application of lithium-potassium glass with $10-40 \%$ content of the potassium component, as a 
binder, the effect of which is usually demonstrated by a considerable synergetic surge of viscosity. The strength of coatings based on liquid glasses of such a composition, is even lower than that of coatings based on pure lithium glass.

4. Prospects are opened up for solving the problems, arising in connection with the low strength of coatings based on lithium liquid glasses, through application of combined liquid Li-, Na-, K-glasses.

1. Gorpenyuk, V.N., Pokhodnya, I.K., Marchenko, A.E. (1971) About procedure of evaluation of electrode coating strength. Svarochn. Proizvodstvo, 8, 45-46 [in Russian].

2. Brykov, A.S. (2009) Silicate solutions and their application: Manual. St.-Petersburg, St.-PGTI (TU) [in Russian].

3. Lukyanova, O.I., Uvarova, I.Yu. (1967) To study of interaction between high-basic calcium silicates and high-silica sodium silicates. Doklady AN SSSR, 172 (3), 645 [in Russian].

4. Marchenko, A.E., Skorina, N.V., Voroshilo, V.S., Shevchenko, L.A. (1979) On some technological problems caused by interphase processes in production of welding electrodes. CMEA, Coordination Center on Problem of Development of Sci. Principles... Information documents. Kiev, Naukova Dumka, 1, 50-157 [in Russian].

5. Uchino, T., Sakka, T., Iwasaki, M.-J. (1991) Interpretation of hydrated states of sodium silicate glasses by infrared and Raman analysis. Am. Ceram. Soc., 4(2), 306-313.

6. Marchenko, A.E., Skorina, N.V., Kiselev, M.O. et al. (2017) Nuclear magnetic spectroscopy study of the structure of liquid glasses for welding electrodes. The Paton Welding J., 1, 41-45.

7. Marchenko, A.E. (2010) On physical-chemical nature of electrode coating strength and technological means of its assurance. In: Proc. of 5th Int. Conf. Dedicated to 20th Anniversary of Association «Electrode» on Welding Consumables. Technologies. Production. Quality. Competitiveness (7-11 June 2010, Artyomovsk, Donetskaya Reg.). Kiev, 78-99.

8. Marchenko, A.E., Skorina, N.V., Suprun, S.A. (2012) Waterretaining capacity of alkaline silicates and its effect on dehydration of electrode coatings. In: Arc welding metallurgy and welding consumables. Kiev, Akademperiodika, 290-302 [in Russian].

Received 13.04.2018 


\title{
INFLUENCE OF TECHNOLOGICAL AND ELECTRICAL PARAMETERS OF ESS IN CURRENT-SUPPLYING MOULD ON ELECTRODE MELTING RATE AND BASE METAL PENETRATION
}

\author{
V.G. SOLOVIOV and Yu.M. KUSKOV \\ E.O. Paton Electric Welding Institute of the NAS of Ukraine \\ 11 Kazimir Malevich Str., 03150, Kyiv, Ukraine. E-mail: office@paton.kiev.ua
}

\begin{abstract}
A calculation experiment was conducted which showed that the controllable electrical parameters of the ESS process can be used to regulate the metal pool shape and electrode melting rate. Dependencies between the depth of electrode deepening into the slag pool, average depth of penetration and uniformity of base metal penetration relative to average penetration depth were determined. A method was proposed for calculation of the depth of electrode deepening into the slag pool by the ratio of currents in CSM. Comparative analysis of three types of single-circuit diagrams of the mould connection to the power source was performed, and an optimum diagram for the required criteria of surfacing quality was proposed. 8 Ref., 1 Table, 12 Figures.
\end{abstract}

Keywords : current-supplying mould, experiment, automation, metal pool, regulation, penetration, bottom plate, electrode, conductivity, diagram of power supply

The electrostatic field generated by the potential difference between the current-carrying parts of the mould is nonuniform due to a complex configuration of inner elements of the mould and their mutual arrangement, even if to assume that the rotation of a liquid slag pool provides homogenization of its properties. First of all, the shape of equipotential surfaces of the field is affected by the value of electrode deepening into the slag pool, its diameter and shape, as well as the used type of diagram for connection of the current-supplying mould (CSM) to the power source. The intensity of electric field at each point of the slag pool determines the force and direction of the electric energy flows, which in turn determines the distribution of thermal energy at ESS, influences the electrode melting behavior, uniformity and average penetration depth of product and also the character of a liquid metal crystallization. The problems of mathematical modeling of electrical parameters of electroslag processes were given attention in many works, for example [1-4], however, there are almost no works on modeling and studying the influence of electrical parameters on the uniformity and average penetration depth of product at ESS in current-supplying mould.

In the work [5], as a result of modeling the electric field in slag pool in the CSM on electrically conductive paper, the authors made the conclusion that a middle section of the mould, due to its electrical conductivity, shunts a part of the slag pool, shifts the region of prevailing heat release into the near-wall region of the mould, leaving a central zone to be relatively cold. However, directly at the mould wall itself, the metal pool remains cold due to the mould water cooling and, due to that, the pool can acquire a specific form of «sombrero».

The authors of the work [6] make a conclusion that varying the values of currents passing to the electrode and mould during surfacing using a «potential» electrode, it is possible to significantly change the shape of the metal pool bottom: from the concave cone-shaped, characteristic for the conventional ESR process, to the convex one in the central part of the deposited layer, inherent in surfacing without electrode.

The aim of the work is to perform mathematical modeling of distribution of the slag pool potential in the CSM by using the PDETool MATLAB package and to conduct a calculation experiment, which will answer the following questions:

- how to use the controllable electrical parameters to regulate the metal pool shape and the electrode melting rate;

- how the value of electrode deepening into the slag pool effects the average penetration depth of product and the uniformity of penetration relative to the average penetration depth; 
- how to use the values of the controllable electrical parameters to calculate the value of electrode deepening into the slag pool;

- which single-circuit diagram (of three types) of the mould connection to the power source is the most optimal for solution of the put problem;

- in which cases it is necessary to use the CSM power supply diagram: single- or two-circuit diagram.

One of the standard boundary value problems in PDETool [7] is the electrostatic problem, which was used in this work, since the subject of study was the distribution of electric field intensity in a slag pool between the electrode surfaces, graphite lining of a current-carrying section of the mould and the bottom plate, to which the potential was applied.

In the proposed statement of the problem, it was assumed that the object has an axial symmetry. Therefore, the two-dimensional model is represented in a cylindrical coordinate system. Moreover, the rotation of the molten slag pool around the mould axis provides an axial homogenization of its properties. We assume that there is a qualitative effect of the electrostatic field and its nonuniformity near the surface of the bottom plate (product) on the nonuniformity and penetration depth of the upper layer of the product in accordance with the Joule-Lenz law. The boundary conditions of the slag pool surface and the forming section of the mould are taken in accordance with the conditions of the Neumann problem, while those for the boundaries of the electrode surfaces, the mould graphite bushing and the bottom plate were taken in accordance with the Dirichlet problem conditions.

The accepted model and the carried out calculation experiment do not pretend to obtaining numerical interrelations of input and output variables which could be used in surfacing, but allow evaluating the qualitative relationship of the mentioned variables, correctly planning and simplifying the experimental surfacing to obtain the quantitative interrelations.

The equation of electrostatics with respect to a scalar electric potential is

$$
-\operatorname{div}(\varepsilon \nabla V)=\rho \varepsilon_{0},
$$

where $\varepsilon$ is the relative dielectric permeability of the medium; $\varepsilon_{0}=8.85 \cdot 10^{-12} \mathrm{~F} / \mathrm{m}$ is the absolute dielectric permeability of vacuum (basic electric constant); $V$ is the scalar electric potential; $\rho$ is the scalar field of the volumetric density of electric charge.

The value of relative dielectric permeability of slag is accepted as $\varepsilon=70$. In connection with the lack of data on this parameter in the literature, the value $\varepsilon$ for this parameter is assumed equal to the relative dielectric permeability of sea water. To solve the boundary value problem of Dirichlet $r=h V$ (where $r$ is the electric potential; $h$ is the weight coefficient), the value $h=1$, and the value of the scalar electrical potential $V=100$ of conventional units were accepted, which provides the evaluation of voltages between the equipotential lines in a percentage relation. To solve the Neumann boundary value problem $\varepsilon \nabla V+q V=g, q$ is the coefficient determining the influence of $V$ value in the model, taken equal to 0.7 , and $g$ is the charge on side surfaces of a forming section of the mould, is accepted as equal to $<10^{-10}$ C, i.e. $g=0$. For a slag pool $\rho=0$. Visualization of scalar elliptic PDEs allowed using the «method of graphic images», which is successfully applied in the calculation of fields of charged bodies, located near plane or cylindrical conducting surfaces [8].

Problem statement. As a result of modeling, it is necessary to determine the nature of effect of values of the electrode diameter $d_{\mathrm{e}}$, the electrode deepening into the slag pool $h_{\mathrm{d}}$, the level of the metal pool $h_{\mathrm{m}}$ relative to the level of the lower edge of the current-carrying section of the mould on the controllable electrical parameters of ESS in CSM.

The geometric characteristics and constants of the model are:

- inner diameter of the mould forming part is $180 \mathrm{~mm}$;

- cylindrical electrode of diameter $d_{\mathrm{e}}: 40(a), 90$ (b) and $130 \mathrm{~mm} \mathrm{(c);}$

- two-section mould (without middle section);

- height of graphite lining wetted with slag (wet part), $20 \mathrm{~mm}$;

- distance from the bottom edge of graphite lining to the metal pool mirror $h_{\mathrm{m}}: 30(a), 50(b)$ and $80 \mathrm{~mm}$ (c). The depth of the slag pool is, respectively, $h_{\mathrm{s}}: 50$ (a), $70(b)$ and $100 \mathrm{~mm}(c)$.

- value of electrode deepening into the slag pool $h_{\mathrm{d}}: 10(a), 20$ (b) and $40 \mathrm{~mm}(c)$.

Figure 1 shows the examples of models of electrostatic fields for CSM with different diagrams of connections to the source, different diameters of electrodes, with different depths of slag pool and different values of electrode deepening.

There are three types of diagrams for connecting the elements of the working zone of the mould (WZM) to the power source (PS) - the diagram using the «potential» electrode (type «E») in Figure 2, $a$, the diagram using the «potential» mould (type «M») in Figure 2, $b$ and the diagram using the "potential» bottom plate (type «B») in Figure 2, $c$.

Calculations of currents of the bottom plate, electrode and mould at the diagram using a "potential» bottom plate (type «B»). With the diagram of CSM supply of type «B» the highest current passes through the bottom plate, which is equal to the sum of currents 


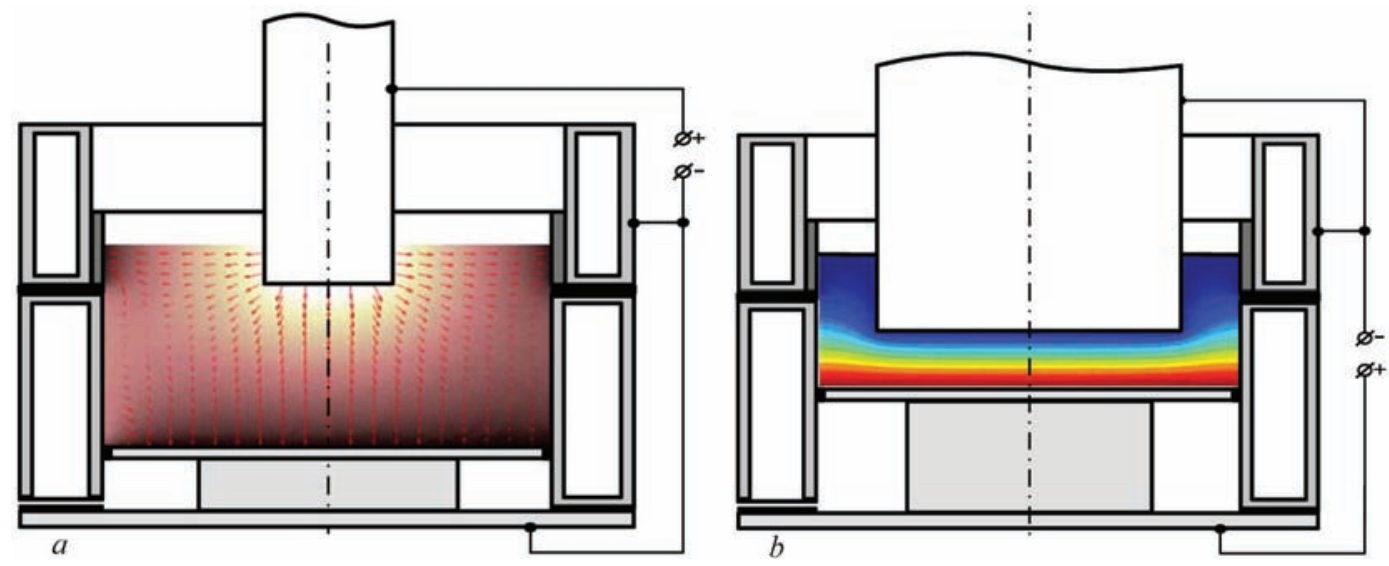

Figure 1. Examples of calculation of intensity of electric field and field with equipotential lines: $a$ - for CSM, switched-on according to the diagram with a "potential» electrode, $d_{\mathrm{e}}=40 \mathrm{~mm}, h_{\mathrm{s}}=100 \mathrm{~mm}$ and $h_{\mathrm{d}}=20 \mathrm{~mm} ; b-$ for CSM, switched-on according to the diagram with a «potential» bottom plate, $d_{\mathrm{e}}=130 \mathrm{~mm}, h_{\mathrm{s}}=70 \mathrm{~mm}$ and $h_{\mathrm{d}}=40 \mathrm{~mm}$

passing through the electrode and mould. In this way, the best heating of product is provided, but the efficiency of melting the electrode is lower than, for example, in connecting CSM to the source according to the diagram with a «potential» electrode (type «E»).

Figure 3 shows the calculated values of the currents of the bottom plate $I_{\mathrm{b}}$, electrode $I_{\mathrm{e}}$, and mould $I_{\mathrm{m}}$ depending on the value of electrode deepening $h_{\mathrm{d}}$ and on the electrode diameter $d_{\mathrm{e}}$, at the slag pool depth $h_{\mathrm{s}}=100 \mathrm{~mm}$.
As is seen from the diagram of Figure 3, $a$, the electrode current $I_{\mathrm{e}}$ during deepening into a slag pool is increased almost in the proportion to the value of deepening, since the slag pool conductivity is increased with increasing the area of the «wet» part of electrode and the distance from the electrode to the product, and also with increasing $d_{\mathrm{e}}$. During deepening the electrode, the current of the mould $I_{\mathrm{m}}$ decreases, it is affected by «screening» of the graphite lining of electrode, which has the same potential as
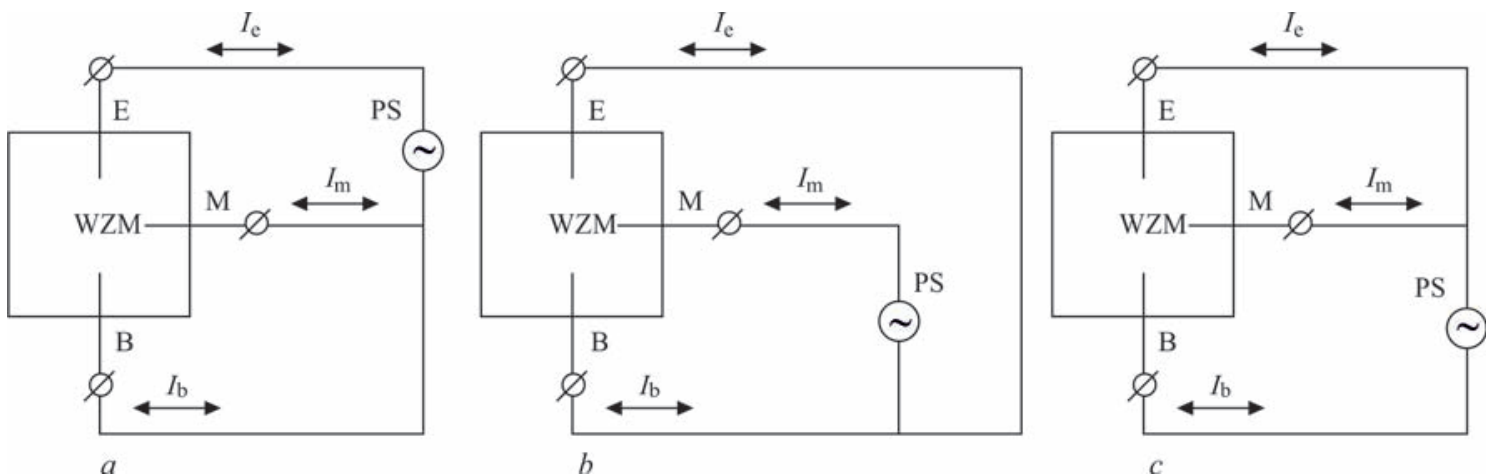

Figure 2. Diagrams of connecting the elements of working zone of mould to the power source with the use of: $a$ - potential electrode (type «E»); $b$ - potential mould (type «M»); $c$ — potential bottom plate (type «B»)
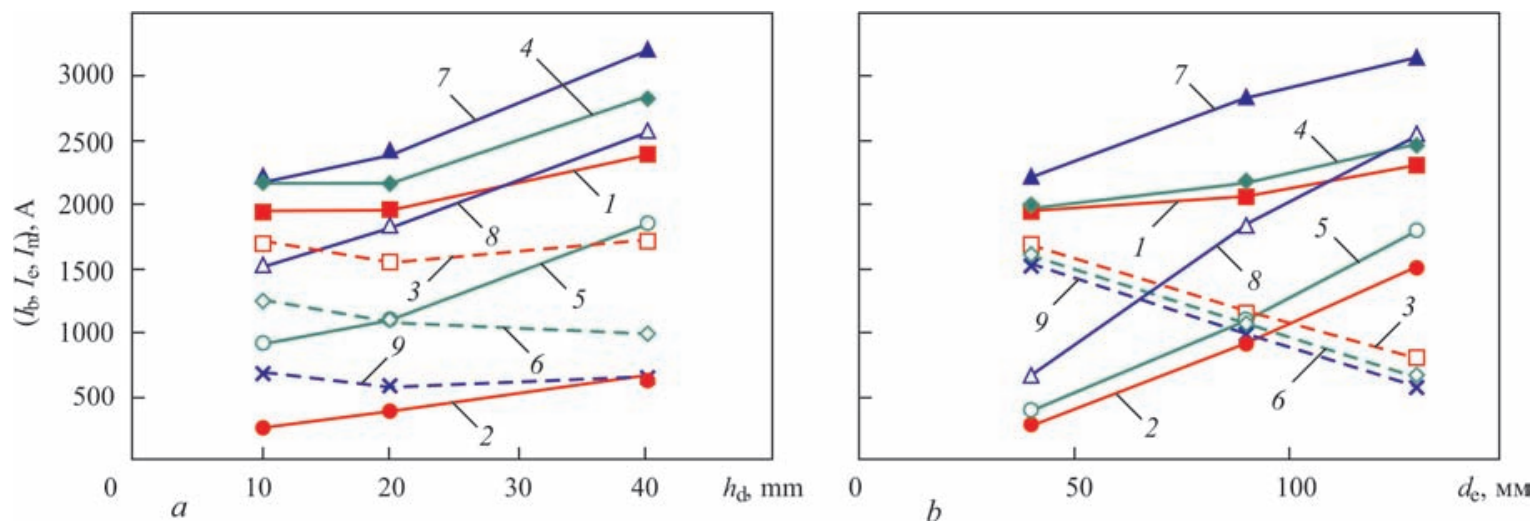

Figure 3. Changes of currents of bottom plate $I_{\mathrm{b}}$, electrode $I_{\mathrm{e}}$ and mould $I_{\mathrm{m}}$ depending on: $a$ - value of electrode deepening $h_{\mathrm{d}}: 1$, 2, $3-I_{\mathrm{b}}, I_{\mathrm{e}}, I_{\mathrm{m}}$, respectively (at $\left.d_{\mathrm{e}}=40 \mathrm{~mm}\right) ; 4,5,6-I_{\mathrm{b}}, I_{\mathrm{e}}, I_{\mathrm{m}}$, respectively (at $\left.d_{\mathrm{e}}=90 \mathrm{~mm}\right) ; 7,8,9-I_{\mathrm{b}}, I_{\mathrm{e}}, I_{\mathrm{m}}$, respectively $\left(\right.$ at $d_{\mathrm{e}}=$ $=130 \mathrm{~mm}) ; b$ - diameter of electrode $\mathrm{d}_{\mathrm{e}}$, at the depth of slag pool $h_{\mathrm{d}}=100 \mathrm{~mm}: 1,2,3-I_{\mathrm{b}}, I_{\mathrm{e}}, I_{\mathrm{m}}$, respectively $\left(\right.$ at $\left.h_{\mathrm{d}}=10 \mathrm{~mm}\right) ; 4,5$, $6-I_{\mathrm{b}}, I_{\mathrm{e}}, I_{\mathrm{m}}$, respectively (at $\left.h_{\mathrm{d}}=20 \mathrm{~mm}\right) ; 7,8,9-I_{\mathrm{b}}, I_{\mathrm{e}}, I_{\mathrm{m}}$, respectively (at $\left.h_{\mathrm{d}}=40 \mathrm{~mm}\right)$ 

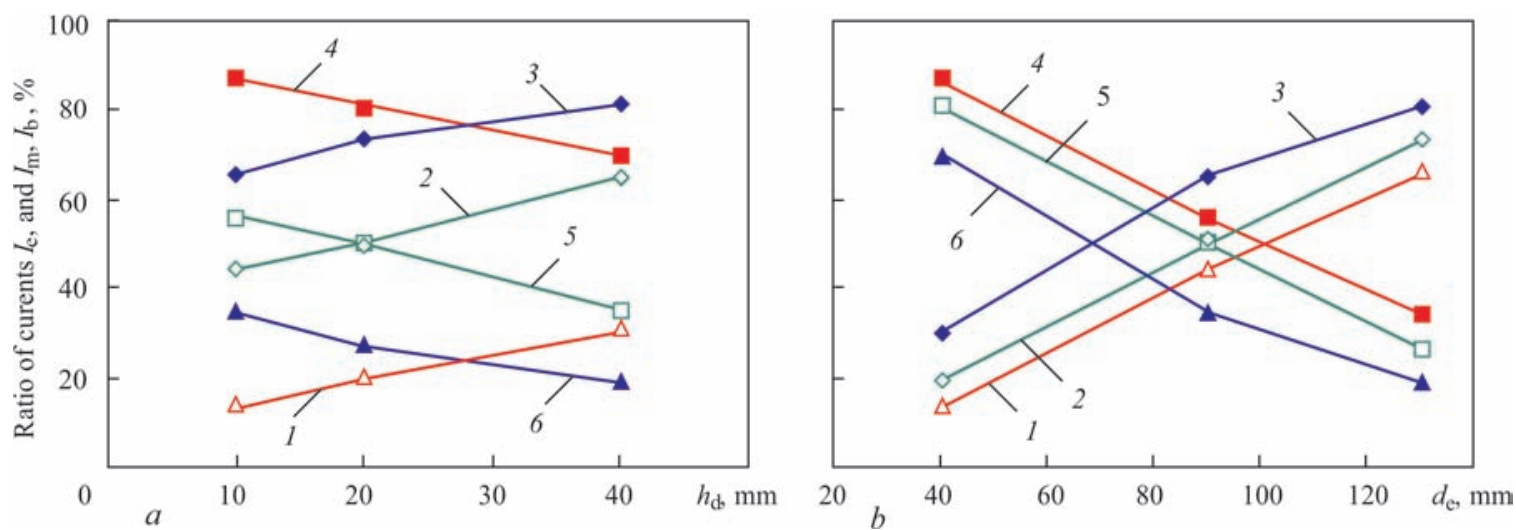

Figure 4. Changes of percent ratio of electrode currents $I_{\mathrm{e}}$ and the mould $I_{\mathrm{m}}$ to the bottom plate current $I_{\mathrm{b}}$ depending on: $a$ — value of electrode deepening $h_{\mathrm{d}}: 1-4-I_{\mathrm{e}} / I_{\mathrm{b}}, I_{\mathrm{m}} / I_{\mathrm{b}}$, respectively (at $\left.d_{\mathrm{e}}=40 \mathrm{~mm}\right) ; 2,5-I_{\mathrm{e}} / I_{\mathrm{b}}$ and $I_{\mathrm{m}} / I_{\mathrm{b}}$, respectively $\left(\right.$ at $\left.d_{\mathrm{e}}=90 \mathrm{~mm}\right) ; 3,6-I_{\mathrm{e}} /$ $I_{\mathrm{b}}$ and $I_{\mathrm{m}} / I_{\mathrm{b}}$, respectively (at $d_{\mathrm{e}}=130 \mathrm{~mm}$ ); $b$ - diameter of electrode $d_{\mathrm{e}}$, at the depth of slag pool $h_{\mathrm{s}}=100 \mathrm{~mm}: 1-4-I_{\mathrm{e}} / I_{\mathrm{b}}$ and $I_{\mathrm{m}} / I_{\mathrm{b}}$, respectively (at $\left.h_{\mathrm{d}}=10 \mathrm{~mm}\right) ; 2,5-I_{\mathrm{e}} / I_{\mathrm{b}}$ and $I_{\mathrm{m}} / I_{\mathrm{b}}$, respectively (at $\left.h_{\mathrm{d}}=20 \mathrm{~mm}\right) ; 3,6-I_{\mathrm{e}} / I_{\mathrm{b}}$ and $I_{\mathrm{m}} / I_{\mathrm{b}}$, respectively (at $\left.h_{\mathrm{d}}=40 \mathrm{~mm}\right)$

the graphite lining, and which during deepening into the slag pool and approaching a product, undertakes a greater percentage of the source total current. With deepening the electrode, the current of the bottom plate $I_{\mathrm{b}}$ increases. It should be taken into account that $I_{\mathrm{m}}$ and $I_{\mathrm{e}}$ at $d_{\mathrm{e}}=90 \mathrm{~mm}$ are close in values, and at deepening to $20 \mathrm{~mm}$, they are even equal. At $d_{\mathrm{e}}=40 \mathrm{~mm}$, the current of the mould $I_{\mathrm{m}}$ exceeds the current of the electrode $I_{\mathrm{e}}$, and at $d_{\mathrm{e}}=130 \mathrm{~mm}$, we observe the other situation: the electrode current exceeds the mould current. From the diagram in Figure 3, $b$, a weak influence of the electrode diameter $d_{\mathrm{e}}$ on the current of bottom plate $I_{\mathrm{b}}$ and its strong influence on $I_{\mathrm{e}}$ and $I_{\mathrm{m}}$ are seen at the small deepening of the electrode.

At the diagrams of Figure 4, $a$, it is seen that for $h_{\mathrm{d}}=10 \mathrm{~mm}$, the current of the mould prevails over the electrode current only at $d_{\mathrm{e}}<100 \mathrm{~mm}$, at $d_{\mathrm{e}}>$ $>100 \mathrm{~mm}$ the situation changes to the opposite one. For $h_{\mathrm{d}}=20 \mathrm{~mm}$, the mould current prevails over the electrode current at $d_{\mathrm{e}}<90 \mathrm{~mm}$, at $d_{\mathrm{e}}>90 \mathrm{~mm}$ the situation changes to the opposite one. For $h_{\mathrm{d}}=40 \mathrm{~mm}$, the mould current prevails over the electrode current at $d_{\mathrm{e}}<70 \mathrm{~mm}$, at $d_{\mathrm{e}}>70 \mathrm{~mm}$ the situation changes to the opposite one.

At the value of the depth of the slag pool $h_{\mathrm{s}}=$ $=100 \mathrm{~mm}$ from the diagrams in Figure 4, $b$, it is seen that at $d_{\mathrm{e}}=40 \mathrm{~mm}$ over the entire range of changes $h_{\mathrm{d}}$, the mould current has a greater effect on the process as compared to the current of the electrode. At $d_{\mathrm{e}}=90 \mathrm{~mm}$ at $h_{\mathrm{d}}>20 \mathrm{~mm}$, the current of the electrode prevails over the current of the mould. At $d_{\mathrm{e}}=$ $130 \mathrm{~mm}$ over the entire range of changes in $h_{\mathrm{d}}$, the current of the electrode has a greater effect on the process as compared to the mould current.

Obviously, that for ESS in CSM, the electrode current determines its melting rate, the current of the mould plays the role of equalizing the electric field near the product and the bottom plate current deter- mines the penetration depth of the product, i.e. using such diagrams as in Figure 3, it is possible to choose the necessary ratio between the size of the electrode deepening and its diameter.

As is seen from the diagrams in Figure 5 the change in the ratio of currents of the electrode $I_{\mathrm{e}}$ to the mould current $I_{\mathrm{m}}$ from the deepening of the electrode $h_{\mathrm{d}}$ has a pronounced character and corresponds to a practically linear dependence. So, according to the value $I_{\mathrm{e}} / I_{\mathrm{m}}$, it is possible indirectly to calculate such a parameter as the value of deepening $h_{d}$ and to use it for regulating the ESS process. Moreover, the ratio of the currents $I_{\mathrm{e}} / I_{\mathrm{m}}$ should be much less dependent on the change in the slag conductivity due to the change in temperature, than the currents of the electrode and the mould themselves.

Calculation of parameters of electrostatic field near the slag pool bottom (type «B»). The distribution of the electric field intensity over the product surface characterizes the distribution of current den-

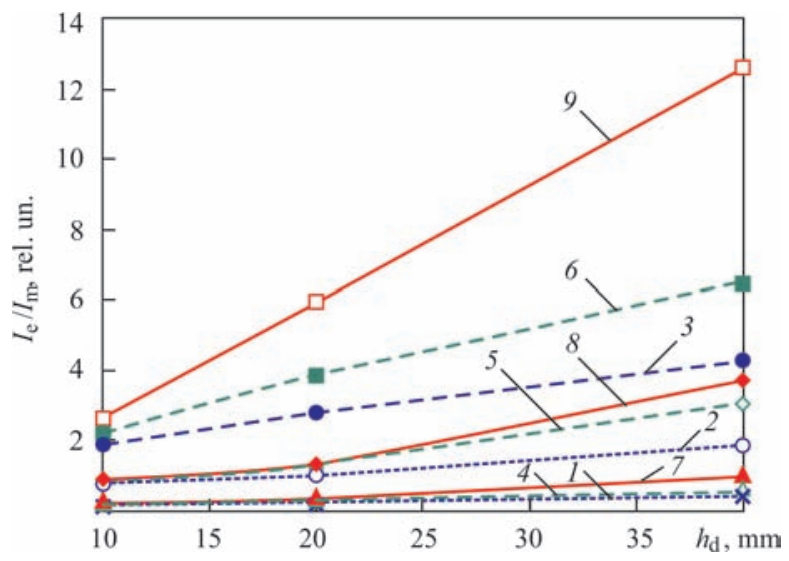

Figure 5. Changes in the ratio of electrode currents $I_{\mathrm{e}}$ to mould current $I_{\mathrm{m}}$, depending on deepening of the electrode $h_{\mathrm{d}}$ at different electrode diameters for different depths of the slag pool $h_{\mathrm{s}}: 1,2$, $3-I_{\mathrm{e}} / I_{\mathrm{m}}\left(\right.$ for $d_{\mathrm{e}}=40,90,130 \mathrm{~mm}$, respectively, at $h_{\mathrm{s}}=100 \mathrm{~mm}$ ); 4, 5, $6-I_{\mathrm{e}} / I_{\mathrm{m}}$ (for $d_{\mathrm{e}}=40,90,130 \mathrm{~mm}$, respectively, at $h_{\mathrm{s}}=$ $=70 \mathrm{~mm}$ ); 7, 8, $9-I_{\mathrm{e}} / I_{\mathrm{m}}$ (for $d_{\mathrm{e}}=40,90,130 \mathrm{~mm}$, respectively, at $h_{\mathrm{s}}=50 \mathrm{~mm}$ ) 

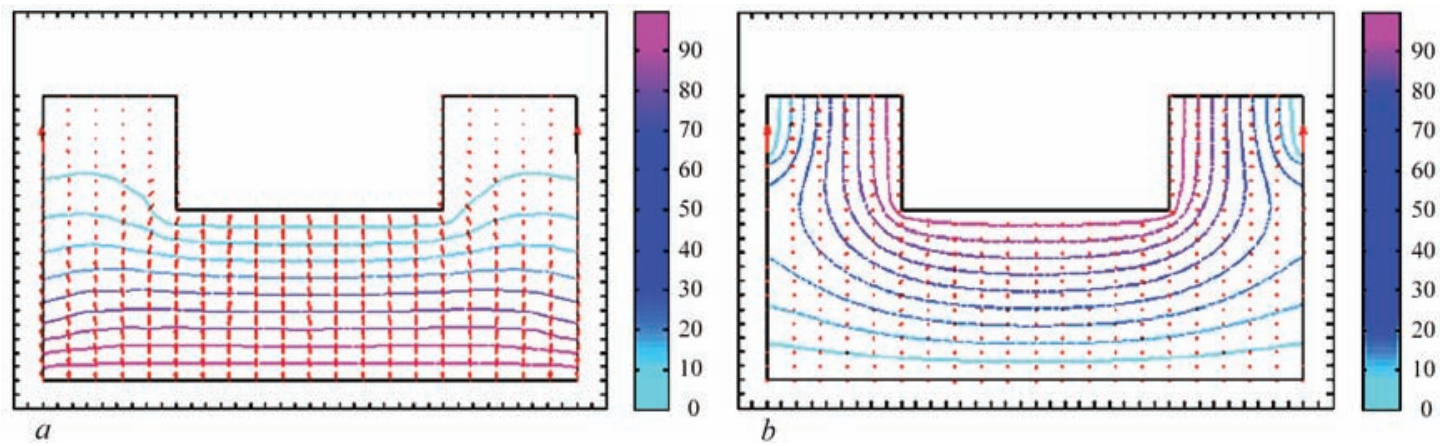

Figure 6. Calculation of shape of equipotential line of electrostatic fields in the vicinity of the slag pool bottom at the electrode deepening $h_{\mathrm{d}}=40 \mathrm{~mm}$ and the diameter of electrode $d_{\mathrm{e}}=90 \mathrm{~mm}$ for the depth of slag pool $h_{\mathrm{s}}=100 \mathrm{~mm}$; $a$ - diagram of connection of type «B»; $b$ - diagram of connection of type «E»

sity and, thus, the relative distribution of the thermal field over the metal pool surface. So, according to the shape of the equipotential lines of the model in the product vicinity, it is possible to predict the relative nonuniformity of penetration $\delta_{\mathrm{p}}$, as well as the relative average surface penetration depth of product $h_{\mathrm{p}}$.

Figure 6 shows an example of calculating the shape of equipotential lines of electrostatic fields near the slag pool bottom during connection of CSM to the source according to the diagram of type «B» and type «E». As is seen in Figure 6, $a$, near the bottom of slag pool (or on the surface of product) for the connection diagram of type « $\mathrm{B} »$, the electric field intensity in the near-wall region of mould is higher than in the product center. The opposite ratio between the intensities is seen while using the connection diagram of type «E».

The relative nonuniformity of penetration $\delta_{p}$ was calculated by the formula:

$$
\delta_{\mathrm{p}}=\frac{\sqrt{\frac{1}{n} \sum_{i=1}^{n}\left(h_{\mathrm{p} i} \overline{\mathrm{h}}\right) 2}}{h_{\mathrm{p}}},
$$

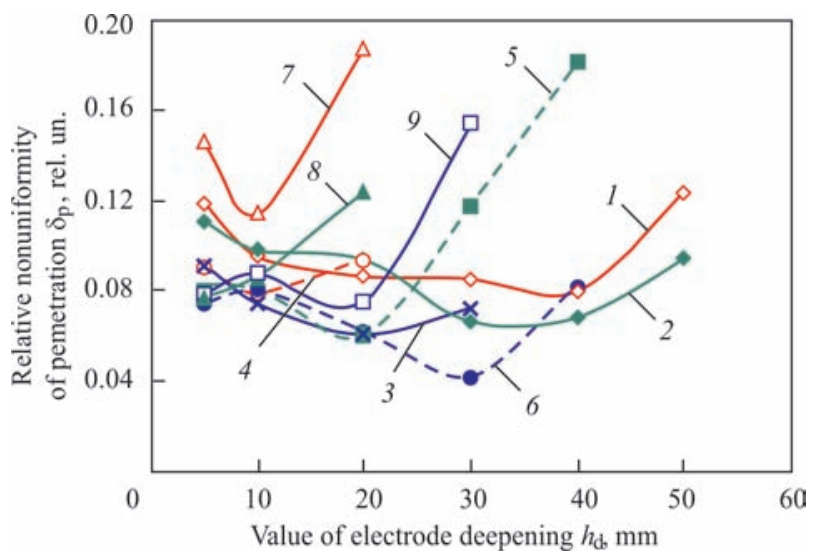

Figure 7. Changes in the relative nonuniformity of penetration $\delta_{\mathrm{p}}$ depending on electrode deepening $h_{\mathrm{d}}$ at different diameters of electrode $d_{\mathrm{e}}$ for different depths of slag pool $h_{\mathrm{s}}: 1,2,3-\delta_{\mathrm{p}}$ (for $d_{\mathrm{e}}=40,90,130 \mathrm{~mm}$, respectively, at $h_{\mathrm{s}}=100 \mathrm{~mm}$ ); 4, 5, $6-\delta_{\mathrm{p}}$ (for $d_{\mathrm{e}}=40,90,130 \mathrm{~mm}$, respectively, at $h_{\mathrm{s}}=70 \mathrm{~mm}$ ); 7, 8, 9- $\delta_{\mathrm{p}}^{\mathrm{p}}$ (for $d_{\mathrm{e}}=40,90,130 \mathrm{~mm}$, respectively, at $h_{\mathrm{s}}=50 \mathrm{~mm}$ ) where the number of measuring points along the mould diameter $n=19$; $h_{p \mathrm{i}}$ is the relative penetration depth at the $i$-th point of measurement, inversely proportional to the distance between the neighboring equipotential lines along the $i$-th coordinate.

From the diagrams in Figure 7 it is seen that the dependences $\delta_{\mathrm{p}}$ on $h_{\mathrm{d}}$ for different diameters of electrodes and the slag pool depths are of extreme nature in the investigated range of $h_{\mathrm{d}}$ changes. The minimum value of the relative penetration depth is observed for $d_{\mathrm{e}}=130$ and $h_{\mathrm{s}}=70 \mathrm{~mm}$ at the value of electrode deepening into the slag pool $h_{\mathrm{d}}=30 \mathrm{~mm}$.

The diagrams of change in the relative average penetration depth $h_{\mathrm{p}}$ depending on the electrode deepening $h_{\mathrm{d}}$ at different diameters of electrode $d_{\mathrm{e}}$ for different slag pool depths $h_{\mathrm{s}}$ are shown in Figure 8. Here we observe that with increase in the deepening of the electrode into the slag pool, that is, when it approaches the product, the average penetration depth of the product grows. An increase in the electrode diameter, as well as a decrease in the slag pool depth, leads to increase in the average penetration depth.

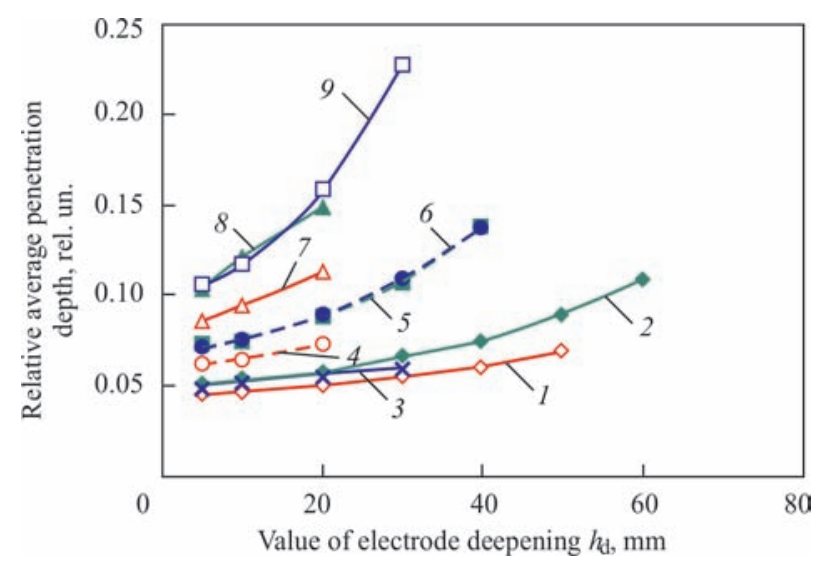

Figure 8. Changes in the relative average penetration depth $\bar{h}$ depending on electrode deepening $h_{\mathrm{d}}$ at different diameters $\stackrel{\mathrm{p}}{\mathrm{p}}$ electrode $d_{\mathrm{e}}$ for different slag pool depths $h_{\mathrm{s}}: 1,2,3-\delta_{\mathrm{p}}$ (for $d_{\mathrm{e}}=$ $=40,90,130 \mathrm{~mm}$, respectively, at $h_{\mathrm{s}}=100 \mathrm{~mm}$ ); 4, 5, $6-\delta_{\mathrm{p}}$ (for $d_{\mathrm{e}}=40,90,130 \mathrm{~mm}$, respectively, at $\left.h_{\mathrm{s}}=70 \mathrm{~mm}\right) ; 7,8,9-\delta_{\mathrm{p}}^{\mathrm{p}}$ (for $d_{\mathrm{e}}=40,90,130 \mathrm{~mm}$, respectively, at $h_{\mathrm{s}}=50 \mathrm{~mm}$ ) 
Figure 9 shows the diagrams of change in the minimum values of relative non-uniformity of penetration $\delta$, depending on the slag pool depth $\mathrm{h}_{\mathrm{s}}$ for different diameters of electrodes $d_{\mathrm{e}}$. It follows from the diagrams that the optimum depth of the slag pool lies in the range of $70-80 \mathrm{~mm}$, and the best value $\delta_{\mathrm{p}}=0.04$ is in the process with electrode $d_{\mathrm{e}}=130 \mathrm{~mm}$.

The similar calculation experiments were carried out for ESS in CSM according to the diagram of connection to the power source with a «potential» electrode (type «E») and with a «potential» mould (type «M»). The volume of this paper does not allow providing all the data obtained from these experiments, so we will present only the generalized results:

1. In the diagram of CSM connection to the power source of type «E», the highest current is passed through the electrode, which is equal to the sum of currents, passing through the bottom plate and mould. Thus, the more effective electrode melting and sufficient heating of product are provided as compared to the connection of «B» type diagram. ESS with CSM connected according to the diagram «E» will have the highest efficiency as compared to the $\langle\mathrm{B} »$ and $\langle\mathrm{M} »$ type connections. The dependence of the ratio of current of the bottom plate $I_{\mathrm{b}}$ to the current of the mould $I_{\mathrm{m}}$ on deepening of the electrode $h_{\mathrm{d}}$ has an essentially nonlinear nature, approaching the exponential one. Nevertheless, this circumstance can not affect the use of the functions $h_{\mathrm{d}}=F\left[I_{\mathrm{b}} / I_{\mathrm{m}}\right]$ for indirect measurement of deepening value and automatic maintenance of the preset value of this parameter. The same as in the diagram of type «B», with increase in electrode deepening into the slag pool, i.e. at its approaching to the product, the average penetration depth of the product is increased. An increase in the electrode diameter as well as a decrease in the slag pool depth, leads to increase in the average penetration depth. The optimum depth of the slag pool, at which the nonuniformity of penetration $\delta_{\mathrm{p}}$ is minimum, corresponds to $h_{\mathrm{d}}=100 \mathrm{~mm}$, and the best value $\delta_{\mathrm{p}}=0.06$ will be for the process with the electrode diameter $d_{\mathrm{e}}=130 \mathrm{~mm}$.

2. Connecting the CSM to the power source according to the diagram of «M» type is less widespread in practice, as far as the current passing through the mould is the sum of currents of the electrode and bottom plate, due to which the electrode melting efficiency and the role of the bottom plate, heating the product, are decreased. Dependence of the ratio of the electrode current $I_{\mathrm{e}}$ to the bottom plate current $I_{\mathrm{b}}$ on the deepening the electrode $h_{\mathrm{d}}$ has a clearly distinct character and can be used for indirect measuring the value of electrode deepening into the slag pool. The dependences $\delta_{\mathrm{p}}$ on $h_{\mathrm{d}}$ for the diagram of type «M» for CSM connection to the power source do not have an

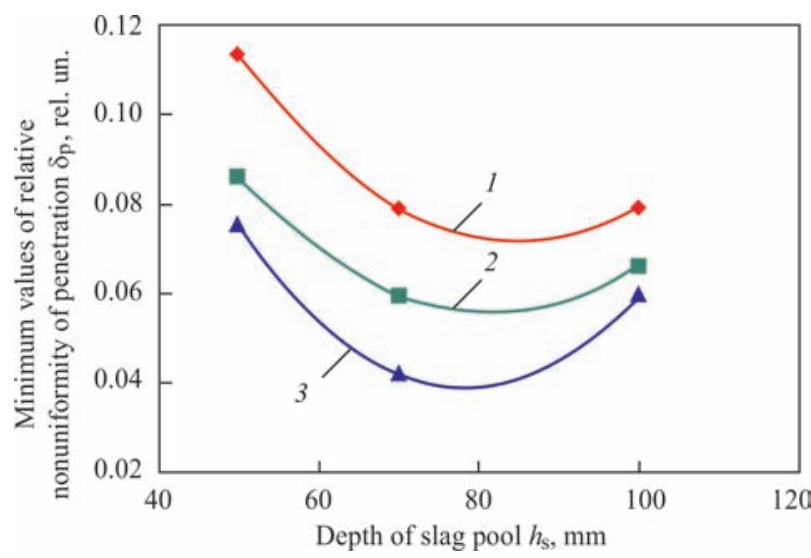

Figure 9. Changes in the minimum values of the relative nonuniformity of penetration $\delta_{\mathrm{p}}$ depending on the slag pool depth $h_{\mathrm{s}}$ at different electrode diameters $d_{\mathrm{e}}: 1,2,3-\delta_{\mathrm{p}}\left(\right.$ for $d_{\mathrm{e}}=40,90$, $130 \mathrm{~mm}$, respectively)

extreme character, they sharply elevate during electrode deepening, and the values $\delta_{\mathrm{p}}$ exceed the values obtained for the connection diagrams of type «B» and «E» by an order. With an increase in electrode deepening into the slag pool, i.e. when it approaches the product, the average penetration depth of the product almost does not change. An increase in the electrode diameter, as well as a decrease in the slag pool depth, leads to an increase in the average penetration depth. The optimum depth of the slag pool for minimizing the nonuniformity of penetration $\delta_{\mathrm{p}}$ corresponds to $h_{\mathrm{d}}=100 \mathrm{~mm}$, and the best value $\delta_{\mathrm{p}}=0.5$ will be for the process with the electrode diameter $d_{\mathrm{e}}=40 \mathrm{~mm}$.

3. The Table shows calculations of the consumed power $\Sigma P$ for ESS at $d_{\mathrm{e}}=90 \mathrm{~mm}, h_{\mathrm{d}}=20 \mathrm{~mm}, h_{\mathrm{s}}=$ $=100 \mathrm{~mm}$ for three types of connection circuits, under the condition that the same power $P_{\mathrm{e}}=99.950 \mathrm{~kW}$ is consumed at the electrode for all the cases considered. It is seen from the calculations that the process during connection according to the diagrams of type «B» and «M», consumes approximately 1.6 times more power than that in the diagram of type «E».

Simulation of two-circuit diagram of CSM supply with a "potential» bottom plate diagram of connection (type «B»). The use of two power sources for carrying out the process of ESS with CSM is considered to be less economical and more cumbersome than supply by one source. However, the use of two-circuit diagram of CSM supply can lead in some

Consumed power at ESS for different connection diagrams

\begin{tabular}{|c|c|c|c|}
\hline \multirow{2}{*}{$\begin{array}{c}\text { Power consump- } \\
\text { tion, } \mathrm{kW}\end{array}$} & \multicolumn{3}{|c|}{ Type of connection diagram } \\
\cline { 2 - 4 } & «» & «E» & «M» \\
\hline$P_{\mathrm{e}}$ & 99.950 & 99.950 & 99.950 \\
\hline$\Sigma P$ & 162.456 & 99.950 & 162.540 \\
\hline$\Sigma P / P_{\mathrm{e}}$ & 1.63 & 1.0 & 1.63 \\
\hline
\end{tabular}




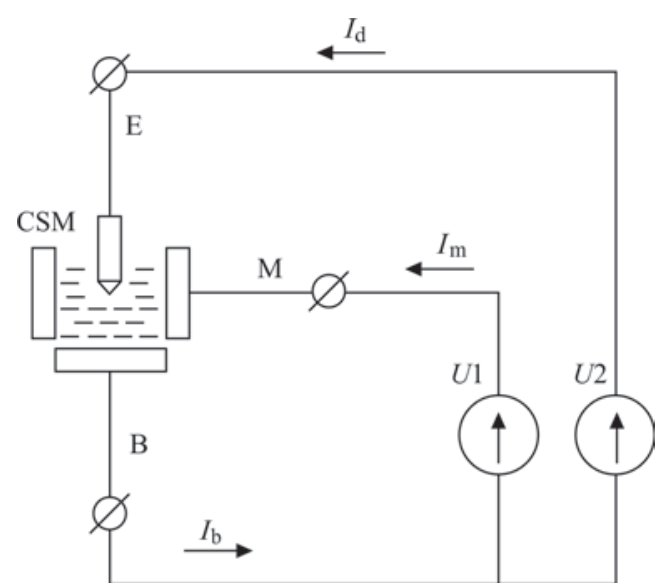

Figure 10. Two-circuit diagram of CSM supply: E, M and B terminals for connection to the electrode, current-carrying section of mould and bottom plate, respectively; $I_{\mathrm{e}}, I_{\mathrm{m}}$ and $I_{\mathrm{b}}$ - current of the electrode, current of the mould and current of the bottom plate, respectively; sources of direct current with voltages $U 1$ and $U 2$, respectively

cases to an improvement in the penetration characteristics of product.

During simulation of two-circuit diagram of CSM supply, a situation was considered where the voltage of the electrode varies with respect to the mould voltage. In this case, the voltage of the mould remains unchanged. In this case, we investigate the changes in the relative average nonuniformity of penetration $\delta_{\mathrm{p}}$ during the hypothetical transition of the power circuit from the diagram of type «B» to the diagram of type «M», namely, the change in $\delta_{\mathrm{p}}$ with an increase in the role of mould in the product penetration.

Figure 10 shows a two-circuit diagram of CSM supply. The voltage at the mould relative to the bottom plate $U 1$ remains unchanged in calculations, and the voltage at the electrode relative to the bottom plate $U 2$ is gradually reduced from the value equal to $U 1$, i.e. $U 1 / U 2=1$ to the value $U 1 / U 2=4$.

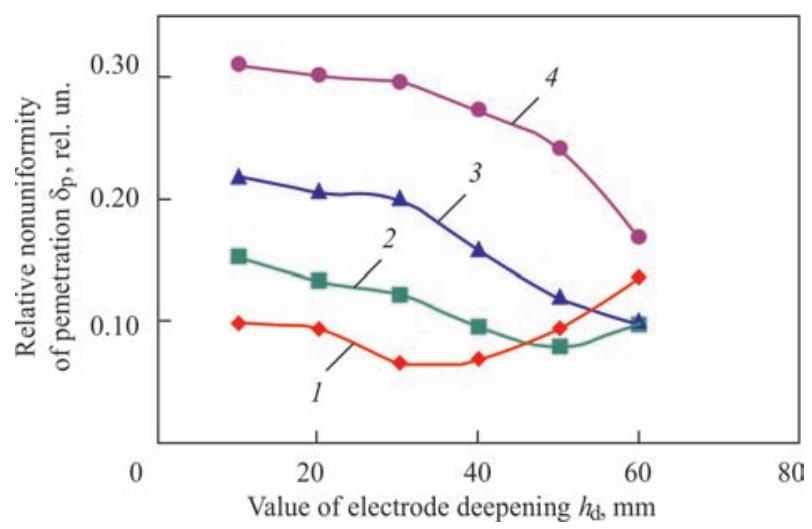

Figure 11. Changes in the relative nonuniformity of penetration $\delta_{\mathrm{p}}$, depending on deepening of the electrode $h_{\mathrm{d}}$ at different voltage ratios on the mould and the electrode $U 1 / U 2$ with an electrode diameter $d_{\mathrm{e}}=90 \mathrm{~mm}$ and depth of the slag pool $h_{\mathrm{s}}=100 \mathrm{~mm}: 1-$ $U 1 / U 2=1 ; 2-1.5 ; 3-2.33 ; 4-4$
The calculation diagrams of the change in relative nonuniformity of penetration $\delta_{\mathrm{p}}$ depending on deepening the electrode $h_{d}$ at different ratios of voltages at the mould and the electrode $U 1 / U 2$ at the electrode diameter $d_{\mathrm{e}}=90 \mathrm{~mm}$ and the depth of the slag pool $h_{\mathrm{s}}=100 \mathrm{~mm}$ are shown in Figure 11.

From Figure 11 it is seen that in the investigated range of the value of the electrode deepening, the best values of $\delta_{p}$ will be at the equality of $U 1$ and $U 2$. When $U 1$ and $U 2$ are equal, the two-circuit diagram is almost a single-circuit one. However, when the electrode is deepened to more than $45 \mathrm{~mm}$ and the ratio of $U 1 / U 2=1.5$, the two-circuit diagram has lower values of $\delta_{\mathrm{p}}$ than that at the single-circuit diagram of connection.

The calculations of parameters of the electrostatic field near the slag pool bottom allowed getting an idea of its shape. For example, Figure 12 shows the calculation distribution of the relative current density $I_{\mathrm{b}}$ along the radius of the product $R_{\mathrm{b}}$ for different values of electrode deepening $h_{\mathrm{d}}$ with a diameter $d_{\mathrm{e}}=$ $=90 \mathrm{~mm}$ (connection diagram of type «E»). The distribution of current density of the bottom plate determines the shape of the metal pool bottom.

\section{Generalization of calculation experiment re-} sults.

1. With the help of calculation experiment, it was found that the main parameters of surfacing by the electrode of a large cross-section (depth and uniformity of penetration) are determined both as the technological parameters (electrode diameter and its deepening into the slag pool of different depth, the number of power sources and the diagram of CSM connection to them), and also as controllable electrical indicators of the process corresponding to these parameters.

2 . It was confirmed that the values $I_{\mathrm{e}} / I_{\mathrm{m}}$ for the diagram of type «B», $I_{\mathrm{b}} / I_{\mathrm{m}}$ for the diagram of type «E» and $I_{\mathrm{e}} / I_{\mathrm{m}}$ for the diagram of type «M», which can be obtained by calculation in the process of surfacing, correspond to such an important parameter as the value of the electrode deepening. The automatic mainte-

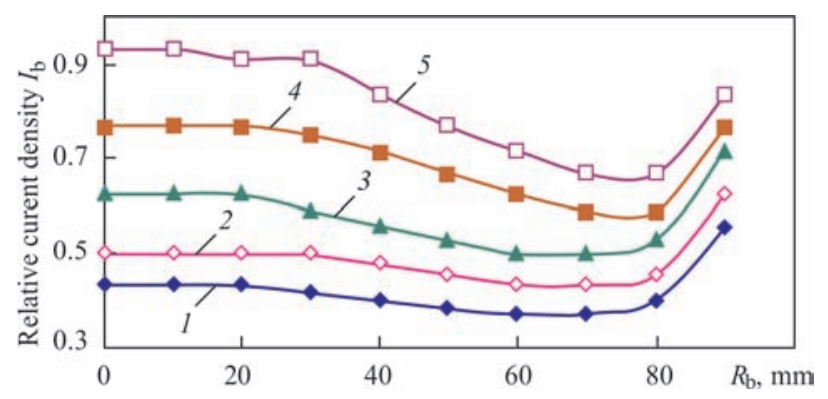

Figure 12. Distribution of relative current density $I_{\mathrm{p}}$ along the radius of the product $R_{\mathrm{b}}$ for different values of deepening of the electrode $h_{\mathrm{d}}$ with a diameter $d_{\mathrm{e}}=90 \mathrm{~mm}$ (connection diagram of type «E»): $I-h_{\mathrm{d}}=10 ; 2-20 ; 3-30 ; 4-40 ; 5-50 \mathrm{~mm}$ 
nance of the preset value of the electrode deepening will provide the necessary uniformity and penetration depth of the product.

3. A comparative analysis of three types of circuits of CSM connection to the power source was carried out, which revealed that the supply circuit of type «B» provides the least nonuniformity of penetration at the minimum penetration depth of the product, and the diagram of type «E» provides a good electrode melting, i.e. the improved process efficiency with acceptable nonuniformity and penetration depth of the product. In ESS with CSM, this gives grounds to use the diagram of type «B» and then the diagram of type «E» at the initial stage of the process. The switching of circuits should be performed automatically.

4. Analysis of the model with a two-circuit diagram of connection did not show special advantages in the quality of penetration at the process using a CSM single-circuit diagram of CSM supply.

1. Troyansky, A.A., Ryabtsev, A.D., Samborsky, M.V., Mastepan, V.Yu. (2002) Application of measuring information system for investigation of ESR process. Metall i Litio Ukrainu, 7-8, 25-26 [in Russian].
2. Troyansky, A.A., Ryabtsev, A.D., Mastepan, V.Yu. (2004) Indirect methods for control of ESR technological parameters based on application of harmonic composition of current and voltage of remelting. In: Abstr. of Papers of Int. Scient. Conf. on Modern Problems of Theory and Practice of Quality Steel Production (Mariupol, 8-10 September 2004). Priazov. STU, 80-82.

3. Troyansky, A.A., Ryabtsev, A.D., Mastepan, V.Yu. et al. (2005) Application of method of current distribution modeling as the base for development of technology of high-quality ingots by CESR method. Metallurg. Protsessy i Oborudovanie, 2, 25-27 [in Russian].

4. Makhnenko, V.I., Demchenko, V.F., Tarasevich, N.I., Krikent, I.V. (1985) Calculation system for investigation of current distribution in slag pool. Problemy Spets. Elektrometallurgii, 1, 14-19 [in Russian].

5. Tomilenko, S.V., Kuskov, Yu.M. (2000) Regulation and stabilization of base metal depth penetration in electroslag surfacing in current-supplying mold. Svarochn. Proizvodstro, 9, 32-35 [in Russian].

6. Tomilenko, S.V., Kuskov, Yu.M. (1999) Power features of electroslag process in current-supplying mold. Avtomatich. Svarka, 2, 51-53 [in Russian].

7. Shmelev, V.E. Partial differential equations toolbox. Toolbox for solution of differential equations in partial derivatives [in Russian]. http://matlab.exponenta.ru/pde/book1/index.php

8. Govorkov, V.A. (1968) Electric and magnetic fields. 3rd Ed. Moscow, Energiya [in Russian]. 


\title{
ALGORITHM OF JOINT LINE «TRACKING» IN TANDEM ARC WELDING
}

\author{
G.A. TSYBULKIN \\ E.O. Paton Electric Welding Institute of the NAS of Ukraine \\ 11 Kazimir Malevich Str., 03150, Kyiv, Ukraine. E-mail: office@paton.kiev.ua
}

\begin{abstract}
The main difficulty, appearing in solution of the problem of automatic «tracking» the line of joint welded in tandem arc welding, is connected with measurement of side deviations from this line of each of electrodes located close to each other in the process of welding. Besides, together with side correction of movement of the electrodes, deviating from the line of joint welded, a need in angular correction of a torch is appeared, which could provide «parallelism» between the line of joint welded and the line, connecting the electrodes. A new approach to the solution of the above-mentioned problem was proposed, based on application of electric arc methods of measurement and application of recurrent procedures of linear and angular correction of the welding torch movement. The results of computer modeling are given in the paper. 8 Ref., 3 Figures.
\end{abstract}

Keywords : tandem arc welding, adaptive control, arc sensors, recurrent algorithms of correction

Among the different welding technologies, used in industrial production, welding with two successive arcs in a shielding gas (Tandem Welding) is considered to be rather challenging, characterized by a higher efficiency and a better quality of welded joints as compared to conventional welding with one arc [1]. The location of electrodes one after another makes a welding pool longer. This, according to [1], provides a more efficient degassing, leading to a decrease in the porosity of a weld, and improves its mechanical characteristics.

At the same time, it is obvious that with all the advantages of tandem arc welding, a good quality of welded joints can be achieved only on the condition that during welding both electrodes move along the line of joint welded. If, for some reason or another, one or both of the electrodes deviate from the indicated line, and if these deviations exceed the admissible value, then, undercuts and other inadmissible defects will be formed in a weld.

In robotic arc welding with one electrode, this problem can be solved using an adaptive control of the movement [2], which refers to the control of a torch movement in a function from the controlled parameters of the outer environment, in particular, from the change in the spatial position of the joint welded. The information about the side deviation of the electrode from the line of joint welded is provided by special sensor devices. Based on this information, the specified movement of the torch is corrected, if necessary. As a result, a kind of «tracking» of the line of joint welded is performed by the welding torch.

(c) G.A. TSYBULKIN, 2018
As for the case of tandem arc welding, providing the «tracking» mode encounters certain difficulties associated with the fact that a rather short distance between two electrodes (10-12 mm) complicates a direct measurement of the side deviation of each electrode separately from the line of joint welded using the existing sensor devices. In addition, because of the fixed position of the electrodes relative to each other, in the welding torch certain difficulties appear in providing «parallelism» between the line connecting these electrodes and the line of joint welded under the conditions where the line of the joint welded can deform directly in the process of welding.

Judging from the information, placed on the sites of well-known foreign companies (see, for example, [3]), the interest to the considered problem is constantly growing. In particular, the Company Kobe Steel developed a special «dual arc sensor», used for tracking in tandem arc welding. In the present paper, a slightly different approach to the problem of «tracking» is offered, which consists in using conventional arc sensors and application of recurrent algorithms for correction of the current position of the torch.

1. Determination of deviations. Figure 1 shows the scheme of possible arrangement of the electrodes $E_{1}$ and $E_{2}$ relative to the axial line of the joint welded (indicated in Figure by the number 1 ). $\varepsilon_{1}$ and $\varepsilon_{2}$ denote the side deviations of the electrodes from the indicated line. The dashed line shows the section $d$, connecting the electrodes $E_{1}$ and $E_{2}$. The location of the electrodes in the welding torch is fixed.

As was mentioned above, the direct measurement of side deviations $\varepsilon_{1}$ and $\varepsilon_{2}$ is connected with great technical difficulties. At the same time, it is known 
[4-8] that in welding of fillet, tee and overlap joints, as well as joints with $\mathrm{V}$-shaped edge preparation, the information on deviations $\varepsilon_{1}$ and $\varepsilon_{2}$ can be obtained indirectly by using arc sensors. A sensitive element of these sensors is the welding arc itself. The theory and principles of designing the arc sensor systems for welding robots are described in the monograph [8].

A peculiar feature of arc sensors is the fact, that they allow determining the present deviation of the electrode end from the line of joint welded on results of the welding current change. Hence, to determine the side deviations of $\varepsilon_{1}$ and $\varepsilon_{2}$ by means of arc sensors, it is sufficient to have only sensors of welding currents. If the welding currents $i_{1}$ and $i_{2}$ (or their deviations $\delta_{1}=i_{1}-i_{\mathrm{n} 1}$ and $\delta_{2}=i_{2}-i_{\mathrm{n} 2}$ from their nominal values $i_{\mathrm{n} 1}, i_{\mathrm{n} 2}$ ) are measured in the extreme positions of the torch at its transverse oscillatory movements, then, according to [8], the desired deviations $\varepsilon_{1}$ and $\varepsilon_{2}$ can be determined by calculation according to the following formulas:

$$
\begin{aligned}
& \varepsilon_{1}=\frac{\delta_{1 R}-\delta_{1 L}}{\delta_{1 R}+\delta_{1 L}}\left(s-v T_{\mathrm{w}}\right), \\
& \varepsilon_{2}=\frac{\delta_{2 R}-\delta_{2 L}}{\delta_{2 R}+\delta_{2 L}}\left(s-v T_{w}\right) .
\end{aligned}
$$

Here the indices $R$ and $L$ denote the values $\delta_{1}$ and $\delta_{2}$ in the extreme right and, respectively, in the extreme left positions of electrodes relative to the line of joint welded; $s$ is the half of the distance between the extreme positions of electrodes; $v$ is the absolute value of the speed of the welding torch transverse movement, and the parameter $T_{w}$, characterizing the dynamic properties of the processes running in the welding circuit, is determined by the formula

$$
T_{\mathrm{w}}=\frac{R_{\mathrm{w}}}{E M},
$$

where $R_{\mathrm{w}}$ is the total resistance of welding circuit; $E$ is the electric field intensity in arc column; $M$ is the parameter, which characterizes the electrical, thermophysical and geometric properties of a consumable electrode. (It is assumed that both welding circuits are identical.)

Therefore, in many practical cases, the side deviation of each electrode separately in tandem arc welding can be determined from the measurements of welding currents passing through these electrodes, followed by calculation using formulas (1) and (2).

2. Correction of welding torch movement. The task of side correction of the welding torch movement consists in eliminating the outlined deviations $\varepsilon_{1}$ and $\varepsilon_{2}$ (directly in the welding process). In other words, the task is to provide the movement of the electrodes $E_{1}$ and $E_{2}$ inside the «band» of a given width $2 \varepsilon_{0}$ (Fig-

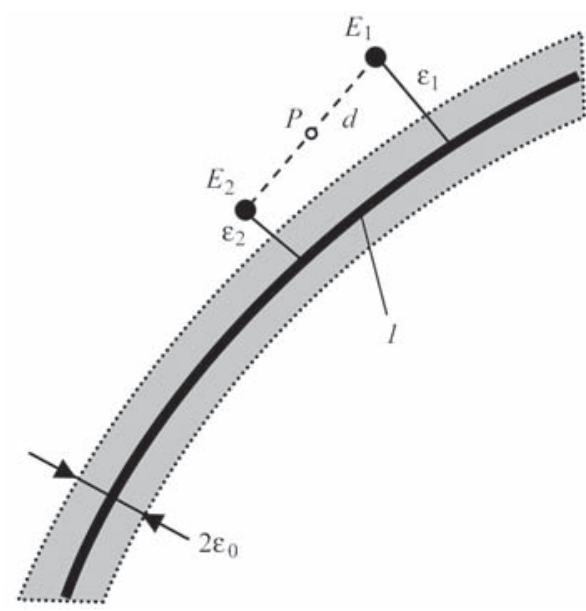

Figure 1. Scheme of arrangement of electrodes relative to the joint welded (see indications in the text)

ure 1), the axial line of which is the line of joint welded.

Here it is necessary to pay attention to the fact that, unlike welding with one arc, it is necessary to correct not only the position of the electrodes $E_{1}$ and $E_{2}$ but also the orientation of the line connecting these electrodes with respect to the line of joint welded.

Mathematically, let us formulate the task of correction in the form of the following requirements:

$$
\begin{aligned}
& \frac{\left|\varepsilon_{1}+\varepsilon_{2}\right|}{2} \leq \varepsilon_{0}, \\
& \frac{\varepsilon_{1}-\varepsilon_{2}}{d} \leq \sin \varphi_{0},
\end{aligned}
$$

where $\varphi_{0}$ is the admissible value of the angle between the section $d$ and the tangent to the line of joint welded.

The formulated problem can be interpreted as the problem of stabilizing the movement of electrodes $E_{1}$ and $E_{2}$ rigidly interconnected within a preset «band». With this formulation of the problem, the stabilization algorithms are conveniently constructed in the form of recurrent relations

$$
\begin{gathered}
u(k+1)=u(k)+\Delta u(k+1), \\
q(k+1)=q(k)+\Delta q(k+1), \quad k=0,1,2, \ldots, .
\end{gathered}
$$

In these relations, $u(k)$ is the position of the point $P$ located in the middle of the section $d$ (see Figure 1 ), relative to the line of joint welded; $q(k)=\operatorname{tg} \varphi(k)$, where $\varphi(k)$ is the angle between the section $d$ and the tangent to the line of joint welded; $k$ is the index indicating the moment of time $k T_{0}$, where $T_{0}$ is the step of time sampling;

$$
\Delta u(k+1)=\left\{\begin{array}{cc}
-\varepsilon_{0}, & \left(\varepsilon(k)>\varepsilon_{0}\right), \\
\varepsilon_{0}, & \left(\varepsilon(k)<-\varepsilon_{0}\right), \\
0, & \left(|\varepsilon(k)| \leq \varepsilon_{0}\right),
\end{array}\right.
$$




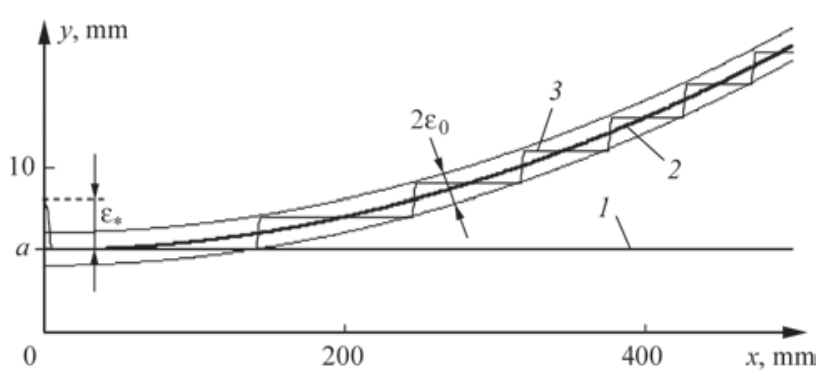

Figure 2. Results of modeling the correction of electrodes position (point $P$ ) relative to the line of joint welded (see indications in the text)

$$
\Delta q(k+1)=\left\{\begin{array}{cc}
-\mu_{0}, & \left(\mu(k)>\mu_{0}\right), \\
\mu_{0}, & \left(\mu(k)<-\mu_{0}\right), \\
0, & \left(|\mu(k)| \leq \mu_{0}\right) .
\end{array}\right.
$$

In (5) and (6) the following designations are introduced: $\mu_{0}$ is a preset number characterizing the admissible degree of «non-parallelism» between the section $d$ and the tangent to the line of joint welded;

$$
\begin{gathered}
\varepsilon(k)=\frac{\left|\varepsilon_{1}(k)+\varepsilon_{2}(k)\right|}{2}, \\
\mu(k)=\operatorname{tg} \varphi(k)-y^{\prime}(k),
\end{gathered}
$$

where $y^{\prime}=d y / d x$ is the angular coefficient of tangent to the line of joint welded, described by the expression $y=y(x)$.

Under the influence of $\Delta u(k+1)$, the electrodes $E_{1}$ and $E_{2}$ are «displaced» (as a one whole) along the normal to the line of joint welded, and under the action of $\Delta q(k+1)$, the welding torch is rotated relative to point $P$, providing «parallelism» between the section $d$ and the tangent to the line of joint welded.

It is seen from expressions (1)-(6), that the stabilization of the welding torch movement in a preset «band» occurs quite simple. First, the side deviations $\varepsilon_{1}(k)$ and $\varepsilon_{2}(k)$ are calculated according to formulas (1) and (2) based on the results of measurements $\delta_{1 R}$, $\delta_{1 L}, \delta_{2 R}, \delta_{2 L}$ at each cycle $k$. Then, in accordance with the logical functions (5) and (6), the correcting actions $\Delta u$ and $\Delta q$ are determined. After this, the correction of the welding torch position is performed according to the laws (3) and (4) at the cycle $(k+1)$.

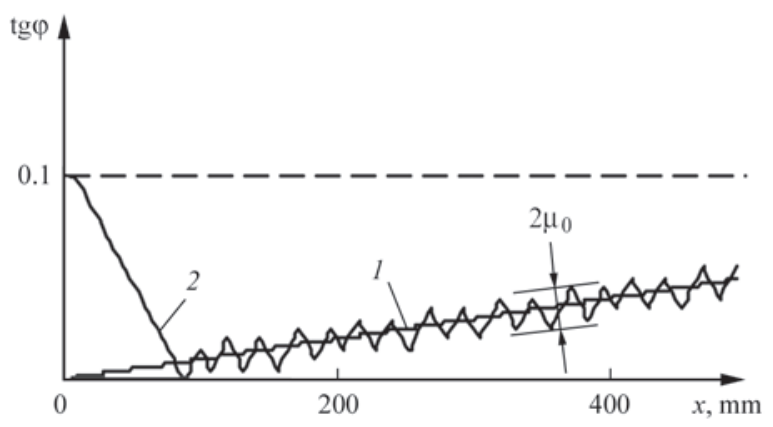

Figure 3. Results of modeling the correction of the section $d$ slope relative to the tangent to the line of joint welded
3. Results of computer modeling. Let us illustrate the effectiveness of automatic correction algorithms (3) and (4) on a certain example (Figure 2). Let the line of joint welded, along which it is planned to move the electrodes in the process of welding, be preset in Cartesian coordinates by equations in a parametric form $x=v_{\mathrm{w}} t, y_{1}=a, t=\left\{0, t_{*}\right\}$. Here $v_{\mathrm{w}}=$ = const is the speed of welding torch movement along the joint welded; $a$ is the constant; $t_{*}=l / v_{w}$, where $l$ is the length of the preset line (in Figure 2 this line is indicated by the number 1 ).

Let us suppose that the line 1 in the process of welding is deformed for one reason or another and takes the form of a line marked with the number 2 . Let us approximate this line by the equations $x=v_{\mathrm{w}} t$, $y_{2}=a+b x^{2}$, in which $b$ is a positive coefficient. Moreover, let us assume that the point $P$ located in the middle of the section $d$ (see Figure 1) before start of welding was at a distance $\varepsilon_{*}$ from the line of joint welded, and the angle between the section $d$ and the tangent to the curve $y_{2}=a+b x^{2}$ was equal to $\varphi_{*}$.

The number 3 in Figure 2 denotes the curve $u(x)$ representing the «trace» of the moving welding torch (point $P$ ) as a result of the correction of its movement on the basis of the algorithm (3). When modeling the correcting control, the following parameter values were used: $v_{\mathrm{w}}=12 \mathrm{~mm} / \mathrm{s} ; l=500 \mathrm{~mm} ; d=10 \mathrm{~mm} ; a=$ $=5 \mathrm{~mm} ; \Delta l=1 \mathrm{~mm} ; b=4 \cdot 10^{-5} / \mathrm{mm} ; \varepsilon_{0}=1 \mathrm{~mm} ; \varepsilon_{*}=$ $=7 \mathrm{~mm} ; \operatorname{tg} \varphi_{*}=0.1, T_{0}=\Delta l / v_{\mathrm{w}}=0.08 \mathrm{~s}$.

From Figure 2 it is seen that although the line of the joint 2 does not substantially coincide with the line 1 , preset by the program, nevertheless, due to the correcting control, the movement of the characteristic point $P$ in the steady state occurs near the line 2, i.e., inside the «band» at a given width $2 \varepsilon_{0}$.

Simultaneously with the correction of the position of welding torch relative to the line of joint welded, its angular correction occurs by turning around the point $P$ in accordance with the algorithm (4). Figure 3 presents the results of modeling the angular correction. As the angular coefficient $\operatorname{tg} \varphi_{*}$, which characterizes the slope of the section $d$ to the welded joint line before the start of welding, the number 0.1 (dashed line) was taken.

The line denoted by the number 1 represents a diagram of functional dependence $y_{2}^{\prime}(x)=2 b x$, and the curve 2 obtained as a result of the angular correction of the torch movement is nothing else than a graphic image of the variation of angular coefficient $\operatorname{tg} \varphi(x)$, which tends to the line $y_{2}^{\prime}(x)$.

From the analysis of these curves it follows that corrective control of the rotation of welding torch leads to the fact that the deviation of angular coefficient $\operatorname{tg} \varphi(x)$ of the section $d$ from the angular coeffi- 
cient of the tangent to the welded joint line $y_{2}^{\prime}(x)$ in the steady state does not exceed the preset value.

Therefore, the general conclusion follows that due to the use of arc sensors as a source of present information about the deviations of electrodes from the line of joint welded and the application of recurrent procedures for correcting the movement of welding torch, control of tandem arc welding acquires adaptive properties. Its peculiarity consists in the fact that not only the positions of electrodes (as a one whole) are corrected in the welding process, but also their orientation relative to the line of joint welded, which provides a high accuracy of electrodes movement along the joint welded. This creates prerequisites for the provision of sufficiently high technological indicators inherent in tandem arc welding.
1. Dilthey, U., Stein, L., Woeste, K., Reich, F. (2003) Latest development and trends in high-efficient welding technologies. The Paton Welding J., 10-11, 146-152.

2. Tsybulkin, G.A. (2014) Adaptive control in arc welding. Kiev, Stal [in Russian].

3. Kobe Steel Company. http://www.kobelco.co.jp/english/welding/files/KWT_2012_2TH.pdf

4. Akulov, L.M., Bukhovets, T.K., Stolovich, A.Yu. (2001) System of weld line tracking by arc. In: Proc. of 2nd Int. Symp. on Welding and Related Technologies (Minsk, Belarus), 136-137 [in Russian].

5. Dolinenko, V.V. (1989) Evaluation and control of torch position using electric parameters of welding arc: Syn. Of Thesis for Cand. of Techn. Sci. Degree. Kiev [in Russian].

6. Yongyi, A., Li, Y. (1991) Arc sensor used in MIG/MAG weld tracking. Transact. China Welding Inst., 12(3), 155-160.

7. Sugitani, Y. (2000) Making best use of the arc sensor. J. of the Jap. Weld. Soc., 69(2), 46-50.

8. Tsybulkin, G.A. (2011) Arc sensor systems for welding robots. Kiev, Stal [in Russian]. 


\title{
MODERN METHODS OF MANUFACTURING THREE-LAYER PANELS OF ALUMINIUM ALLOYS (Review)
}

\author{
Yu.V. FALCHENKO and L.V. PETRUSHINETS
}

E.O. Paton Electric Welding Institute of the NAS of Ukraine

11 Kazimir Malevich Str., 03150, Kyiv, Ukraine. E-mail: office@paton.kiev.ua

\begin{abstract}
Three-layer panels with periodic cellular core from aluminium alloys are promising for application in aerospace products, ground and water transportation. The uniqueness of the three-layer panel design consists in that they are characterized by high values of strength and rigidity at a relatively small mass. The work deals with the main types of three-layer panels, design features of manufacturing the cores, methods to join the honeycomb core strips to each other, as well as the three-layer panel elements into one structure. The objective of the presented review is analysis of modern methods of manufacturing three-layer panels from aluminium alloys. Analysis of published data showed that such methods of joining the three-layer panel elements as adhesive bonding and brazing became the most widely applied. Their main disadvantage, however, is increase of the structure mass due to application of an adhesive or braze alloy. Application of diffusion welding with manufacture of honeycomb core from a stronger titanium alloy for joining three-layer panels or application of a specialized fixture, which allows limiting the degree of plastic deformation of the structure, are promising for welding three-layer panels. 28 Ref., 1 Table, 9 Figures.
\end{abstract}

Ke y w ord s : aluminium alloys, three-layer panels, core, adhesive bonding, brazing, welding

Three-layer panels became widely applied in aircraft manufacturing, shipbuilding, construction and other industrial sectors owing to their unique properties, namely at a relatively small mass these structures are characterized by high values of strength and rigidity. Moreover, they have good vibration and radio engineering characteristics, and sound and heat insulation properties.

«Three-layer panel» term should be understood as a structure consisting of two thin skins (load-carrying layers) with the core placed between them (Figure 1) [1].

The uniqueness of the three-layer panels consists in that the skins reinforced by the core, take up high compressive stresses, exceeding the material elasticity limit. Separation of the load-carrying layers by a certain distance from each other, through application

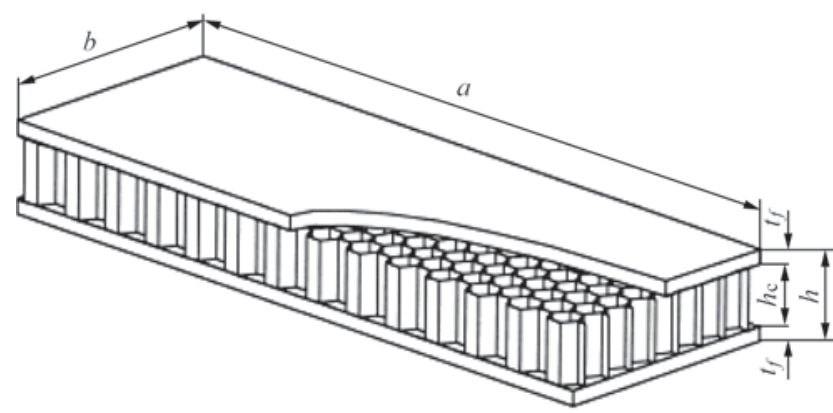

Figure 1. Schematic of a three-layer honeycomb panel [1]

(C) Yu.V. FALCHENKO and L.V. PETRUSHINETS, 2018 of the core, enables achieving a significant ratio of the structure rigidity to its mass.

The core applied in the three-layer panels, can be divided into the following groups:

- solid from homogeneous material;

- solid from anisotropic material;

- lightweight (perforated) core;

- ribbed structures.

Designs of three-layer structures with corrugated (Figure 2) and honeycomb cores (Figure 3) were also developed.

Core density is one of its main characteristics. It is determined by material mass and volume, taken by it between the load-carrying layers. Core density influences the mass of the three-layer structure, and value of strength and rigidity of the core.

In the case of application of the honeycomb core from metal, its density depends on the cell shape, wall (face) width and its thickness, density of material from which the core is made, and method to produce the core [2].

$$
\rho_{\mathrm{c}}=k_{b}\left(\delta_{\mathrm{w}} / a_{\mathrm{w}}\right) \rho_{\mathrm{m}},
$$

where $k_{b}$ is the coefficient allowing for cell forming; $\delta_{w}$ is the thickness of the wall of single face of the cell; $a_{w}$ is the width of the honeycomb wall; $\rho_{\mathrm{m}}$ is the density of core material.

Density of honeycomb core with a hexagonal cell, provided $a_{w}=\delta_{w}, \beta=60^{\circ}$, can be found from the following formula

$$
\rho_{\mathrm{c}}=1.54\left(\delta_{\mathrm{w}} / a_{\mathrm{w}}\right) \rho_{\mathrm{m}} .
$$



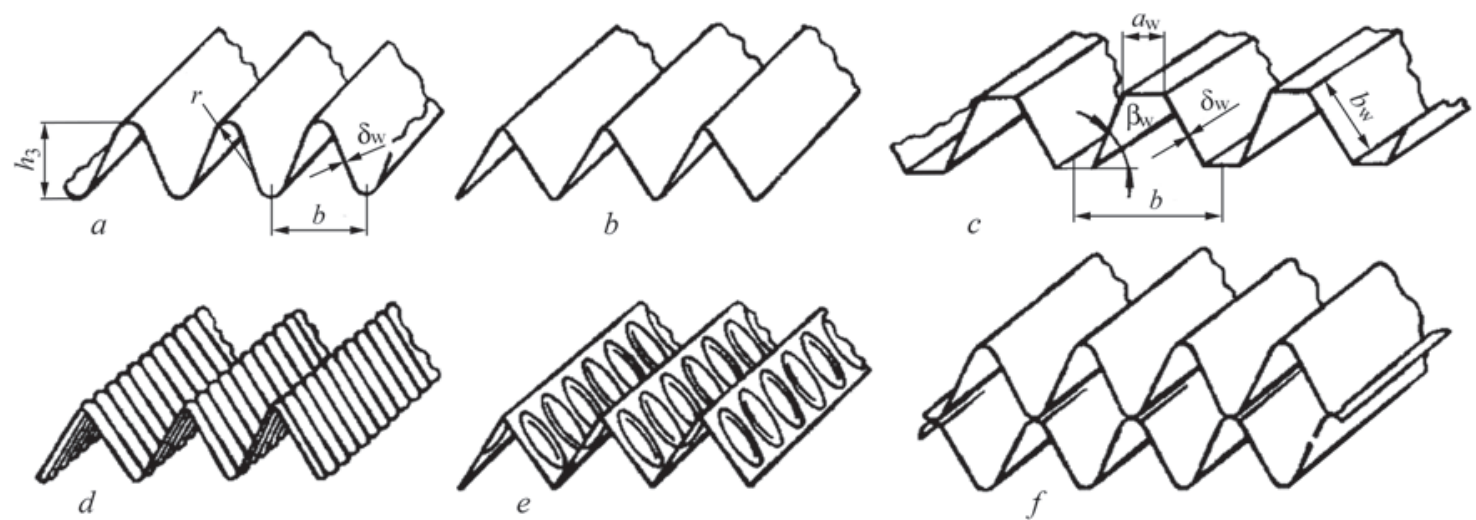

Figure 2. Examples of structures with a corrugated core: $a-\operatorname{sinusoidal;~} b-$ triangular; $c-$ trapezoidal; $d-$ wavy truss; $e-$ rift truss; $f$ - double truss
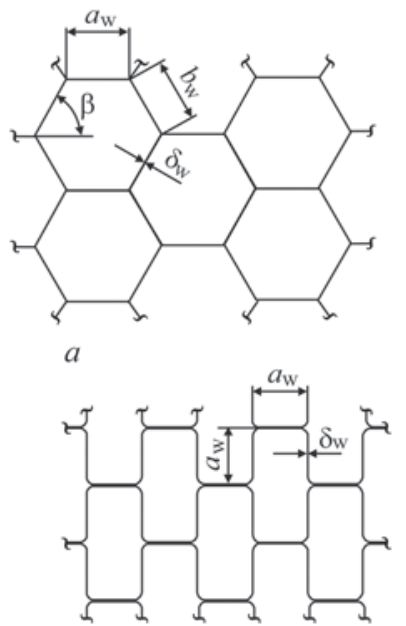

$d$

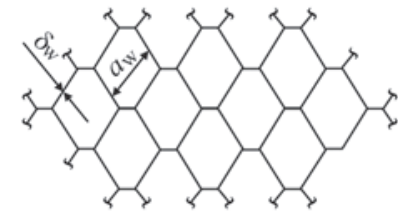

$b$

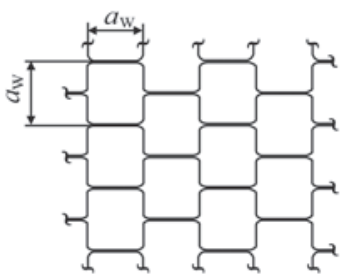

e
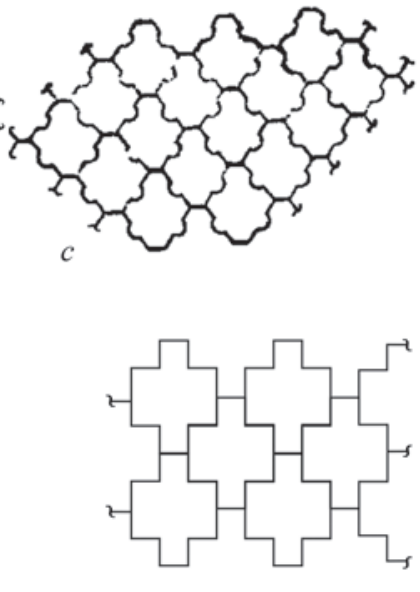

$f$

Figure 3. Examples of honeycomb core structures: $a$ - with hexagonal cell; $b$ - with square cell; $c$ - with square rifted cell; $d, e$ with rectangular cell; $f$ - with cruciform cell [2]

Three-layer panels, particularly those with a honeycomb core, are used in space vehicle structures, as well as in aircraft of various classes and purposes. Such structures can be applied as load-carrying elements in the wing, fuselage, particularly in assemblies, taking up a local load (flaps, fairings) and transverse distributed load (flooring), as well as non load-carrying elements [2, 3]. Application of honeycomb structures from aluminium alloys in the internal layer of a high-speed train nose, as an element, absorbing a considerable amount of energy at frontal collision, is promising [4].

The ability of the core to take the load in the direction of loading of the load-carrying layers depends on the position of its fibers or walls. If the latter are located normal to this direction, the core does not take the load. If they are parallel, the core is loaded. At present, honeycomb cores are used in the majority of cases for three-layer panels from light alloys. They have the following advantages: honeycomb walls are located normal to the load-carrying layers, so that the core does not take the load from the skin, and, as a result, does not buckle out at load increase. Load-carrying layers are reinforced by the honeycomb walls as though in a "continuous» manner (ratio of the honeycomb size to the load-carrying layer thickness $\leq 25$ ), so that the buckling stress of load-carrying layers between the walls is in the plastic region [5]. This

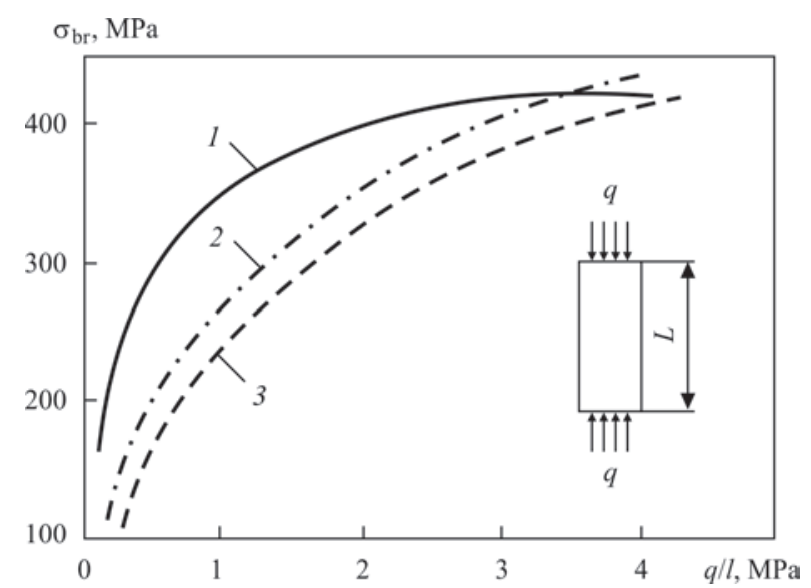

Figure 4. Dependence of breaking stress at longitudinal compression on intensity factor for different designs of the three-layer panels: 1 - panel with honeycomb core; 2 - solid panel; 3 stringer riveted panel 

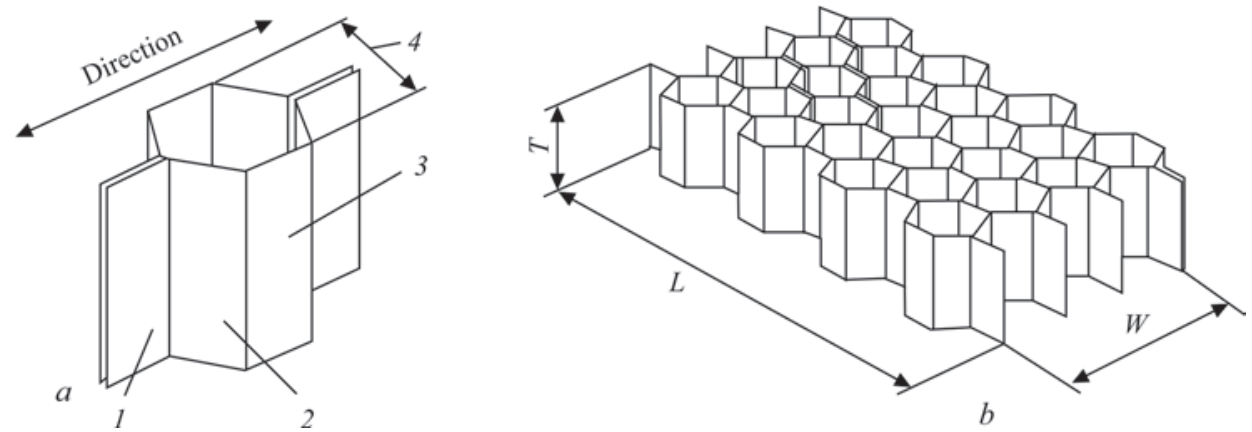

Figure 5. Honeycomb core with hexagonal cells: $a$ — view of isolated cell ( 1 - corrugated strips; 2 — cell faces of single thickness; 3 - cell faces of double thickness; 4 - cell size); $b-$ main parameters of the honeycomb core $(L-$ length; $T-$ thickness; $W-$ width) [8]

is confirmed by high breaking stresses of honeycomb structures at compression (Figure 4) [6].

Despite the large number of honeycomb core structures developed so far, their mass production all over the world has been mastered only for honeycomb core with smooth hexagonal cells. Its output volumes greatly exceed those of production of the other honeycomb core structures taken together. This is attributable to good service characteristics, simplicity of manufacturing and relatively inexpensive process equipment for manufacture of the core with such a type of cells [7].

Honeycomb core (Figure 5) [8] is formed from corrugated strips of material, connected to each other along the outer planes of the corrugations. Each corrugation has the configuration of half of a hexagon, and forms half of the honeycomb cell. Connected to each other corrugated strips form rows of hexagonal cells. Each cell has four faces of single thickness (initial thickness of honeycomb core material) and two faces of double thickness [2].

Honeycomb core can be made from a broad range of aluminium alloys. So, 3003 alloy is often used for manufacture of honeycombs of the commercial class, alloys 5052, 5056 and 2024 are applied in specific structures. Alloy 2024 is used at increased operating temperature (up to $216{ }^{\circ} \mathrm{C}$ ), while cores from other aluminium alloys can operate only up to $177^{\circ} \mathrm{C}$.

The main methods of manufacturing the honeycomb core are as follows: adhesive bonding, resistance welding, brazing and diffusion welding.

Adhesive bonding is the most widely accepted manufacturing method (about $95 \%$ of the total volume of three-layer panel manufacture). In view of the high cost of the process, resistance welding, brazing and diffusion welding are used in manufacture of cores, operating at high temperatures or in aggressive media [3].

There exist two main methods applied for transformation of sheet material into the honeycomb: pack stretching and its manufacturing from profiled strips.

Method of pack stretching is applicable for manufacturing honeycomb cores, the cells of which consist of only six faces. Thicknesses of metallic materials cannot exceed $80 \mu \mathrm{m}$. Here, more favourable conditions for pack stretching are created with increase of the cell side and decrease of initial material thickness, as well as the height of honeycomb core cell. Joining of sheet material is performed by adhesive bonding method. Figure 6 gives the schematic of realization of the method. In order to lower the honeycomb core mass, the adhesive strips are applied on the material from one side of the sheet in most cases. Then, the sheet material is cut to length with subsequent assembly of honeycomb core packs and their adhesive bonding.

Stretching of honeycomb pack or billet is performed in a special unit. At force application to the sections of the pack external sheets, which are located in the place of faces of the future honeycomb cells, the pack will be stretched as a result of bending of the unbonded sections of its sheets. Cells of a hexagonal

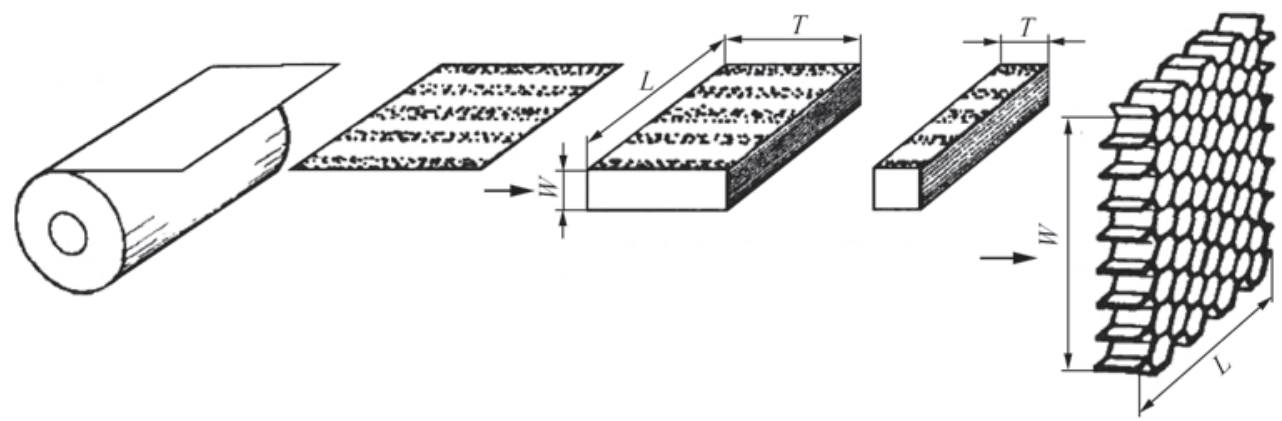

Figure 6. Process of manufacturing the honeycomb core by pack stretching [3] 


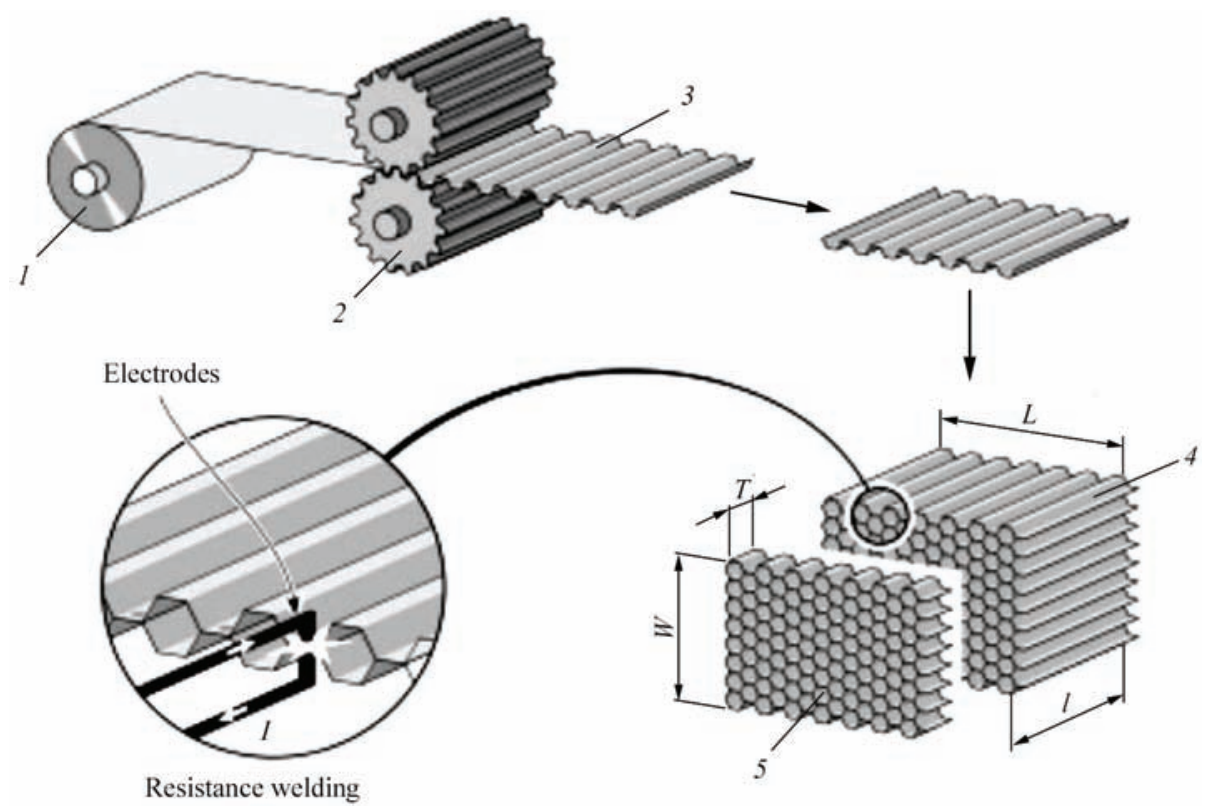

Figure 7. Process of honeycomb core manufacture from profiled strips [9]: 1 - foil coil; 2 - forming rollers; 3 - corrugated foil; 4 - pack of honeycomb cores; 5 - honeycomb core

shape form at a certain degree of stretching, and rectangular cells form at further stretching.

The process of producing the honeycomb core from profiled strips is schematically represented in Figure 7 [9]. Honeycomb cores manufactured by this method, have a more correct geometry of cells, than those produced by pack stretching.

After corrugation, adhesive is applied on the respective surfaces of the sheets. Then they are stacked one upon the other and curing in the oven is performed. Brazing, diffusion or resistance welding can also be used instead of adhesive bonding. These joining techniques allow a significant increase of operating temperature of the honeycomb structure, for instance, up to $700{ }^{\circ} \mathrm{C}$ for stainless steel and Inconel [3].

In three-layer panels joining of the load-carrying layers with the core is performed by different technological processes: adhesive bonding, brazing and welding. Here, bonding of the structural elements takes a leading position.

Producing three-layer honeycomb panels by adhesive bonding. By the data of [10], adhesives have become widely applied in practice in aeronautical products. Film and pastelike adhesives for structur- al applications have a wide range of strength and deformation properties. The adhesives are designed for manufacture of honeycomb and laminated load-carrying structures from metals and polymer composite materials. Adhesive bonds have high long-term strength, vibration resistance, resistance to cracking, impact of climatic factors, and aggressive media. The Table gives the characteristics of film adhesives for structural purposes.

Specifics of producing three-layer panels by adhesive bonding method consists in application of intermediate materials - prepregs, which are sheets of woven or non-woven fibrous materials, impregnated by uncured polymer binders.

In work [11] the influence of preparation of the honeycomb surface on core bonding to the skin, as well as nature of organic solvents, was assessed. It is noted that in order to produce a reliable bond, the resin should flow out of the prepreg (or adhesive) and create symmetrical fillets between the skin external sheet and honeycomb walls. Here, the core edge should be straight and sharp. It should slightly recede from the skin surface, creating an interface between the prepreg, resin and core wall. As noted by the authors, ap-

Characteristic of film adhesives for structural purposes [10]

\begin{tabular}{|c|c|c|c|c|c|c|c|}
\hline \multirow[b]{2}{*}{ Adhesive } & \multirow{2}{*}{$\begin{array}{l}\text { Working tempera- } \\
\text { ture range, }{ }^{\circ} \mathrm{C}\end{array}$} & \multicolumn{6}{|c|}{ Strength characteristics } \\
\hline & & $\tau_{\mathrm{t}}, \mathrm{MPa}$ & $\sigma_{t}, \mathrm{MPa}$ & $S_{\text {del }}, \mathrm{N} / \mathrm{mm}$ & $\gamma, \%$ & $\begin{array}{c}\sigma_{1.5}, \text { MPa (time - } \\
500 \mathrm{~h} \text { ) }\end{array}$ & $\begin{array}{c}\tau_{\max } \text { at } N=10^{7} \\
\text { cycles, MPa }\end{array}$ \\
\hline VK-25 & $-60-200$ & 27 & 22 & $5-6$ & $140-200$ & 18.5 & 9 \\
\hline VK-36 & $-130-160$ & $37 \pm 2.5$ & 50 & $2-3$ & $80-100$ & 34 & 8 \\
\hline VK-50 & $-60-150$ & $25 \pm 5$ & $25 \pm 5$ & 10 & $135-150$ & 17 & 10 \\
\hline VK-51 & $-60-80$ & $40 \pm 2.5$ & - & 3 & $70-120$ & 32.4 & 9 \\
\hline VK-51A & $\begin{array}{l}-69-80 \\
\end{array}$ & $37.5 \pm 2.5$ & - & 3 & 40 & 22.4 & 9 \\
\hline
\end{tabular}




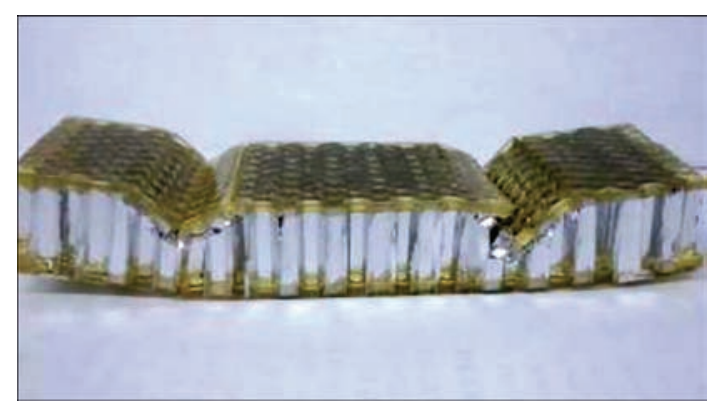

Figure 8. View of the sample after compression tests [14]

plication of wet grinding over 320 emery paper allows achieving the best quality of bonding. The quality of the bond can also be influenced by the nature of organic solvent. Aggressive solvents can leave a layer of oligomers on contact surfaces that adversely affects the strength characteristics of the three-layer panel.

In study [12] it is established that the main cause for failure of panels produced by adhesive bonding, is loosening of the adhesive under the impact of load and its subsequent failure. Investigations, described in [13], also show that increase of the amount of the adhesive up to 2.5 times (from 0.4 up to $1.0 \mathrm{~kg} / \mathrm{m}^{2}$ ) does not influence the nature of its behaviour under load, and practically does not lead to increase of fatigue strength of the three-layer honeycomb panel.

By the data of work [4], at shear testing of panels (Figure 8) the combination of aluminium core with a binder from a layer of epoxy resin does not exhibit instability - the sample does not undergo any catastrophic changes under load. At load increase, the aluminium of the honeycomb core was compressed because of rigidity of the composite layer. The authors note that cracks in the composite layer and core initiated after the pressure applied by the press exceeded the yield limit of the aluminium core that led to decrease of the load-carrying capacity of the three-layer panel.

Brazing three-layer panels. Braze alloys for brazing aluminium and its alloys can be applied in the form of wire, powder, paste, foil, cast rods, wash-

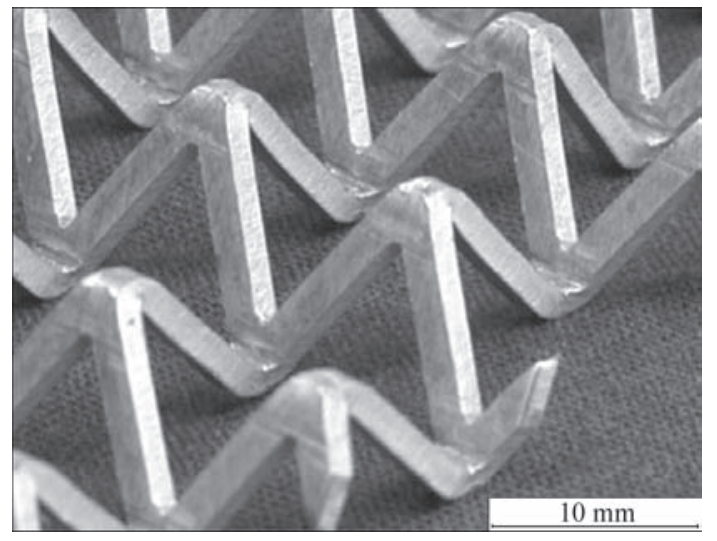

Figure 9. Core in the form of a tetrahedral latticed truss from 6061 alloy [18] ers, and cladding layer. The most technologically advanced method is cladding of the brazed metal with it. Here, the layer of the braze alloy is relatively uniform, and there is no need for fastening the braze alloy at item assembly for brazing, or adding to the flux the chlorides, containing a servicing agent, as the braze alloy has already been applied in the sites of joint formation on the surface of the parts being brazed and there is no need to improve its flowability.

In order to ensure making sound brazed joints of aluminium and its alloys, the braze alloys should meet the following main requirements: braze alloy melting temperature should be below that of aluminium alloys; molten braze alloys should readily wet the base metal and fill the gaps between the parts being brazed; braze alloys should ensure the required strength and corrosion resistance of brazed joints; thermal expansion coefficients of the brazed metal and braze alloy should be approximately the same.

Main braze alloys applied for brazing aluminium and its alloys, can be conditionally divided into three groups:

- aluminium-based braze alloys, ensuring high strength of brazed joints and high corrosion resistance, with melting temperature in the range of $450-630{ }^{\circ} \mathrm{C}$;

- zinc-based braze alloys, characterized by sufficiently high strength and being relatively corrosion-resistant, with melting temperature in the range of $300-450{ }^{\circ} \mathrm{C}$;

- low-melting braze alloys, based on tin, lead, cadmium, gallium, with melting temperature below $300{ }^{\circ} \mathrm{C}$. These braze alloys have a low strength and corrosion resistance. The advantage of these alloys is their low melting temperature, and, therefore, also brazing temperature [15].

In brazing, similar to adhesive bonding, the braze alloy should form symmetrical fillets in the point of contact of the skin with honeycomb core. Here it should be noted that application of both the adhesive, and braze alloy results in increase of the three-layer panel mass. Another factor, limiting application of brazing when joining three-layer panel elements, is braze alloy interaction with base metal in service, leading to thinning of the honeycomb core walls, and formation of cracks at its base [16].

For joining complex-shaped items the authors [17] recommend applying a mixture of Nocolok flux with Si particles on the conjugated surfaces, instead of the traditional cladding with $\mathrm{Al}-\mathrm{Si}$ system braze alloy, which should be followed by brazing in a vacuum furnace.

In [18] the brazing method was used to join a tetrahedral latticed core (Figure 9) from AA6061 aluminium alloy to skins from AA6951 alloy. AA4343 
alloy with 6.8-8.2 \% silicon, was applied on panel surfaces as braze alloy. Then, the assembly was coated by Handy Flo-X5518 flux and placed into a muffle furnace. Brazing was performed at the temperature of $595 \pm 5{ }^{\circ} \mathrm{C}$. Brazing duration was not more than $5 \pm 1 \mathrm{~min}$, that allowed lowering the negative impact of silicon diffusion from the braze alloy on the joint strength properties. Subsequent heat treatment at $500{ }^{\circ} \mathrm{C}$, soaking for $30 \mathrm{~min}$ with quenching in water and ageing at $165{ }^{\circ} \mathrm{C}$ for $1140 \mathrm{~min}$, allows increasing the core strength up to maximum values, and thus increasing the compressive strength of the panel from 9 up to $20 \mathrm{MPa}$.

Authors of work [19] applied ultrasonic soldering with $\mathrm{Sn}-\mathrm{Pb}-\mathrm{Zn}$ solder ( $\mathrm{Sn}-29.2 \mathrm{~Pb}-6 \mathrm{Zn}-1 \mathrm{Ag}-$ 0.38Cu-0.42Bi wt.\%) for joining a three-layer honeycomb panel from 6061 aluminium alloy. Solder melting temperature was $190.68{ }^{\circ} \mathrm{C}$. Heating of the assembly was performed at the rate of $15^{\circ} \mathrm{C} / \mathrm{s}$ at ultrasonic vibration of $100-980 \mathrm{~W}$ at $20 \mathrm{kHz}$ frequency. Increase of ultrasound power to $980 \mathrm{~W}$ at simultaneous reduction of mounting gap to $0.1 \mathrm{~mm}$ allowed minimizing the angle of wetting by the solder. Optimum soldering time is $45 \mathrm{~s}$. After soldering the solder exhibits four zones: zone enriched in Sn; zone enriched in $\mathrm{Pb}$; $\mathrm{Sn}-\mathrm{Pb}$ eutectic phase and zone, enriched in $\mathrm{Al}$. Despite the relatively low temperature of the process, soldering leads to partial dissolution of aluminium in the solder.

Methods of three-layer panel welding. Laser welding. Laser welding can be used to join relatively thick elements (from $0.5 \mathrm{~mm}$ ) of the three-layer panels. This method is applicable for joining the trapezoidal core to the skins [20].

Application of this kind of welding, particularly, when joining sheet elements, is associated with formation of a number of defects (pores, splashes, convexities and craters), prevention of which requires following a number of recommendations. Welding is performed in the pulsed mode. To prevent splashes, the authors [21] point to the need to ensure a larger surface of the weld pool in the initial period of welding by smoothly increasing the laser power at the start of the pulse. Appearance of cavities can be avoided by smoothly lowering the power that allows setting the speed of the beam exit from the channel below that of the channel filling with the melt. Maintaining laser power on the level, which corresponds to channel appearance threshold, also prevents formation of the convexity and crater.

Diffusion welding. Chemical treatment of the surfaces before welding is given a special place in diffusion welding of aluminium and its alloys. The oxide film can be removed by etching or mechanical clean- ing methods. Chemical etching is the most widely spread method of preparation of the surfaces of aluminium and its alloys to be welded. After removing oxides from the surfaces of aluminium parts to be welded, it is believed to be rational to cover them by resins, lacquers or polymers based on styrene, decomposing without residue at heating in vacuum.

Welding of aluminium and its alloys without interlayers is performed at the temperature of 500$600{ }^{\circ} \mathrm{C}[22]$.

By the data of [23], the temperature of vacuum diffusion welding of wrought aluminium alloys after mechanical cleaning of surfaces to be joined is usually lower than that of the alloy heating for quenching. Optimum parameters of welding AMg5 and AMg6 alloys are as follows: $T_{\mathrm{w}}=500{ }^{\circ} \mathrm{C} ; P_{\mathrm{w}}=10 \mathrm{MPa}, t_{\mathrm{w}}=$ $=10 \mathrm{~min}$, vacuum of $1.33 \cdot 10^{-3} \mathrm{~Pa}$. Here, as noted by the authors, the interface between the welded parts is absent on welded joint microstructure, that is indicative of formation of a monolithic joint. Welding of the alloys in the above modes does not lead to degradation of their mechanical properties, as coagulation of intermetallics in the joint zone is absent, that improves the mechanical properties and increases the ductility of metal.

Application of interlayers which form eutectics with aluminium and other alloy components at heating, enables breaking up the oxide film, activating the processes of diffusion interaction of aluminium alloys and lowering the welding temperature [24]. Copper, magnesium, and zinc in the form of foils or coatings can be used as interlayer materials. In the case of interlayers from zinc, the temperature of welding the joints is equal to $480-500{ }^{\circ} \mathrm{C}$, those from magnesium 470 $490{ }^{\circ} \mathrm{C}$, and from copper - $400-450{ }^{\circ} \mathrm{C}$. Joint quality largely depends on the thickness of interlayers. At more that $3 \mu \mathrm{m}$ thickness the quantity of the eutectic is quite high. The eutectic is partially removed from the joint zone due to deformation. Reduction of interlayer thickness to 1-2 $\mu \mathrm{m}$ allows producing joints of a higher strength, reaching $0.85-0.95 \%$ of that of welded wrought alloys.

The technological aspects of diffusion welding of aluminium alloys are considered in greater detail in [25]. Sufficiently strong joints of aluminium alloys were produced through application of thin interlayers from low-melting metals, namely zinc and gallium. Gallium was applied by mechanical rubbing in the solid or liquid state. Diffusion welding was conducted at the temperature of $420-500{ }^{\circ} \mathrm{C}$. As stated by the authors of [25], gallium is completely dissolved in the base material during the time of isothermal soaking of $240 \mathrm{~min}$. Shear strength of the joints from alumini- 
um-magnesium alloys AMg6 and 01570 through gallium underlayer is equal to $180-210 \mathrm{MPa}$.

More effective is application of a copper interlayer of $0.8-1.0 \mu \mathrm{m}$ thickness. At isothermal soaking for 20-30 min and diffusion welding temperature of $500{ }^{\circ} \mathrm{C}$, the process of material recrystallization is actively developing in the joint zone.

Analyzing the results of Auger spectral analysis the authors come to the conclusion that $\mathrm{Al}-\mathrm{Mg}-\mathrm{Cu}$ alloy of eutectic composition forms on the contact boundary as a result of interdiffusion at the stage of isothermal soaking. Presence of the liquid phase promotes breaking up of the oxide film.

Effect of superplasticity is realized in welding 01570 alloy. Recrystallization of the alloy joint zone occurs at the temperature of $472-477^{\circ} \mathrm{C}$ and proceeds actively at contact with thin copper interlayer. Strength at shear testing of the joint of 01570 alloy through an interlayer of copper $1 \mu \mathrm{m}$ thick reaches $260 \mathrm{MPa}$. Readily reproducible values $( \pm 15 \mathrm{MPa}$ ) are achieved in the case, if the coating is applied on both the surfaces being joined ( $0.5 \mu \mathrm{m}$ on each).

Work [26] gives the results of studies on diffusion welding in vacuum of three-layer panels with platelike, cellular and corrugated cores, produced with application of forming devices. Investigations were conducted on alloys of $\mathrm{Al}-\mathrm{Mg}, \mathrm{Al}-\mathrm{Zn}-\mathrm{Mg}$, and $\mathrm{Al}-$ $\mathrm{Cu}-\mathrm{Mg}$ systems. Sheet thickness was equal to $2 \mathrm{~mm}$, panel size was 500x500 mm, building height was up to $30 \mathrm{~mm}$. Prior to welding the blanks were degreased with subsequent chemical etching in $70 \%$ nitric acid. Then ion etching was performed on the respective surfaces of the skins and core, which was followed by deposition of copper (or mechanical cleaning by a metal brush). Diffusion welding was conducted in the following mode: welding temperature of $500-510{ }^{\circ} \mathrm{C}$, pressure of 5-10 $\mathrm{MPa}$, and welding time from 30 to $60 \mathrm{~min}$. In welding sheet blanks common grains form in the joint zone in all three cases, and isolated discontinuities are also observed in the alloy of $\mathrm{Al}-$ $\mathrm{Mg}$ system. Subsequent heat treatment of the joints from alloys of $\mathrm{Al}-\mathrm{Zn}-\mathrm{Mg}$ and $\mathrm{Al}-\mathrm{Cu}-\mathrm{Mg}$ systems (quenching + ageing) allows increasing strength up to the level close to the base material. Shown is the possibility of producing a sound joint of aluminium alloys without a copper underlayer, due to increasing the degree of deformation. Samples in which metal deformation in the joint zone was equal to $70-90 \%$ (370-420 MPa) had maximum shear strength.

Proceeding from the above, one can come to the conclusion that diffusion welding in vacuum is a promising method for joining the skins to the thinwalled core, as this process does not have the weighting and weakening effect of the adhesive and braze alloy on the performance of the three-layer panel. However, as was shown above, at diffusion welding of aluminium alloys the recommended parameters are temperature $T_{\mathrm{w}}=500-600{ }^{\circ} \mathrm{C}$, and specific pressure $P_{\mathrm{w}}=5-10 \mathrm{MPa}$. These parameters of the process cannot be applied in welding the three-layer panels from aluminium alloys, because of the loss of stability by the thin-walled core, that makes it necessary to lower the heating temperature and search for technological solutions, that would provide a permanent joint. Solution of the arisen problem can be application of forming devices that will allow avoiding unlimited deformation of the core [27], or welding of combined panels, in which the honeycomb core is made of a stronger material, for instance, titanium alloy, and the skin is from aluminium alloy [28]. During welding at the respective temperature under pressure the titanium alloy ribs are embedded into the aluminium alloy, and the aluminium fills all the gaps between the protrusions due to creep. This process is accompanied by fragmentation of the brittle oxide film on aluminium, thus promoting formation of a strong joint.

1. Paik, J.K., Thaymballi, A.K., Kim, G.S. (1999) The strength characteristics of aluminum honeycomb sandwich panels. Thin-Walled Structures, 35, 205-231.

2. Panin, V.F., Gladkov, Yu.A. (1991) Structures with filler material: Refer. book. Moscow, Mashinostroenie [in Russian].

3. Bitzer, T. (1997) Honeycomb technology. Materials, design, manufacturing, applications and testing. Springer-Science+Business Media Dordrecht.

4. Amraei, M., Shahravi, M., Noori, Z. et al. (2013) Application of aluminium honeycomb sandwich panel as an energy absorber of high-speed train nose. J. of Composite Materials, 48(9), 1027-1037.

5. Khertel G. (1965) Thin-walled structures (structural elements, determination of accurate sizes and design in aircraft construction and other engineering fields). Moscow, Mashinostroenie [in Russian].

6. Slivinsky, V.I., Tkachenko, G.V., Slivinsky, M.V. (2005) Efficiency of application of honeycomb structures in flying vehicles. Vestnik Sib. Aerokosmich. Un-ta im. Akad. M.F. Reshetnyova, 4, 169-173 [in Russian].

7. Ivanov, A.A., Kashin, S.M., Semenov, V.I. (2000) New generation of honeycomb filler materials for aerospace engineering. Moscow, Energoatomizdat [in Russian].

8. Kindinger, J. (2001) Lightweight structural cores. ASM Handbook, Vol. 21: Composites, 3, 180-183.

9. Haydn N.G.Wadleya, Norman, A. Fleckb, Anthony G. Evans (2003) Fabrication and structural performance of periodic cellular metal sandwich structures. Composite Sci. and Technology, 63, 2331-2343.

10. Lukina, N.F., Anikhovskaya, L.I., Dementieva, L.A. et al. (2007) Adhesives and adhesive materials for items of aircraft engineering. Svarochn. Proizvodstvo, 5, 19-27 [in Russian].

11. Khan, S., Loken H.Y. (2007) Bonding of sandwich structures - the facesheet/honeycomb interface - a phenomenological study. In: Proc. of SAMPE 2007 (Baltimore, June 2007), 1-9.

12. Yi-Ming Jen, Li-Yen Chang (2009) Effect of thickness of face sheet on the bending fatigue strength of aluminum hon- 
eycomb sandwich beams. Engineering Failure Analysis, 16, 1282-1293.

13. Yi-Ming Jen, Chin-Wei Ko, Hong-Bin Lin (2009) Effect of the amount of adhesive on the bending fatigue strength of adhesively bonded aluminum honeycomb sandwich beams. Int. J. of Fatigue. 31, 455-462.

14. Shuliang Cheng, Xuya Zhao, Yajun Xin et al. (2015) Experimental study on shear property of integrated sandwich panel of aluminum honeycomb and epoxy resin. The Open Mechanical Engin. J., 9, 1000-1006.

15. Nikitinsky, A.M. (1983) Brazing of aluminium and its alloys. Moscow, Mashinostroenie [in Russian].

16. Sporer, D., Fortuna, D. (2014) Selecting materials for brazing a honeycomb in turbine engines. Welding J., 93(2), 44-48.

17. Kumagai, M. (2003) Recent technological developments in welding of aluminium and its alloys. Welding Int., 17(3), 173-181.

18. Gregory, W. Kooistra,Vikram, S. Deshpande, Haydn N.G. Wadley (2004) Compressive behavior of age hardenable tetrahedral lattice truss structures made from aluminium. Acta Materialia, 52, 4229-4237.

19. Ding Min, Zhang Pei-lei, Zhang Zhen-Yu et al. (2010) A novel assembly technology of aluminum alloy honeycomb structure. Int. J. Adv. Manuf. Technol., 46, 1253-1258.

20. Ferraris, S., Volpone, L.M. (2005) Aluminum alloys in third millennium shipbuilding: Materials, technologies, perspec- tives. In: Proc. of 5th Int. Forum on Aluminium Ships (Tokyo, Japan, 11-13 October 2005), 1-11.

21. Levin, Yu.Yu., Erofeev, V.A. (2008) Calculation of parameters of pulsed laser welding of thin aluminium alloys. Svarochn. Proizvodstvo, 4, 20-24 [in Russian].

22. Bachin, V.A., Kvasnitsky, V.F., Kotelnikov, D.I. et al. (1991) Theory, technology and equipment for diffusion welding. Moscow, Mashinostroenie [in Russian].

23. Kozakov, N.F. (1968) Diffusion welding in vacuum. Moscow, Mashinostroenie [in Russian].

24. Gurevich, S.M. (1990) Reference book on welding. Kiev, Naukova Dumka [in Russian].

25. Sergeev, A.V. (1990) Diffusion welding of aluminium alloys. In: Achievements and perspectives of development of diffusion welding. Moscow, 48-54 [in Russian].

26. Chudin, V.N., Timokhov, A.P., Terentiev, M.M. et al. (1992) Diffusion welding of hollow structures of high-strength aluminium alloy sheets. Svarochn. Proizvodstvo, 10, 5-7.

27. Falchenko, Yu.V., Ustinov, A.I., Petrushynets, L.V. et al. (2017) Device for diffusion welding of three-layer honeycomb panels. Pat. 113424 Ukraine, Int. Cl. B23K 20/00, B23K 20/14 [in Ukrainian].

28. Bashurin, A.V., Mastikhin, E.Yu., Kolmykov, V.I. (2010) Diffusion welding of hollow bimetal panels. Zagotov. Proizvodstva v Mashinostroenii, 1, 13-15 [in Russian].

Received 25.04.2018 


\title{
HIGH SPEED FRICTION WELDING OF TITANIUM ALLOYS - STRUCTURE AND PROPERTIES OF JOINTS
}

\author{
D. MIARA ${ }^{1}$, J. MATUSIAK ${ }^{1}$, A. PIETRAS ${ }^{1}$, M. KRYSTIAN ${ }^{2}$ and M. DYNER ${ }^{3}$ \\ ${ }^{1}$ Institute of welding \\ 44-100, Gliwice, Str. Bl. Czeslava 16-18, Poland. E-mail: adam.pietras@is.gliwice.pl \\ ${ }^{2}$ Austrian Institute of Technology \\ Str. Giefinggasse 4, 1210, Vienna, Austria. E-mail: marciej.krystian@univil.ac.at \\ ${ }^{3}$ Plant of Medical Instruments CHIRMED \\ Str. Mstowska 8A, 42-240 Rudniki, Czestochowy, Poland. E-mail: m.dyner@chirmed.pl
}

\begin{abstract}
The article presents test results concerning the high speed friction welding (HSFW) of titanium alloys Ti64 ELI and CP-Ti. In addition, the article presents tests results related to the welding process and the formation of flash. The quality of welds was assessed on the basis of non-destructive tests (visual tests) and destructive tests (static tensile tests and bend tests). The tests resulted in the identification of the correlation between HSFW conditions when joining titanium alloys, i.e. Ti64 ELI, CP-Ti, and the quality of welds. Consequently, the tests led to the determination of the optimum range of welding parameters as regards the strength of joints. 8 Ref., 2 Tables, 6 Figures.
\end{abstract}

K e y w o r d s : friction welding, titanium alloys, structure and properties

Introduction. Conventional friction welding (FW) and high speed friction welding (HSFW) are solid-state joining processes and belong to few processes utilising friction heat emitted during the technological process [1-3].

Most metals (including titanium alloys) are joined using friction welding, where the kinetic energy of the relative motion of elements subjected to welding is transformed into friction heat. There are many various manners in which surfaces to be joined move in relation to each other, where the simplest and most commonly used in industrial practice is rotational motion.

During welding, elements heated by friction heat are pressed against each other by friction downward force, which leads to the movement of metal in the welding area outside the friction-plasticised contact to the so-called metal flash [3, 4]. After the appropriate heating and plasticisation of the material in the welding area the relative motion of elements stops. The joint is obtained after the complete stoppage of motion and the exertion of additional upsetting force so that the contact surfaces of elements could reach the distance of atomic force action. The welding process leads to the formation of a compact structure across the entire cross-section of elements being joined. During friction and upsetting the elements being welded become shorter [3, 4]. Conventional friction welding is usually performed at rotation rates restricted within the range of $500 \mathrm{rpm}$ to $5000 \mathrm{rpm}$ [5].

High speed friction welding (HSFW) is a variety of conventional friction welding (FW), where the process of welding is preformed using rotation rates reaching approximately $25000 \mathrm{rpm}$ [6]. The use of the above-named high rotation rates significantly changes joining conditions in comparison with the conventional method of friction welding. The foregoing can be observed when analysing the correlation between the element shortening rate and the rate of friction as well as the change in the thickness of a layer subjected to plastic strain and the change in the friction rate. Because of significantly varying weld formation mechanisms during the HSFW process it is possible to considerably reduce the time of welding (to sever-

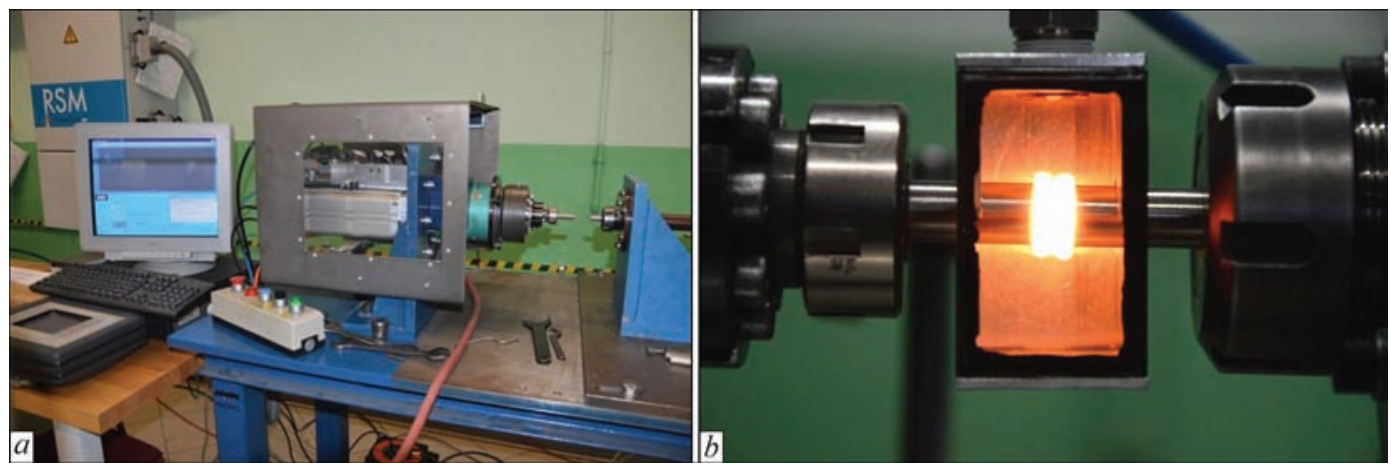

Figure 1. RSM400 HSFW machine: $a$ — welding station with the measurement system; $b$ — welding of titanium Ti64 ELI [1] 
Table 1. Chemical composition of the titanium alloys used in the tests

\begin{tabular}{|c|c|c|c|c|c|c|c|c|c|}
\hline \multirow{2}{*}{ No. } & \multirow{2}{*}{ Alloy designation } & \multicolumn{8}{|c|}{ Chemical element content, \% } \\
\hline & & $\mathrm{Al}$ & V & $\mathrm{O}$ & $\mathrm{Fe}$ & $\mathrm{C}$ & $\mathrm{N}$ & $\mathrm{H}$ & $\mathrm{Ti}$ \\
\hline 1 & Ti64 ELI (Ti6Al-4V) & 5.930 & 3.960 & 0.103 & 0.180 & 0.023 & 0.002 & - & Rest \\
\hline 2 & CP-Ti & - & 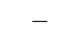 & 0.210 & 0.220 & 0.010 & 0.040 & 0.001 & Rest \\
\hline
\end{tabular}

al seconds) and decrease diameters of elements being welded (to a mere $5 \mathrm{~mm}$ ).

Both during the conventional and the high speed friction welding process attention is drawn primarily to the identification of the appropriate range of welding parameters, particularly to the correlation between the rotation rate of the spindle and the downward force. The foregoing is particularly important when adjusting optimum welding parameters in relation to individual materials as it affects the joint formation mechanism and joint properties.

Test stand. The welding process was performed using an RSM400 HSFW station (Figure 1, a) and bars having a diameter of $10 \mathrm{~mm}$ and made of titanium alloys Ti64 ELI and CP-Ti. The chemical composition and selected physical properties of materials in the as-delivered state used in the tests are presented in Tables 1 and 2. The materials were welded in the similar material joining configuration. The welding station was provided with an additional housing preventing the access of oxygen to the argon-shielded process. The welding process and the housing with the shielding gas are presented in Figure $1, b$.

The tests of the HSFW of titanium alloys Ti64 ELI and CP-Ti were performed using the following welding parameters:

- during the welding of titanium alloy Ti64 ELI: rotation rate $v_{\mathrm{n}}=20000 \mathrm{rpm}$, friction time $t_{\mathrm{t}}=0.5 \mathrm{~s}$, friction downward force $f_{\mathrm{t}}=3 \mathrm{bar}$, upsetting time $t_{\mathrm{s}}=$ $=3 \mathrm{~s}$ and upsetting force $f_{\mathrm{s}}=6 \mathrm{bar}$;

- during the welding of titanium alloy CP-Ti: rotation rate $v_{\mathrm{n}}=20000 \mathrm{rpm}$, friction time $t_{\mathrm{t}}=0.5 \mathrm{~s}$, friction downward force $f_{\mathrm{t}}=1 \mathrm{bar}$, upsetting time $t_{\mathrm{s}}=$ $=3 \mathrm{~s}$ and upsetting force $f_{\mathrm{s}}=3$ bar.

Visual tests. Selected welds of titanium alloys Ti64 ELI and CP-Ti made using the HSFW process are presented in Figure 2. The obtained friction welds were characterised by the specific shape of flash, the size of which varied in relation to the material subjected to welding. The flash formed during the welding of titanium alloy CP-Ti was significantly larger than that formed during the welding of titanium alloy Ti64 ELI.

Macroscopic metallographic tests. All of the test welds were subjected to macroscopic metallographic tests. The test specimens were cut out mechanically and subjected to grinding and polishing until the obtainment of appropriate smoothness. The metallographic tests were performed in accordance with the requirements of the PN-EN ISO 17639:2013-12 standard [7]. The structure of related metallographic specimens was revealed using the Keller's reagent. Macrostructures of
Table 2. Selected properties of the titanium alloys used in the tests

\begin{tabular}{|c|c|c|c|c|}
\hline \multirow{2}{*}{ No. } & \multirow{2}{*}{ Alloy designation } & \multicolumn{3}{|c|}{ Minimum properties } \\
\cline { 3 - 5 } & & $R_{\mathrm{p} 0.2}, \mathrm{MPa}$ & $R_{\mathrm{m}}, \mathrm{MPa}$ & $A_{50 \mathrm{~mm}}, \%$ \\
\hline \multirow{2}{*}{1} & Ti64 ELI (Ti6Al-4V) & 795 & 860 & 10 \\
\hline 2 & $\mathrm{CP}-\mathrm{Ti}$ & 610 & 520 & 22 \\
\hline
\end{tabular}

selected welds made of titanium alloys Ti64 ELI and CP-Ti using the HSFW process are presented in Figure $9, a, b$ respectively. The macroscopic metallographic test results revealed that the structure of the welds was proper and characteristic of the friction welding method. The size and shape of flashes depended on a material subjected to welding and applied welding process parameters. The materials subjected to welding revealed various HAZ areas and the distribution of individual zones in the welding area.

Tensile tests. The mechanical properties of the welds made using the HSFW process were identified in a static tensile test performed in accordance with the requirements of PN-EN ISO 4136:2013-05E [8]. The joints were subjected to uniaxial tension performed using an INSTORN 4210 testing machine. The tests were performed at ambient temperature and a strain rate of $5 \mathrm{~mm} / \mathrm{min}$. The test results concerning the strength of the friction welds made of titanium alloys Ti64 ELI and CP-Ti using the HSFW process are presented in Figure 4. The test results are presented in relation to the base material of alloy Ti64 ELI and that of CP-Ti. As regards titanium alloy Ti64 ELI, the mean strength of the base material amounted to 906.7 MPa, whereas the mean strength of the friction welds amounted to $916.8 \mathrm{MPa}$, i.e. was on average by $1.1 \%$ higher than that of the base material. The materials in the welding area were hardened during the welding process. As regards titanium alloy CP$\mathrm{Ti}$, the mean hardness of the base material amounted to $662.2 \mathrm{MPa}$, whereas the mean value of friction welds (HSFW) amounted to $660.6 \mathrm{MPa}$, i.e. was by a mere $0.3 \%$ lower than that of the base material. The

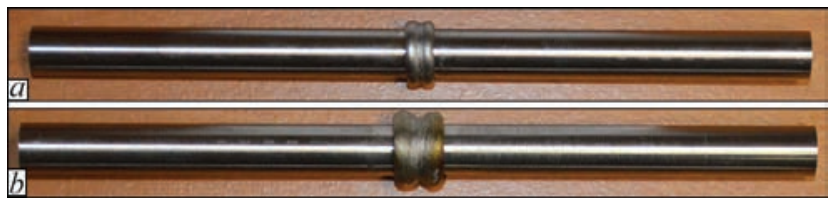

Figure 2. Welds in titanium alloys Ti64 ELI (a) and CP-Ti (b) made using the HSFW process [1] 


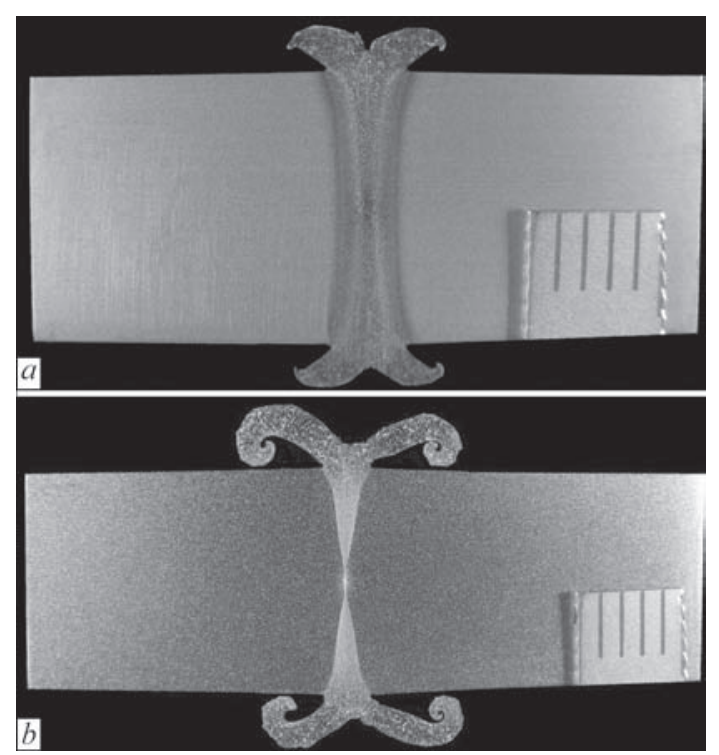

Figure 3. Macrostructures of the welds in titanium alloys Ti64 ELI (a) and CP-Ti (b) made using the HSFW process [1]

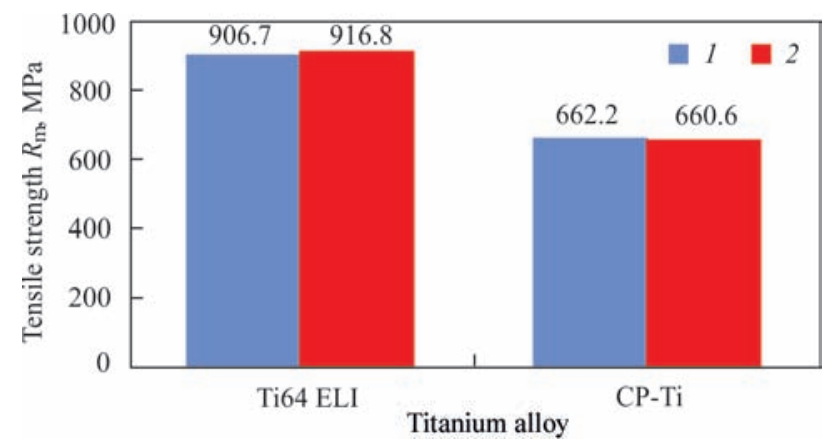

Figure 4. Tensile strength of titanium alloy Ti64 ELI and CP-Ti [1]: 1 - parent material; 2 - welded material

above-presented high mean tensile strength values revealed that the welds made using the HSFW process were characterised by high and repeatable quality. The weld after being subjected to the tensile test is presented in Figure 5.

Bend tests. Selected friction welds were also subjected to bend tests. The bend tests of all three test specimens made of titanium alloy Ti64 ELI proved successful, i.e. the specimens reached an assumed bend angle of $180^{\circ}$. In terms of the specimens made of titanium alloy $\mathrm{CP}-\mathrm{Ti}$, the assumed angle amounting to $180^{\circ}$ was reached by two out of three specimens. One specimen made of CP-Ti reached a bend angle of $50^{\circ}$ and developed a brittle crack in the base material, indicating the high quality of the welded joint. An example of the weld after the bend test is presented in Figure 6 .

\section{Conclusions}

- The above-presented tests and analyses of test results justified the formulation of the following conclusions:

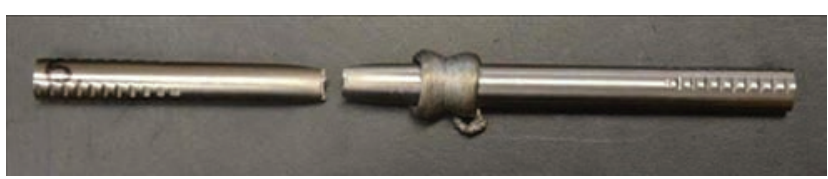

Figure 5. Test specimen made of titanium alloy Ti64 after the tensile test [1]

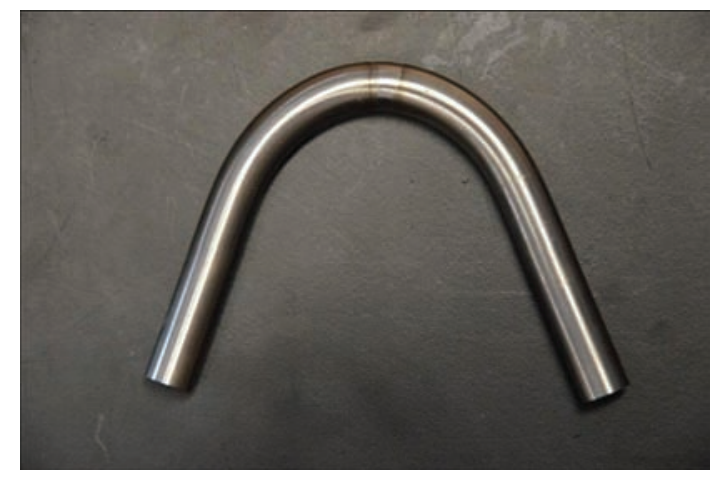

Figure 6. Test specimen made of titanium alloy Ti64 after the bend test [1]

- Titanium alloys Ti64 ELI and CP-Ti can be welded using the high speed friction welding (HSFW) method. Appropriately adjusted welding conditions enable the obtainment of high-quality joints characterised by required mechanical properties.

- Appropriately adjusted welding process parameters ensure process stability and joint repeatability.

- The internal structure of both materials subjected to welding (titanium alloy Ti64 ELI and CP-Ti) was continuous and did not reveal the presence of «nojoint» traces or the lack of joint integrity (tightness).

- The friction welding process performed using a special welding programme makes it possible to properly heat fragments of internal surfaces of titanium bars and, after exerting appropriate force, to obtain a joint characterised by required tensile and bend strength.

1. (2016) Project Anti-bacterial optimization of high-strength, severe-plastic-deformed titanium alloys for spinal implants and surgical tools - SPD-BioTribo) www.M-ERA. NET/2015/02/2016 (2016-09-2018-08-31) report no. 2.

2. Zadroga, L., Pietras, A., Papkala, H. (2004) Studium i badania warunków łączenia materiałów różnoimiennych nowoczesnymi metodami zgrzewania tarciowego. Report of Research Instytutu Spawalnictwa, Gliwice.

3. Klimpel, A. (1999) Technologie zgrzewania metali i tworzyw termoplastycznych. Wydawnictwo Politechniki Śląskiej, Gliwice.

4. Michalski, R., Kamiński, Z. (1975) Zgrzewanie tarciowe. WNT, Warszawa.

5. Michalski, R. (1980) Typizacja procesu zgrzewania tarciowego. Praca badawcza nr T-17, Instytut Spawalnictwa, Gliwice.

6. Materials of HARMS \& WENDE.

7. (2013) PN-EN ISO 17639:2013-12: Badania niszczące spawanych złączy metali - Badania makroskopowe i mikroskopowe złączy spawanych.

8. (2013) PN-EN ISO 4136:2013-05E: Badania niszczące złączy spawanych metali - Próba rozciągania próbek poprzecznych. 


\section{ALL-UKRAINIAN FESTIVAL OF SCIENCE}

XII All-Ukrainian Festival of Science was held in Kyiv on May 18-19, 2018.

By tradition opening of the scientific holiday took place at the E.O. Paton Electric Welding Institute of the NAS of Ukraine. The Festival was opened by Prof. Anton Naumovets, the First Vice-President of the National Academy of Sciences of Ukraine, head of Section of Physical, Engineering and Mathematical Sciences of the NAS of Ukraine.

Greetings from Andriy Parubiy, the Head of Verkhovna Rada of Ukraine, was announced to Festival opening participants by Prof. Vyacheslav Bogdanov and greetings from Prof. Borys Paton, the President of the National Academy of Sciences of Ukraine, by Prof. Anton Naumovets, the Chief Scientific Secretary of the NAS of Ukraine.

The audience enjoyed a literature-musical concert program prepared by the pupils of specialized school No. 49 with advanced study of French.

The welcoming speech was given by Madame Isabelle Dumont, Ambassador Extraordinary and Plenipotentiary of France to Ukraine. She expressed her fascination with performances of young participants of the Festival, who show excellent results in studying French thanks to their teachers and own enthusiasm. Madame Ambassador also noted that there is a great honor for this meeting to welcome the import guest, namely Prof. Serge

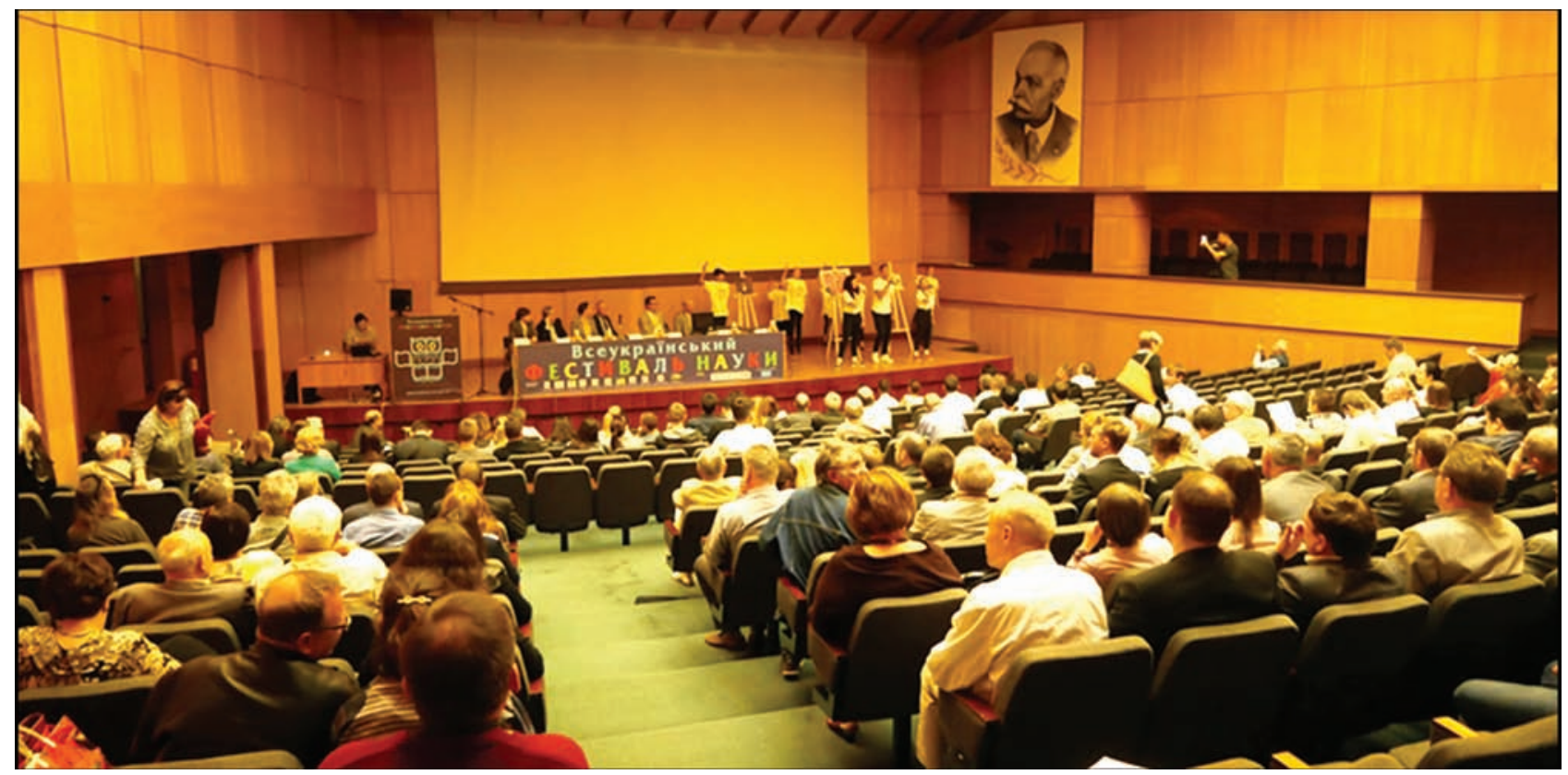

In the conference hall of the Festival

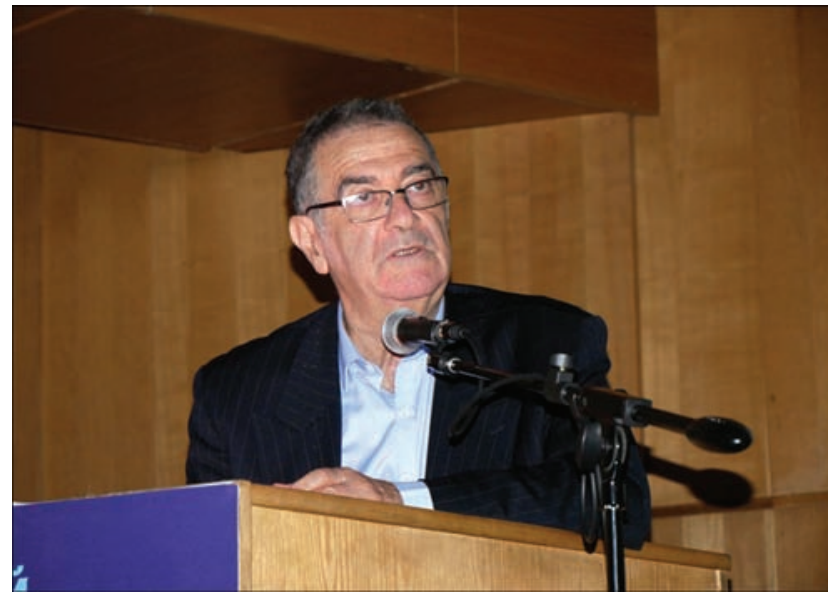

Presentation of Nobel prise winner Prof. Serge Haroche

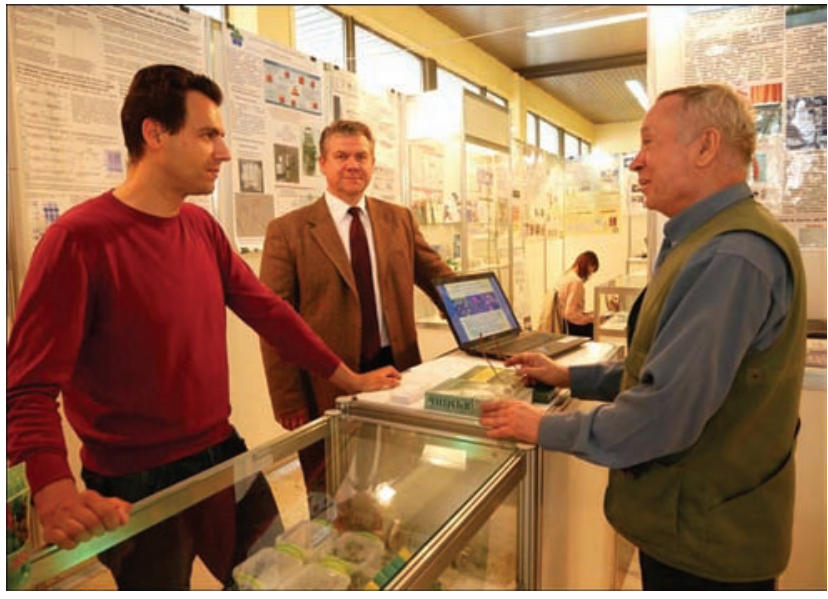

At the exhibition of scientific achievements of organizations of the NAS of Ukraine 


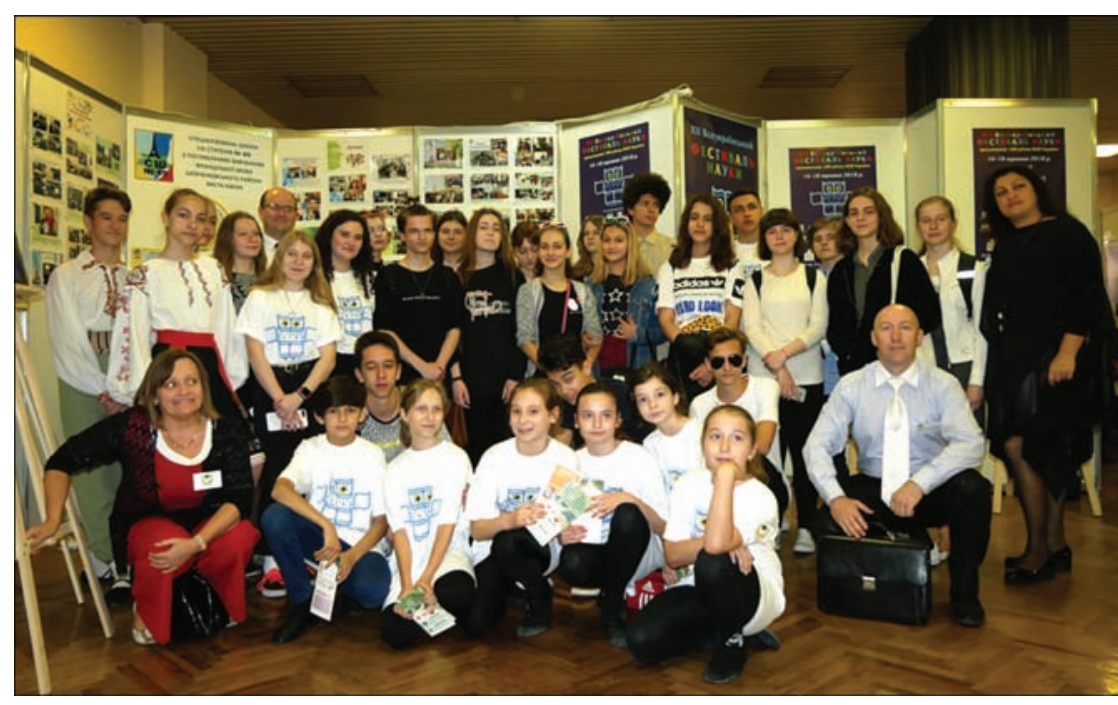

Participants of the Minor Academy of Sciences of Ukraine

namely Prof. Serge Haroche, the prominent French physicist, Nobel Prize Winner for Physics 2017. Madame Dumont in short words told about bilateral scientific cooperation between France and Ukraine, in particular about «Erasmus+» and «Horizont 2020» programs. According to her words such a cooperation is developing from year to year.

At last Madame Ambassador underlined that France, which is first of all known for its culture, gastronomy, perfumery, fashion etc., assumes that science is a priority sphere. She said, «Our presence

here proves the importance of support of scientific directions».

Prof. A. Naumovets awarded the French guests with the honors of the NAS of Ukraine, namely Acknowledgment of the Presidium of the NAS of Ukraine («for significant personal contribution to development of international scientific cooperation») to Madame Dumont and Certificate for awarding a rank of «Doctor Honoris Causa of the National Academy of Sciences of Ukraine» («for significant contribution in development of science, social progress, peace, mutual understanding and cooperation between the nations») to Prof. S. Haroche. Nobel laureate Prof. Serge Haroche gave a lecture on the topic of his investigations.

Prof. Vitaliy Kalchenko, Institute of Organic Chemistry of the NAS of Ukraine, read the lecture «Supermolecular chemistry - achievements for health care and ecology».

At the end of festivities the best academic scientific publications were awarded and Certificates of Festival participants were presented.

In course of the Festival an exhibition-presentation of scientific achievements of the organizations of the NAS of Ukraine was also held at the E.O. Paton Electric Welding Institute. During it the scientists of 50 academic institutes presented around 400 their developments.

The graduates of the Minor Academy of Sciences of Ukraine and pupils of Kyiv schools demonstrated scientific and technical works and made the poster presentations.

It is necessary to note that this Festival is carried out every year for the purpose of popularization of scientific achievements of Ukraine, engagement of youth of researches, rise of authority and prestige of science in Ukrainian society. In general more than 1 thou of events took place all over Ukraine in scope of the XII All-Ukrainian Festival of Science, held during May 16-18, 2018. There were Doors Open Days in academic scientific and higher education institutions, presentations of prominent domestic and foreign scientists with popular lectures, exhibitions, excursions to laboratories and museums, round table meetings, quests, presentations of innovative developments, poster presentations, green laboratories, scientific cafes, demonstration of popular-science films, etc.

This year the XII All-Ukrainian Festival of Science was organized by the National Academy of Sciences of Ukraine, Ministry of Education and Science of Ukraine, Ministry of Youth and Sport of Ukraine, National Center «Minor Academy of Sciences of Ukraine», National Academy of Medical Sciences of Ukraine, National Academy of Agrarian Sciences of Ukraine, National Academy of Legal Sciences of Ukraine, National Academy of Arts of Ukraine, Taras Shevchenko National University of Kyiv, Igor Sikorsky National Technical University of Ukraine «Kyiv Polytechnic Institute». The Partners of the Festival became the Embassy of France in Ukraine and «Institut Francais Ukraine».

More information about the XII All-Ukrainian Festival of Science is in a photograph album on Facebook page of the Academy: https:// www.facebook.com/NASofUkraine/posts/1861024640863657.

Press Service of the NAS of Ukraine 